\title{
Fetoplacental circulation : measurements, techniques and applications
}

Citation for published version (APA):

Ruissen, C. J. (1990). Fetoplacental circulation : measurements, techniques and applications. [Doctoral Thesis, Maastricht University]. Maastricht University. https://doi.org/10.26481/dis.19901122cr

Document status and date:

Published: 01/01/1990

DOI:

$10.26481 /$ dis. $19901122 \mathrm{cr}$

Document Version:

Publisher's PDF, also known as Version of record

\section{Please check the document version of this publication:}

- A submitted manuscript is the version of the article upon submission and before peer-review. There can be important differences between the submitted version and the official published version of record.

People interested in the research are advised to contact the author for the final version of the publication, or visit the DOI to the publisher's website.

- The final author version and the galley proof are versions of the publication after peer review.

- The final published version features the final layout of the paper including the volume, issue and page numbers.

Link to publication

\footnotetext{
General rights rights.

- You may freely distribute the URL identifying the publication in the public portal. please follow below link for the End User Agreement:

www.umlib.nl/taverne-license

Take down policy

If you believe that this document breaches copyright please contact us at:

repository@maastrichtuniversity.nl

providing details and we will investigate your claim.
}

Copyright and moral rights for the publications made accessible in the public portal are retained by the authors and/or other copyright owners and it is a condition of accessing publications that users recognise and abide by the legal requirements associated with these

- Users may download and print one copy of any publication from the public portal for the purpose of private study or research.

- You may not further distribute the material or use it for any profit-making activity or commercial gain

If the publication is distributed under the terms of Article $25 \mathrm{fa}$ of the Dutch Copyright Act, indicated by the "Taverne" license above, 


\section{FETOPLACENTAL CIRCULATION}

Measurements techniques and applications 



\title{
FETOPLACENTAL CIRCULATION
}

\author{
Measurements techniques and applications
}

\section{PROEFSCHRIFT}

ter verkrijging van de graad van doctor aan de Rijksuniversiteit Limburg te Maastricht, op gezag van de Rector Magnificus, Prof. Dr. F.I.M. Bonke. volgens het besluit van het College van Dekanen, in het openbaar te verdedigen

op donderdag, 22 november 1990 om 14.00 uur

$$
\text { door }
$$

\section{Cornelis Jan Ruissen}


Promotores:

Prof.Dr. J. de Haan

Prof.Dr. R.S. Reneman

Co-promotores: $\quad$ Dr.Ir. A.P.G. Hoeks

Dr. H.J. Hoogland

Beoordelingscommissie: Prof.Dr. J.W. Arends (voorzitter)

Prof.Dr. K. Marsal (University of Lund, Sweden)

Prof.Dr. H.A.J. Struyker Boudier

Prof.Dr. H.J.J. Wellens

Prof.Dr. J.W. Whadimiroff (Erasmusuntversiteit Rotterdam)

CIP-DATA KONINKLIJKE BIBLIOTHEEK, DEN HLAAG

Ruissen, Cornelis Jan

Fetoplacental circulation : measurements techniques and

applications /Cornelis Jan Rulssen. - Maastricht:

Datawyse. - III.

Thesis Maastricht. - With ref. - With summary in Dutch.

ISBN 90-5291-035-9

SISO 605.5 UDC 612.64(043.3) NUGI 743

Subject headings: fetoplacental ctrculation / umbilical

artery / Doppler.

Produktie en layout: Datawyse Maastricht, Ruud Leliveld

Omslag ontwerp: Kees Rulssen

Druk: Krips Repro Meppel

Het versch hjnen wan dtt proefschrift werd mede mogelijk gemaakt door financlële steun van het Scholten-Cordes Fonds in Den Haag en de firma's Pie Medical te Maastricht en Schering Nederland B.V. te Weesp. 
Voor mijn ouders, die letterlijk

aan de wieg stonden van dit proefschrift 


\section{ABBREVIATIONS}

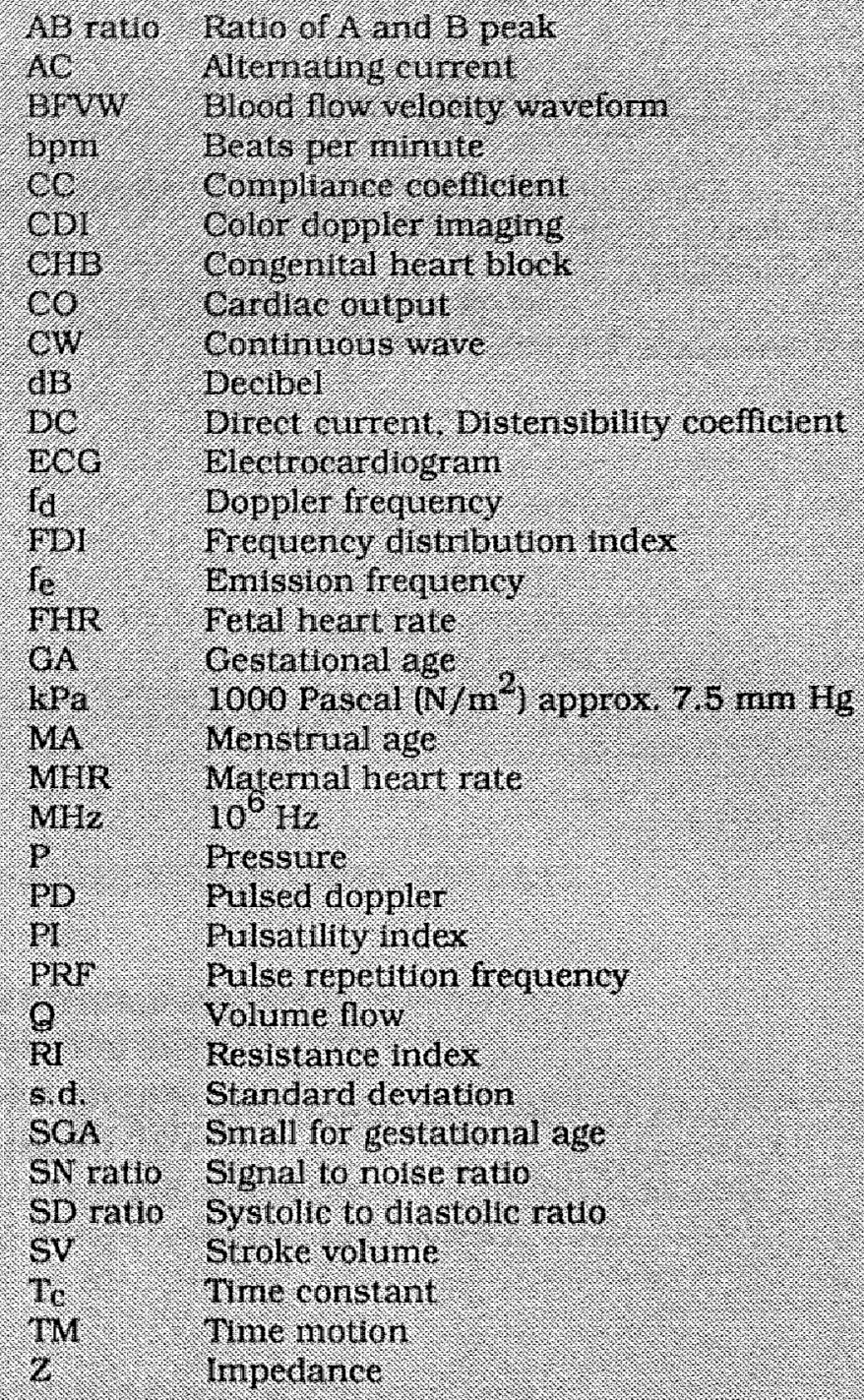

The word "doppler" in this thesis is written without a capital. This is not meant as an impoliteness to Christian Johann Doppler, but because the word is used as an adjective, similar to voltage source or ohmmeter. 


\section{CONTENTS}

\section{Introductory Chapters}

CHAPTER 1 General introduction 9

CHAPTER 2 Physical background of fetoplacental circulation 15

2.1 Introduction 16

2.2 Vascular system 17

2.3 Working hypothesis 20

2.4 Simulation of the umbilical cord 21

CHAPTER 3 Physical aspects of fetal doppler measurements 25

CHAPTER 4 Review of the literature 37

\section{Validity Studies}

CHAPTER 5 Variability of PI measurements 45

CHAPTER 6 The influence of maternal exercise on the Pulsatility Index

of the umbilical artery blood flow velocity waveform $\quad 57$

\section{Circulation Studies}

CHAPTER 7 Some characteristics of the umbilical artery blood flow velocity waveform as function of measurement site $\quad 63$

CHAPTER 8 Umbilical blood flow velocity PI and placental impedance: a study in fetal lambs 71

$\begin{array}{lll}\text { CHAPTER } 9 & \text { Diameter changes of fetal vessels } & 77\end{array}$

CHAPTER 10 The influence of bradycardia on the PI of the umbilical artery blood flow velocilty waveform 89

CHAPTER 11 Post delivery umbilical cord blood flow velocity waveforms 99

\section{Conclusions}

CHAPTER 12 General conclusions 103

Summary $\quad 107$

References 109

Samenvatting 123

Nawoord 125

Curriculum Vitae 127 

Chapter 1

GENERAL INTRODUCTION 


\section{General introduction}

Fetal wellbeing is in principal dependent on interactions with the mother. One of these interactions, the circulatory link between the placenta as an organ of exchange, and the growing fetus, has been the subject of investigation for many centuries. As early as the 4th century BC. Herophilus of Alexandria expressed his ideas regarding the anatomy and function of the umbilical cord. In the Middle-Ages, several prominent scientists published their opinions on the vascular connection between mother and fetus. In the 16 th century Fabricius reported on various aspects of the umbilical circulation, although its physiological background was not fully understood. He described the anatomy of the fetal lamb and suggested an overlap of two sorts of vessels: maternal vessels which like "sleeves" surrounded the fetal placental vascular system. Despite all this scientific interest in the umbilical cord, the placenta and its function, our knowledge of this fetal system is still limited due to the restricted accessibility of the structures concerned under physiological conditions.

Because a major part of fetal growth disturbance is associated with problems in the uteroplacental and fetoplacental circulation, it is important to monitor hemodynamic parameters and to detect deviations in an early phase of pregnancy. At present, a number of methods are availlable to assess fetal growth and condition:

- the traditional external determination of the size of the uterus

- fetal biometry by ultrasound measurements

- fetal blood flow velocity measurements

- fetal cardio(toco)graphy

- fetal electrocardiogram (ECG)

The external measurement of the uterine size is inaccurate due to various interfering factors such as the amount of amniotic fluid. maternal posture and the lack of standardized measurement procedures. With ultrasonography, the size of the fetus and its organs (e.g. the placenta) can be studied prospectively. To monitor fetal and placental growth, longitudinal follow-up studies are needed. Fetal blometry, however, mainly provides information on static anatomical structures, although the movement of these structures can be studied in time with the Time Motion (TM) display. Nevertheless, in many situations it is more important to have information on the functional behavior of systems than to obtain static information. Notwithstanding the fact that a disturbance in fetal growth will often lead to deteriorated hemodynamic performance, specific parameters are necessary to provide information on the actual hemodynamic condition. In this respect fetal blood flow velocity stu- 
dies with doppler ultrasound techniques are of great importance. In this way. hemodynamic parameters can be monitored longitudinally. Since the introduction of doppler ultrasound in obstetric practice, it is possible to obtain information on the function of the circulatory system which cannot be obtained in any other noninvasive way.

Fetal cardiography reflects the reaction patterns of the Fetal heart rate (FHR), which are associated with normal fetal movements, and reflect pathological conditions only under extreme circumstances. In addition, the interpretation of the cardiogram is still a matter of discussion. Fetal electrocardiography is not applicable as a routine measurement at the present state of the art because of technical difficulties in separating maternal and fetal ECG.

Fetal blood flow velocity measurements are promising in monitoring fetoplacental circulation, which is related to fetal condition as well. Various aspects of this measurement technique, however, are still unknown and have to be investigated before introduction in the clinical situation. Study of the fetoplacental circulation is hampered by various problems. The placenta is an organ which only exists during pregnancy, an emotional period of life, determined by protective feelings towards the growing child. Therefore, and this applies to the placenta maybe more than to any other part of the human body, ethical considerations make placental experiments almost impossible. As it is clear that invasive techniques in humans are not applicable, other methods were developed to study the fetomaternal interaction and the role of the placenta:

\section{Experiments in various animal species:}

- sheep, monkeys, rats

2. Noninvasive measurement techniques:

- X-ray

- isotopes

- hormones

- MRI

- mass spectrometry

- cardiotocography

- statical ultrasound investigations: anatomy, growth

- dynamical ultrasound doppler studies: function, behavior

\section{Model studies:}

- computer models of the circulation $[4,14,63,163]$

Fetal sheep are frequently used in physiological research. A sheep placenta has a structure differing from the human placenta and also the umbilical cord differs with respect to the number of vessels. Nevertheless, knowing these restrictions, sheep experiments have yielded results that are applicable to the human situation and have increased our knowledge of the human fetal circulation. Regulating mechanisms and the brain sparing effect were first recognized in fetal sheep, and the results of these experiments are applied to the clinical situation. The choice of certain animal species as a model for the 
human situation is not only determined by the resemblance to physiology in man, but also by the expertise and experience in a research institute. That is the reason why for the animal experiments presented in this thesis, fetal sheep were used as a model. X-ray examination, isotopes and hormonal monitoring are obsolete methods due to harmful side-effects or inaccuracies. MRI and mass spectrometry are future developments the value of which has yet to be established. The contribution of ultrasound techniques in the clinical situation has already been discussed above. Beside this, doppler techniques are used in the study of fetal physiology. Computer models allow the study of reaction patterns of a circulatory system to various stimuli. The data on which the models are based, however, should be provided by animal experiments and from data of the human situation.

The aim of this thesis is to describe circumstances under which doppler velocity waveform analysis can be used and to provide data to supplement the knowledge of feto-umbilical circulation, of which at present, insufficient data is avallable. A working hypothesis is proposed in chapter 2 . There is indicated what is already known about this circulatory system, and which aspects have to be studied in the future. The information is mainly obtained by doppler ultrasound investigations under various conditions. Doppler ultrasound is based on the doppler principle and gives information on moving structures, such as heart valves, but more importantly, on blood flow velocity in vessels [179]. In this way, the time dependent behavior of blood flow velocity can be studied, providing insight into the function of organs involved in the circulation. Because valuable information can only be obtained if the measurement method is understood well, the advantages and limitations of various doppler techniques will be discussed in detail in chapter 3. It should be emphasized, however, that doppler ultrasound can only display blood flow velocities, and that for the calculation of blood volume flow, more parameters are required. In addition, doppler ultrasound can not measure the biochemical function of circulating blood, such as for example, oxygen saturation. A good circulation does not necessarily mean a good oxygenation; the placental transfer processes determine the availability of oxygen and nutrients. One should be cautious with regard to the relationship between doppler recordings of the umbilical arteries and placental function. Only under extreme conditions such as Absent End Diastolic Velocities (AEDV) or reversed blood velocities, blood velocity waveforms in these arteries are probably related to decreased placental function. The time dependent frequency content of the doppler signal must be analyzed to obtain the relevant parameters. Because the angle of insonation is generally not known, angle independent parameters have been developed. Several ratio-parameters have been proposed, such as the Pulsatility Index (PI), which is the difference between the maximum and minimum frequency, divided by the time averaged mean, and the Systolic-Diastolic (SD) ratio, defined as the maximum frequency divided by the minimum frequency. These parameters give a simplified description of the blood flow velocity curve, but obscure much of the potential information such as the 
time-dependent behavior. In addition, the patho-physiological principles of these parameters are not fully understood, so that their use is empirical. In chapter 4 an overview is given of the various clinical applications. An important aspect of the introduction of a new diagnostic method is the reproducibility in various situations and the comparability between different investigators. A method gains in value when results of various centers can be compared. In chapter 5 the variability of the calculation of the PI, performed by a number of research centers, is studied. The influence of various conditions is discussed in chapter 6. Doppler blood velocity waveform analysis can be used to study fetoplacental circulation. In the next chapters various aspects of the circulatory system are studied. The dependency of the blood velocity waveform (BVWF) and the velocity profile on the measurement site is presented in chapter 7.

Another question to be addressed, is whether there will be alternative methods in the near future to circumvent the problems described above. Because the placenta is the most important organ with respect to circulation and exchange, measurements close to the placenta and within the placenta itself will provide the most relevant information. Due to the limitations of echo and doppler ultrasound techniques with respect to accuracy and localization. it is obligatory to measure in a vascular system far away from the organ of interest. It is clear that color doppler ultrasound can be of great help in focussing on the placenta. Localization problems can then be reduced, the small vessels of the placenta can be studied and the relationship between blood flow and anatomy is an invaluable addition to the present possibilities of ultrasound.

By virtue of the increased localization accuracy, the time dependent behavior of small structures such as vessel walls, can be studied. A recent development is the measurement of the vessel wall displacement, as a reflection of local blood pressure and vessel wall characteristics. In chapter 9, this new technique is presented; its clinical value has yet to be demonstrated. Other technological advances such as digital signal processing and increased calculation power at higher speeds, incorporated in ultrasound equipment may lead to new diagnostic tools.

Animal experiments also contribute to our knowledge of the fetal physlology. In chapter 8 an experimental setup is described which may yield valuable information.

In one particular case (chapter 10), it was possible to study the influence of persistent bradycardia on the PI of the umbilical artery BVWF. In addition, other hemodynamic parameters were followed longitudinally. Although doppler ultrasound has certain accepted applications, widespread clinical use is still doubtful. Well designed clinical trials have to be performed to assess the value of doppler measurements in the clinical management of patients. The first aim should be a cost-effective improvement of patient management, and not the development of technologies in itself. In the meantime, we must continue to increase our knowledge on the patho-physiological background of the parameters used (chapter 11). 

Chapter 2

\section{PHYSICAL BACKGROUND OF FETOPLACENTAL CIRCULATION}




\section{Physical background of fetoplacental circulation}

\subsection{INTRODUCTION}

The human circulation has always been of great interest to scientists. In 1628, William Harvey presented his concept of the circulatory system. It was only in the 19th and 20th century, that, due to the increase in knowledge of human physiology, the major principles of the umbilical circulation were elucidated, although even now some aspects are not fully understood [74]. Many of the relationships between blood pressure, flow, FHR, resistance and compliance in physiological conditions can only be inferred from animal experiments in rather unphysiological circumstances, or from the scarce data obtained in humans, such as postnatal placental volume, FHR and extrapolated data from the neonatal period.

Much of the interesting data became available from sheep experiments, in the early fifty's when Reynolds performed his cinematographic studies with $\mathrm{X}$-ray contrast [139]. Recently, new data is obtained by providing fetal vessels with pressure and flow catheters in combination with ultrasound doppler techniques. such as for example the experiments of Hasaart and his group. Maulik et al. and other investigators $[42,66,67,68,81,102]$. The sheep placenta differs morphologically and hemodynamically from the human placenta. Therefore, it is questionable if results of these experiments can be extrapolated to the human situation. Other animal models are also hampered by the same problem. It is remarkable that many of the hemodynamic studies were performed in the early fifty's $[36,138,139]$, and that up until the last few years, no papers on the anatomic properties and their relation to hemodynamics have been published.

Ultrasound techniques make it possible to perform measurements in the human situation under physiological conditions, because of its noninvasive nature. This is restricted, however, to the measurement of blood velocities. Measurements of the systemic or local pressure, one of the most important parameters, is not feasible, although in chapter 10 a new method is presented that may yield information about the local pressure pulse. 
The human fetoplacental circulation can be divided into five major components:

- the fetal heart which is the driving force of the circulating blood

- the fetal aorta and iliac arteries from which the umbilical arteries branch off

- the umbilical cord itself, that supplies as well as drains the placenta

- the placenta as the exchange organ for oxygen, nutrients and metabolites.

- the vena cave

The heart is a pulsating pump. By filling and subsequent ejection of the left ventricle, the tissues in the human body are supplied with circulating blood, containing oxygen and nutrients. For an optimal exchange, blood flow should have a low mean velocity related to the length of the capillary bed without rapid accelerations and decelerations, to enable the red blood cells to take part in the exchange process. Hence, there is a discrepancy between the pulsatile pumping heart and the continuous flow demanded by tissues. A pump, delivering continuous flow, is unlikely in human anatomy. From mechanical engineering it is known, that continuous flow pumps require rotating parts, structures that are hard to imagine in tissues. The pulsatile flow generated by the left ventricle should, therefore, be damped, or filtered by a low-pass filter, to a more or less continuous flow. The required damping function is partially provided by the fetal thoracic aorta. which is an ellastic vessel with a high compliance in order to temporarily store blood after contraction of the left ventricle. The diameter alters during pregnancy from a very small embryonic vessel to about 4.5 millimeters at 28 weeks and 7 millimeters at 40 weeks, depending on fetal weight [95]. In addition, the diameter is dependent on the heart cycle (chapter 9).

From about 16 weeks of pregnancy, it is possible to measure blood flow velocities with doppler ultrasound in the fetal aorta. From the thoracic aorta, blood flows into the abdominal aorta and then into the lliac vessels which form the origin of the umbilical arteries. In the fetal aorta a high pulsatility is present due to the contraction of the left ventricle: in the placenta the pulsatility is almost absent to facilitate exchange processes. Therefore, there is a pulsatility gradient between fetal aorta and placenta.

Within the fetal abdomen the umbilical arteries run along the bladder before they enter the cord. The mean length of the cord after delivery is about $50 \mathrm{~cm}$ with a wide range of 25 to more than $100 \mathrm{~cm}$. The arterles in the cord are spirally, in fact helically, embedded together with the umbilical vein in Wharton's jelly. Extensive biometry on umbilical cords was performed by Edmonds [36] who also reviewed the work of others. He reported on the direction of the helices and the number of turns. He cited the rule of Leonardo 
da Vinci: "the length of the umbilical cord is equal to the length of the child in every stage of his age". Although large deviations from this rule are reported, it roughly illustrates the development of the cord in relation to fetal size. The number of turns in the cord varies from 0 to 36 , with an average of 11 turns per cord. He reviewed several authors who gave varying numbers but it is clear that there is a wide physiological range in length and twisting of the umbilical cord. This helical course is thought to be a mechanical prevention against kinking, but may also be of hemodynamic importance with respect to blood flow. Reynolds [139] suggested that the umbilical cord forms a "pulsometer pump" in order to supply the driving force for venous drain. In this case the pulsatility of the umbilical arteries is a conditio sine qua non for venous return. He was puzzled by the fact that a low pressure difference of about $2.0 \mathrm{kPa}(15 \mathrm{~mm} \mathrm{Hg})$ between the placental bed and the vena cava of the fetus is able to maintain a considerable volume flow of blood. The pressure difference over the umbilical vein is even lower and is estimated at only 0.3 to $0.6 \mathrm{kPa}$. However, the resistance of the umbilical vein is very low. Based on Poiseuille's law the resistance is about $2 \cdot 10^{7}\left[\mathrm{Nsm}^{-5}\right]$ for a length of $0.5 \mathrm{~m}$ and a radius of $4 \mathrm{~mm}$ [30]. For a venous flow of 0.3 liter per minute (100 $\mathrm{ml} / \mathrm{min} / \mathrm{kg}$ at a fetal weight of $3 \mathrm{~kg}$ ), which is a reasonable average, a pressure of only $0.1 \mathrm{kPa}$ is required, which is lower than the actual pressure. As a result, in steady state conditions, flow can be maintained by normal hemodynamic proportions. It is debatable, however, whether the resistance and pressure relations can be approximated by these simple calculations. If the placenta is considered to behave as a Starling resistor (see below). then the pressure surrounding the placenta should be taken into account. In addition, when the fetus changes its position with respect to the placenta, a hydrostatic pressure of $10 \mathrm{~cm}$ water can occur (when the fetus is above the placenta), which is equivalent to approximately $1 \mathrm{kPa}$. Under these circumstances the pulsations of the umbilical arteries together with the sphincter function in the fetal liver may be essential in maintaining venous flow. In this concept, Wharton's jelly is hemodynamically important, because it enables the pulsations of the umbilical arteries to be transferred to the vein. Finally, the pulsatile flow through the spiraled umbilical arteries cause little elongations rather than diameter changes, affecting the flow through the straight umbilical vein.

When the hemodynamic parameters are translated into an electrical ana$\log$. the curves of the cord may represent a coil which introduces an inductance that constitutes a low-pass filter. This, together with the high compliance of the placenta, may reduce pulsatility. The theoretical three dimensional calculation of the influence of a curve in a straight vessel is extremely difficult. Therefore, an in vitro experiment was carried out to estimate this influence. The results are presented in section 2.4 . It may be concluded that, in theory, the helical course of the umbilical arteries can contribute to the dampening of the pulsatility in the cord. In practice its influence will be 
marginal because of the limited number of turns and the large pitch (distance between turns].

The wall of the umbilical artery has no adventitia, no continuous elastic lamellae and contains only a few thick collagen fibers [121], but has a high content of muscular fibers. Consequently its compliance is low and as a result the pulsatility of blood flow will change only marginally. The diameter of the umbilical arteries increases slightly towards the placenta and is approximately 2-3 millimeter, again depending on the gestational age.

Shortly before the umbilical arteries enter the placenta, they anastomose. After entering the placenta the arteries divide into several branches (typically 4-8), somewhat smaller than the umbilical arteries, that run radially across the surface of the placenta. In the chorion these branches divide quickly into smaller vessels that supply the primary and secondary stem villi. Because of numerous anastomoses between the arteries on both sides, the pressure, and hence blood flow and velocities are normally equal in both arteries; discordance between the arteries is rare [65].

The placenta has a low resistance and high compliance in order to dampen the pulsatility of blood flow from the umbilical arteries and to serve as a reservoir for blood. Investigations of Trudinger et al. [167] suggest a 10 fold reduction in resistance due to the extensive branching of the arteries soon after entering the chorionic plate. Hasaart et al. [69] assume the existence of a placental sluice flow or waterfall mechanism at the fetal side of the placenta. Model studies of Thompson and Stevens [163], however, suggest that the umbilical impedance is in the same order as the placental resistance. Other investigators consider the placenta to be a Starling resistor (fig. 1), in which the surrounding pressure, in combination with the inflow and outflow pressures, determine the total flow through the resistor [172]. Applying this model, the placental resistance cannot simply be calculated from the pres-

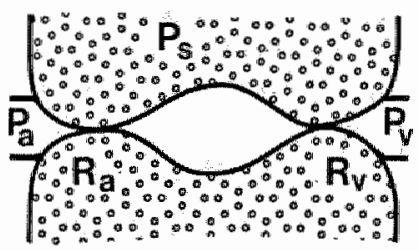

1

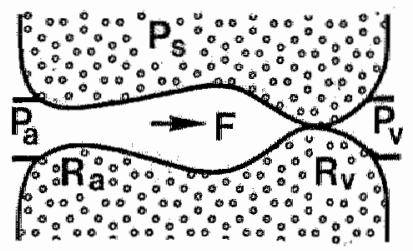

2

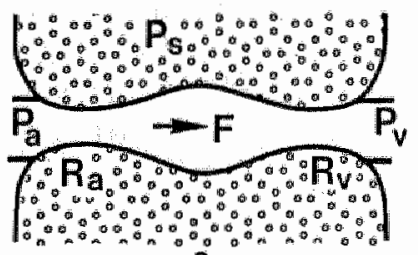

3

Figure 1:

Diagram of a Starling resistor as a model for the placental vascular system.

$P_{\mathrm{s}}=$ surronding pressure. $P_{\mathrm{a}}=$ arterlal pressure. $\mathrm{Pv}_{\mathrm{v}}=$ venous pressure $\mathrm{F}=\mathrm{flow}_{\text {, }}$

$R_{a}=$ arterlal resistance, $R_{V}=$ venous resistance.

1: $F=0, P_{s}>P_{a}>P_{V}$

2: $F \approx\left(P_{a}-P_{s}\right) / R_{a}, P_{a}>P_{\text {a }}>P_{v}$

3: $F=\left(P_{a}-P_{v}\right) /\left(R_{a}+R_{w}\right), P_{a}>P_{v}>P_{s}$ 


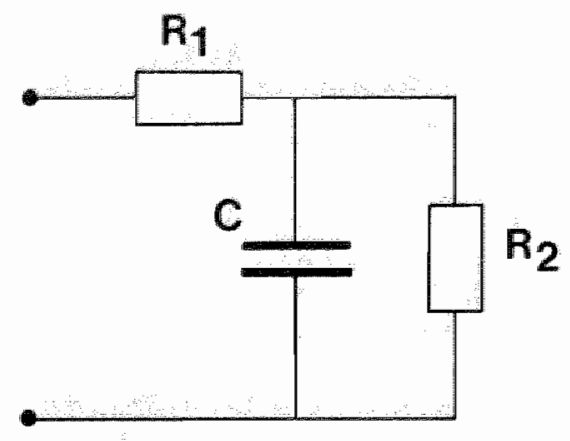

Figure 2:

Electrical model of the feto-placental circulation

$R_{1}=$ umbilical resistance, $R_{2}=$ placental resistance, $\mathrm{C}=$ placental compliance sure difference and the flow, because there is a nonlinear relationship between these two. One should be aware of this mechanism when assessing the relationship between pressure and flow in sheep experiments, although this phenomenon seems to be important only under extreme conditions [69].

It can be concluded that the hemodynamics of the feto-umbilical circulation are complex and still incompletely understood. However, both Thompson and Stevens [163] and Reuwer et all. [137], with a different approach " arrive at the same conclusion with respect to the behavior of the PI. If the feto-pla-

cental circulation is imagined as two resistors and a capacitor (see also chapter 10 ), where $R_{1}$ is the umbilical resistance and $R_{2}$ the placental resistance (fig. 2), there appears to be a linear relationship between the PI and the ratio of $R_{1}$ and $R_{2}$. Although this model is an approximation of the true circulation, it shows the applicability of the PI. However, in both approaches the influence of the pulsatility at the input of the cord (determined by the compliance of the aorta) is neglected.

\subsection{WORKING HYPOTHESIS}

From the above data the following working hypothesis can be inferred: the heart, being necessarily a pulsatile pump, ejects the left ventricular volume into the compliant thoracic aorta. As a result, a large diameter change occurs in the aorta and the pressure pulse is reduced, whereas the volume flow and hence the blood flow velocity * wll become pulsatile. Along the course of the abdominal aorta, the pressure pulse is gradually flattened, although, at the entry into the umbilical cord, a considerable pulse pressure is still present, of about half that of the aorta. The diameter change as function of the distance from the heart also decreases. The pulsatility of the flow, and hence the pulsatility of the velocity, gradually decreases up until the umbilical cord input. From that point, near to the fetal abdomen, the pressure pulse remains unchanged due to the muscular nature of the umbilical arteries, and also the pulsatility of the velocity is virtually unchanged. The diameter change of the umbilical arteries is, therefore, small. The pulsatility in the umbilical arteries contributes to the venous return, and enables a higher time averaged mean flow than would be possible under continuous flow conditions. Only within 
the placenta, a continuous flow is required; and by virtue of the high compliance of the placenta. the pressure pulse is reduced to a very low value. Due to the decrease in impedance, or vascular resistance, the pulsatility of the flow, and, hence, the pulsatility of the velocity are reduced as well. From the placenta, continuous blood flow enters the umbilical vein and is driven to the fetal liver by the hemodynamic pressure difference, and facilitated by the pump-action of the umbilical arteries on the vein. From the liver, blood returns to the right atrium to re-enter the circulation. In the next chapters. data will be provided to substantiate this hypothesis, although not all aspects can be verified. Chapter 7 discusses differences in vascular dynamics between the umbilical arteries and the fetal aorta with respect to the Pulsatility Index, to show that the umbilical cord has little impact on local hemodynamics. In chapter 8 some experiments are presented in which the influence of placental compliance on the PI was investigated. Chapter 9 is dedicated to the vascular compliance of the fetal aorta and the umbilical arteries. Chapter 10 describes an attempt to investigate the site dependency of blood flow velocities in the umbilical cord.

\subsection{SIMULATION OF THE UMBILICAL CORD WITH RESPECT TO ITS TORTUOUS NATURE}

To investigate whether the umbilical cord contributes by its coiled anatomy to the dampening of the pulsatility of the blood flow, a simulation experiment was carried out with sillicon rubber tubing.

With an electrical, pump fluid was pumped through the tube. At the input and the output of the tube the pressure $P$ was measured with a pressure sensor and the flow $Q$ through the tube was recorded with an electro magnetic (EM) flow meter. The pressure difference across the tube divided by the flow gives the impedance $Z$ of the tube:

$$
Z(t)=\frac{P(t)_{\text {out }}-P\left(t_{\text {in }}\right.}{Q(t)}
$$

The impedance was measured under steady state flow conditions (DC) and during a pulsatile flow through the tube (AC) with a pulse rate of $2 \mathrm{~Hz}$. In both experiments the tube was mounted, both stretched over its full length, and coiled, with the number of turns as parameter (fig. 3). The inner diameter of the tube was $3 \mathrm{~mm}$ and the dlameter of the coll was 32 or $43 \mathrm{~mm}$ in the DC measurement and $32 \mathrm{~mm}$ in the AC experiment. The diameter of the tube, its compliance and the input pulse shape and frequency were selected to make the system as a whole hemodynamically comparable to the umbilical artery. The fluid was simply degassed water with $\mathrm{NaCl}$, added to increase conductivity. 


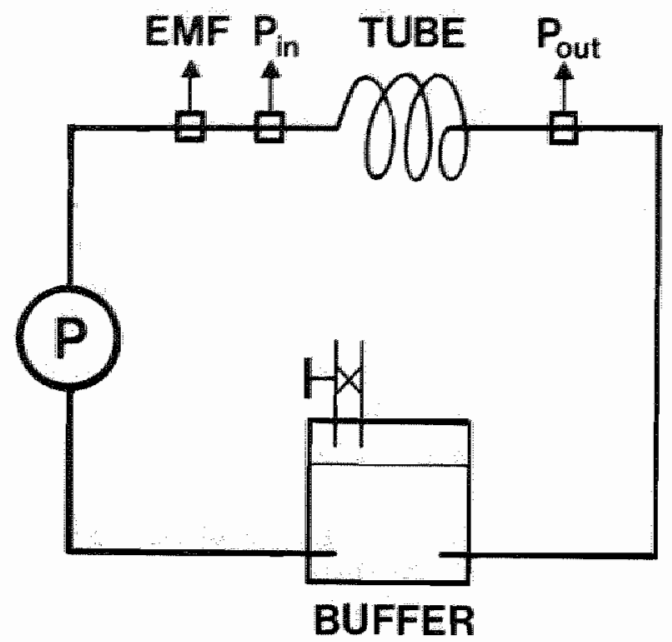

Figure 3:

Experimental setup of the simulation measurements

$P=$ pump. $E$ MF $=$ Electro Magnettc Flow meter, $P_{\text {in }}$. Pont $=1 n$ put and output pressure. The buffer vessel acts as bubble trap to remove air bubbles

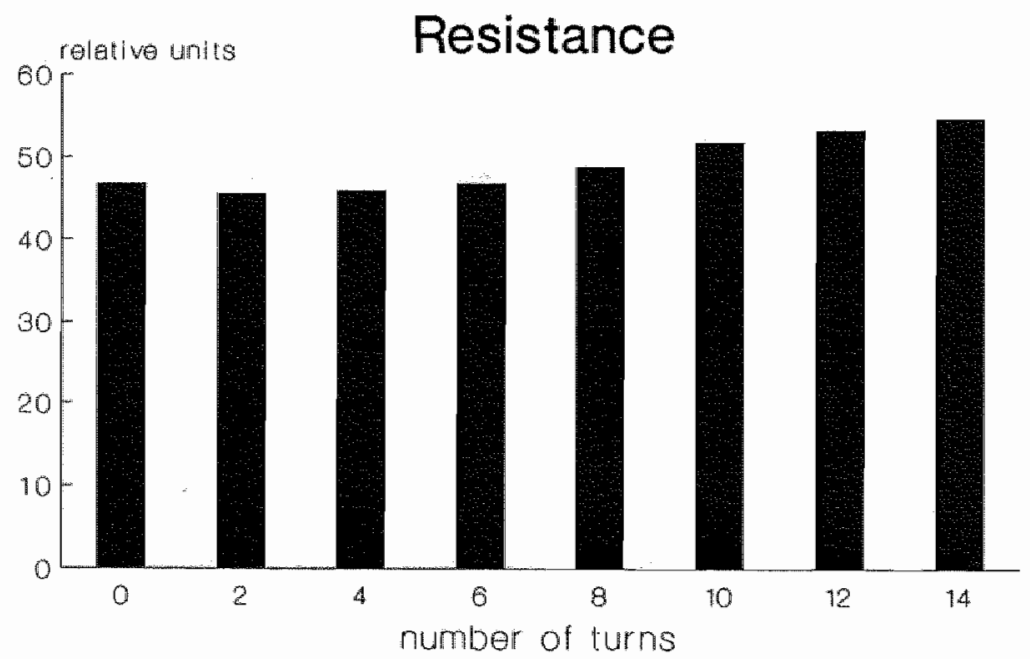

DC $110 \mathrm{w} 3 \mathrm{~mm}$

\section{Figure 4:}

Resistance as function of the number of turns. Diameter coll $=32 \mathrm{~mm}$. Flow is DC. Vertical units are arbititary 
The signals of the pressure and flow transducers were recorded on an analog instrumentation recorder, which preserved the phase information in the pulsatile flow experiment, and analyzed on a personal computer by high speed digitizing and signal processing.

It is stated that, in both the steady state and the pulsatile condition, flow depends on the pressure difference between input and output. In figures 4 and 5 , the resistance is depicted as function of the number of turns, both for a coil diameter of 32 and $43 \mathrm{~mm}$ ( $\mathrm{n}=0$ indicates a straight tube).

Only at low flow rates, there appeared to be a slight dependency of the impedance (in the DC situation equal to the resistance) on the flow. The total impedance in the tube is almost completely determined by its inner diameter. given by Poiseuille"s law [108]:

$$
R=\frac{8 \rho L}{\pi r^{4}}
$$

where $L=$ length of the tube, $r=$ radius, $p=$ viscosity of the fluid, $R=$ resistance and is nearly independent of the colling of the tube. In pulsatile flow conditions, the impedance calculation includes the pulsatile character of flow and pressure that could be influenced by the number of turns. Figure 6 shows the impedance of the tube as function of the number of turns. A clear rise of the impedance can be noticed as the number of turns increases with a possible linear relationship between $\mathrm{n}$ and the impedance.

\section{Resistance}

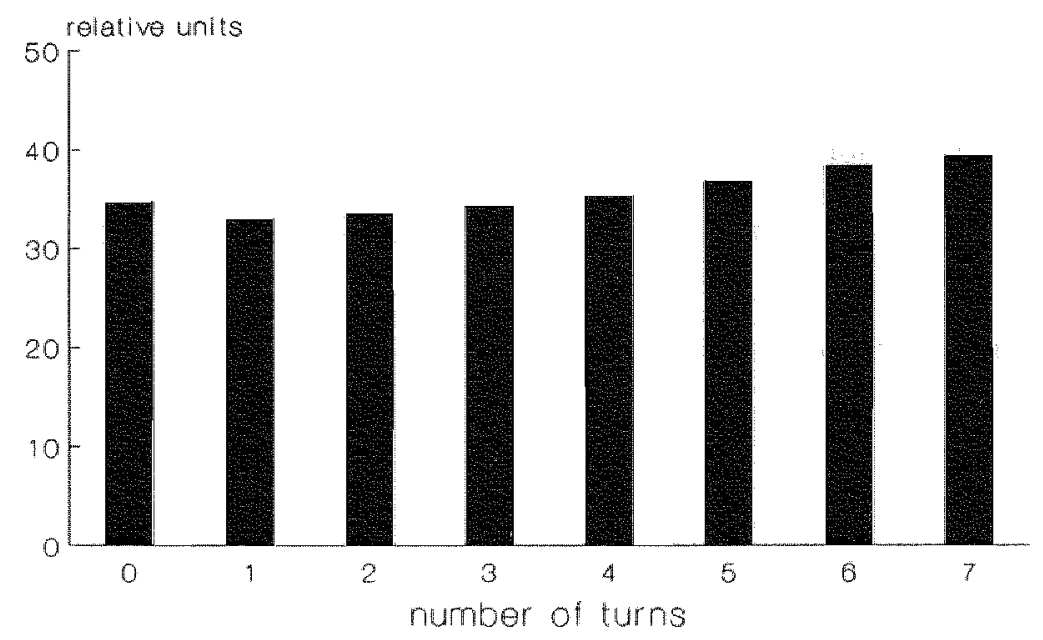

DC $110 w 43 m$

\section{Figure 5:}

Resistance as function of the number of turns. Diameter coll $=43 \mathrm{~mm}$. Flow is DC.

Vertical units are arbitrary 


\section{Impedance}

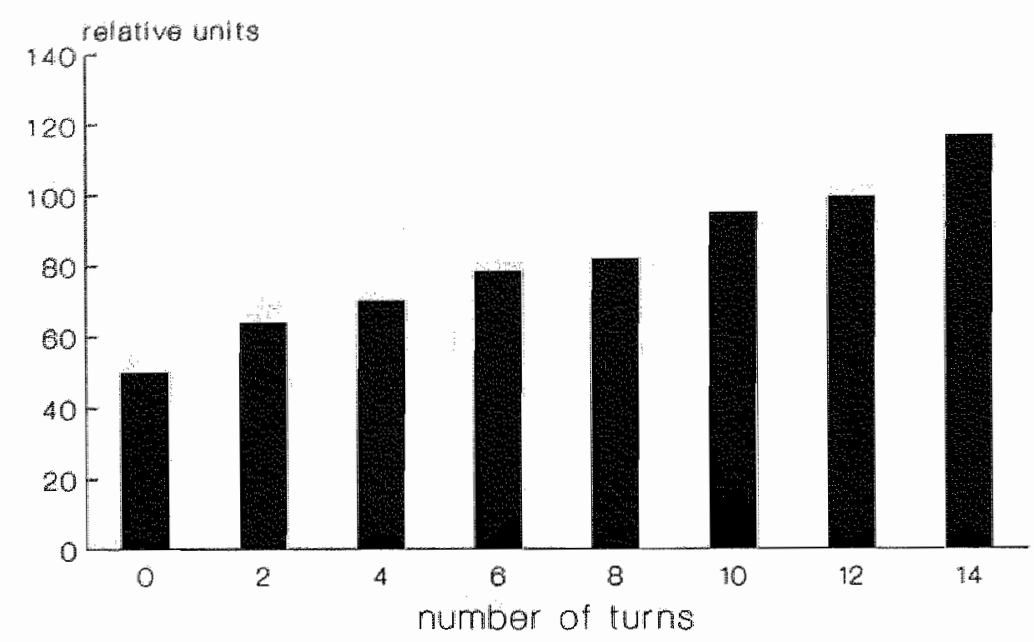

pulstilla

\section{Figure 6:}

Impedance as function of the number of turns. Diameter coll $=32 \mathrm{~mm}$.

Flow is pulsatile with a rate of $2 \mathrm{~Hz}$. Vertical units are arbitrary

In discussing the results, it should be mentioned that this simulation model was not meant to mimic the umbilical circulation, but only to investigate whether coiling of a tube with the same diameter and magnitude of coiling as the umbilical artery, increases the impedance under steady state and pulsatile conditions. The diameter of the applied tube, its compliance and length, the use of simple water and other experimental conditions, do not match the physiological situation in the fetoplacental circulation. Nevertheless, the conclusion can be drawn that in DC conditions moderate coiling of a vessel does not alter its impedance to flow. In pulsatile conditions, with an input pulse rate $(120 /$ minute $)$ in the same magnitude as the fetal heart rate and a vascular system comparable to the umbilical artery, coiling might contribute to the impedance of the vessel and hence could play a role in the dampening of the pulsatility. 


\section{Chapter 3}

\section{PHYSICAL ASPECTS OF FETAL DOPPLER MEASUREMENTS}

C.J. Ruissen, J.M.G. v. Vugt, H.J. Hoogland, A.P.G. Hoeks, J. de Haan Technical aspects of fetal doppler measurements Gynecol Obstet Invest 24: 1-13 (1987) 


\section{Physical aspects of fetal doppler measurements}

\section{INTRODUCTION}

One of the first applications of doppler ultrasound in obstetrics was the measurement of volume flow in the umbilical vein in the assumption that blood flow was a parameter for fetal wellbeing. Because doppler ultrasound is only capable of measuring the velocity of the blood, the diameter of the vessel had to be measured by pulsed-echo. Due to several factors, the inaccuracy of these measurements is high [145]. The results of various investigators differ by more than $50 \%$. Due to this considerable spread in values, volume flow measurements in the umbilical vein were considered to be of limited value.

For the description of the velocity waveform of the umbillical artery, various indices are used. The use of these indices in the description of the waveform can also lead to misinterpretation. Some of the inaccuracies in blood flow measurements are caused by physical and technical limitations present in all ultrasound methods. This chapter gives a general description of some of these sources of error.

\section{PHYSICAL FACTORS}

\section{Emission frequency}

Uitrasound is a mechanical wave which travels in a medium and is attenuated by tissues in the human body [185]. Attenuation consists of two main components: absorption and scattering. The process of absorption is very complex; there are several ways in which ultrasound is absorbed in a medium such as thermal absorption, non-thermal relaxation and attenuation due to shear viscosity [184]. In general. attenuation is proportional to the emission frequency and the distance back to the receiver.

$$
A=k \cdot f e \cdot d
$$

$A=$ attenuation, $\mathrm{f}_{\mathrm{e}}=$ emission freq., $\mathrm{k}=$ constant, $\mathrm{d}=\mathrm{distance}$

As a rule of thumb, attenuation is $1 \mathrm{~dB}$ per $\mathrm{cm}$ per $\mathrm{MHz}$ in normal tissue, but in amniotic fluid this value is lower. The decibel (dB) is a unit to describe attenuation with respect to an arbitrary level. For a $2 \mathrm{MHz}$ doppler system the 
attenuation is $16 \mathrm{~dB}$ if the vessel of interest is $80 \mathrm{~mm}$ below the transducer. [16 dB means that the received signal is about 7 times weaker, under the condition that it is completely reflected by the vessel).

Thus the higher the frequency, the higher the attenuation. Because the depth of the vessel of interest is anatomically determined, attenuation can be influenced only by selecting the emission frequency properly. In obstetric measurements, where the vessels are far away from the transducer, a low emission frequency should be selected.

\section{Backscattering}

Only interfaces of structures having different acoustic impedances, will return acoustic information back to the receiver. In doppler measurements the main principle is back-scattering of the ultrasound because the dimensions of the reflecting particles, i.e. the red blood cells, are much smaller than the wavelength of the ultrasound used. A red blood cell has a disc shape size of about $7 \cdot 10^{-6} \mathrm{~m}$ and the wavelength of $2 \mathrm{MHz}$ ultrasound is about $0.75 \mathrm{~mm}$.

This backscatter phenomenon varies with the fourth power of the frequency, as long as the wavelength is much larger than the dimensions of the scatterers. Thus, the intensity I of the received doppler information increases sharply with frequency:

$$
I=K \cdot f^{4}
$$

where $\mathrm{k}$ is constant and $\mathrm{f}_{\mathrm{e}}$ is the emission frequency.

The result of the combination of attenuation and backscattering is that in an ideal situation, a low frequency should be selected in order to obtain a low attenuation and a high frequency to obtain a high scattering intensity. This is contradictory. Baker et al. [16] showed that there is a relationship between the incident ultrasound frequency and the depth of investigation to obtain an optimal signal to noise ratio (SN ratio), where noise is defined as all the unwanted signals caused by the equipment and other sources:

$$
f_{e}=\frac{15 \cdot \log e}{(A \cdot d)}
$$

where $f_{e}$ is the emission frequency. $A$ is the attenuation and $d$ is the depth of investigation. For example for a vessel $6 \mathrm{~cm}$ under the skin an emission frequency of about $1 \mathrm{MHz}$ would be optimal. Because other factors than signal to noise (e.g. probe size, beam characteristics) also determine the frequency, the actual frequency used may be higher or lower than this theoretical value. 


\section{Continuous Wave versus Pulsed doppler}

Two kinds of doppler equipment are used in obstetrics: Continuous Wave (CW) doppler and Pulsed doppler (PD). CW doppler makes use of two crystals: one converts electrical signals into mechanical (acoustic) signals which are transmitted into tissue, and the other crystal converts the received acoustic information into electrical signals for further processing [150] (fig. 1a). The emitted signal produces a continuous beam of ultrasound. Signal processing is based on the doppler formula:

$$
f_{d}=\frac{2 \cdot V \cdot f_{e} \cdot \cos \alpha}{C}
$$

In this equation $\mathrm{f}_{\mathrm{d}}$ is the doppler shift, $\mathrm{v}$ is the velocity of the reflecting particles, $\cos \alpha$ is the angle between the direction of the velocity and the ultrasound beam, $c$ is the velocity of ultrasound in human tissue and $\mathrm{fe}_{\mathrm{e}}$ is the emission frequency. This formula is valid only when $\mathrm{v} \ll<$, which is the case in all diagnostic situations. Because of the continuous nature of the emission signal, there is no direct way of knowing from which depth and thus from which vessel signals are received.

Pulsed doppler systems can be seen as modified pulsed echo systems as they also emit periodically bursts of ultrasound into the body. The basic principle of a PD system can be expressed by the relationship: $S=v \cdot t$, where $\mathrm{S}=$ displacement, $\mathrm{v}=\mathrm{vellocity}$ and $\mathrm{t}=$ time difference. $\mathrm{So} \mathrm{v}=\mathrm{S} / \mathrm{t}$. By measuring the displacement of a reflector between two bursts of ultrasound it is possible to calculate the velocity of that reflector. The time difference is set by the pulse repetition frequency (PRF) of the pulsed doppler system.

The PD system utilizes only one crystal for both emission and reception of ultrasound (fig. 1b). The pulsed nature adds the possibility of measuring distances, or measuring within a particular window: the range gate of the single gate pulsed doppler system. The shorter the window, the more selective the doppler information originating from a particular region of interest that can be obtained. This is an advantage when interrogating vessels because the vessel walls produce high amplitude low frequency doppler signals that can mask low amplitude high frequencies from blood. By selecting a particular site within the vessel, only signals from that site will be considered.

\section{Sample volume}

The acoustic energy from the emitting transducer is radiated in the form of a beam. In PD systems, the dimensions of this beam, combined with the length of the sample gate and the characteristics of the receiver, determine the sample volume: the volume from which velocity information is received [76]. Inappropriate positioning of the sample volume with respect to the vessel of interest can introduce errors [58]. 


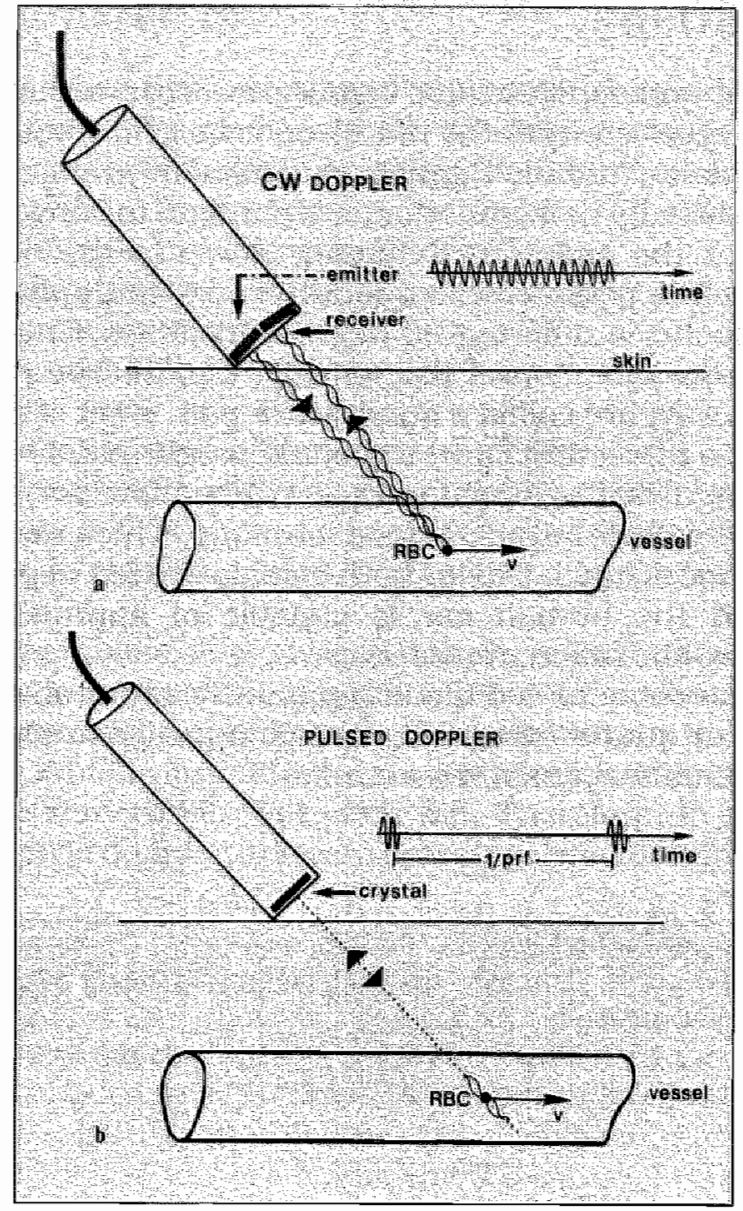

\section{Figure 1:}

a. Dlagram of the application of a CW doppler system. RBC=Red Blood Cell; Vevelocity. The emitter produces a continuous ultrasound beam.

b. Pulsed doppler system. The emitter produces bursts of ultrasound spaced 1/PRF in time

\section{Signal processing}

The received signals require further processing in the form of mean or maximum frequency estimation to obtain useful information. There are several ways to achieve this; all have typical advantages and disadvantages, but in specific situations, some are to be preferred. 


\section{Aural evaluation}

The most direct and sophisticated signal processor is the human ear. The reflected signals received from the red blood cells in the vessel are electronically converted into an audible signal in the frequency range of $50-15.000 \mathrm{~Hz}$. Normally this is done by demodulation, a technique to convert the small high frequency shift at the emission frequency down to the audio range. This demodulation is often performed in quadrature i.e. multiplication with a pair of reference frequencies differing 90 degrees in phase. This is necessary in order to retrieve the direction of the velocity. (fig. 2). The two audio signals generated in this way, are called a quadrature-pair, a set of signals that differ also 90 degrees in phase but have the same amplitude. From these signals one cannot distinguish the direction by ear. Therefore another technique is added, sometimes called the outphaser-technique, which results in separated forward and reverse signals. One or both signals are fed to an amplifier and a loudspeaker, and the human ear is capable of appraising the different frequencies and so the different velocities.

Pure auditive assessment is difficult to quantlfy and is observer dependent. One should aim at quantitative assessment, in order to enable comparable serial measurements for prospective studies.

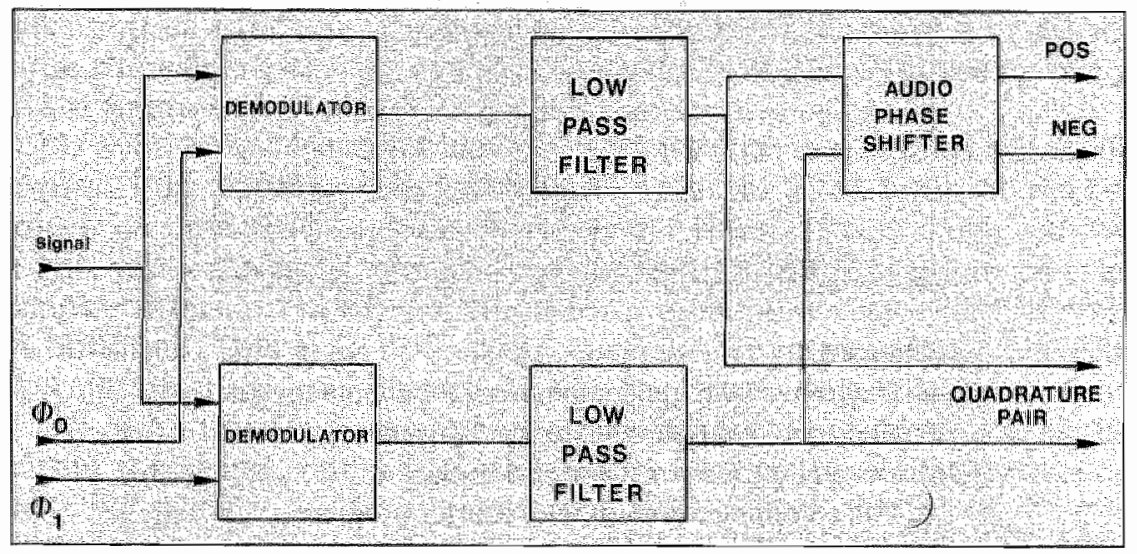

\section{Figure 2:}

Block diagram of the circultry for demodulation, the generation of quadrature doppler signals and the phase shifting necessary to retrieve the direction for the forward and reverse (positive and negative) signals 
Several methods have been developed to convert the audio signals into a simple curve or figure. The audio signals can be fed into a circuit called a zero-crossing detector, which gives an estimation for the instantaneous root mean square value of the frequencies in the doppler signal (mean frequency). The zerocrosser is simple but has several drawbacks:

- it can follow the variations in the velocities only to a certain extent, by which fast transitions are obscured

- it only provides reliable information in case of sufficiently high SN-ratios ( $20 \mathrm{~dB}$ )

- even in this ideal situation, zerocrossers perform well only for signals with a small bandwidth with respect to the average frequency.

- high amplitude, low frequency signals from the vessel walls, especially for $\mathrm{CW}$-systems, mask the frequency information from the red blood cells

For example a parabolic flow gives a doppler signal with a relative large bandwidth resulting in an error of about $16 \%$. For asymmetric spectra the error becomes larger and unpredictable $[96,129,134]$. In the case of signals from fetal vessels, which normally have a wide bandwidth and sometimes a poor SN-ratio, the zerocrosser will often fail. Therefore, in mean frequency estimation in obstetric doppler, the zero crossing detector should not be used.

\section{Other frequency estimators}

Another way to reduce the large amount of data in the audiosignal is the frequency-follower. This circuit follows the mean or maximum frequency of the doppler signal as function of time more accurately. Several types of frequency estimators are described in the literature [149,154], but it is beyond the scope of this chapter to discuss these in detail. In general, they are more accurate than zerocrossers, but all frequency followers will become inaccurate below a certain SN-ratio and in case of large bandwidth signals. The maximum frequency though is less sensitive to these conditions and that is why assessment of the maximum envelope of the doppler signal is to be preferred.

\section{Frequency analysis}

Frequency analysis or spectral analysis. 1.e. decomposition of a signal in its frequency components, is performed with a spectrum analyzer. It is beyond the scope of this overview to describe the different characteristics of these devices, but the main feature is that they analyze all the different frequencles in the audio signals and calculate the amplitude or intensity of each fre- 
quency or frequency band for a given segment of the doppler signal [ 59 . 100,134 ]. The output or (frequency-) spectrum is written on an monitor or a strip of paper in order to obtain a hardcopy of the spectrum (fig. 3).

The result is not an estimation of the mean or other frequency, but simply a display of the amplitude of all frequencies and hence of all the velocities in

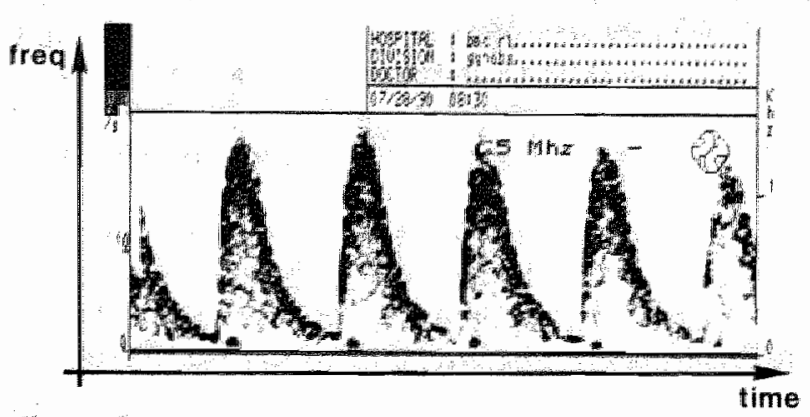

Figure 3:

Frequency spectrum of a doppler signal of the umbilical artery the vessel as a function of time. The mean frequency or median frequency has to be calculated from the data in the memory of the spectrum analyzer. The maximum frequency outline however is easily seen on the display. That is why the maximum frequency outline is often used in the calculation of the signal parameters.

\section{Filters}

In electronic equipment, filters are often used to eliminate unwanted signals, although some of the wanted signals will also be lost. In doppler equipment, lowpass filters are used to remove noise above a certain frequency where information is not expected. Normally this kind of filtering causes no problems. However, when the cutoff frequency of the lowpass filter is set too low, information may be lost in the fetal aorta where frequencies are high. This leads to an under-estimation of the mean and the maximum frequency.

Highpass filtering is used mainly to remove low frequency, high amplitude signals from vessel walls and slow moving structures. Especially in venous signals, but also in signals from the umbilical artery, low frequencies are also generated by slowly moving erythrocytes. In this case valuable information is lost when the cutoff frequency of the filters is too high. This causes an overestimation of the mean frequency by the mean frequency estimator. Moreover, in the diastolic phase, blood flow velocitles may be so low, that the frequencies fall beneath the filter cutoff frequency and will be lost, leading to a false zero enddiastolic value. The selected cutoff frequencies must be related to the emission frequency and the expected frequencles in the doppler signals. When possible, one should select several filter values to check if low doppler frequencies are present, to obtain an optimal result. When using a spectrum analyzer, these problems are readily seen on the display, but with 
other methods one might be unaware of these errors. Several other cosmetic manipulations may lead to erroneous results when not used and understood properly.

\section{Parameter calculation}

As stated in the introduction, the measurement of volume flow is not feasible as a clinical routine [58,145]. For the calculation of flow, both the diameter and the average velocity over the cross sectional area of the vessel as function of time are required according the formula:

$$
Q(t)=v(t) \cdot A(t)=\frac{v(t) \cdot \pi \cdot D(t)^{2}}{4}
$$

where $A(t)$ is the area of the cross section of the vessel and $v(t)$ is the velocity averaged over the cross section. To determine the velocity of blood within a vessel it is necessary to know the angle between the insonating doppler beam and the vessel. Small errors in the angle can cause large errors in the flow calculation. Errors in the measurement of the diameter cause even larger errors in the result, because the diameter is squared. Consequently the cumulated errors are large. Therefore, parameters have been developed to extract information from the velocity signal in order to assess fetal condition.

Because the angle of insonation is generally unknown, absolute values of

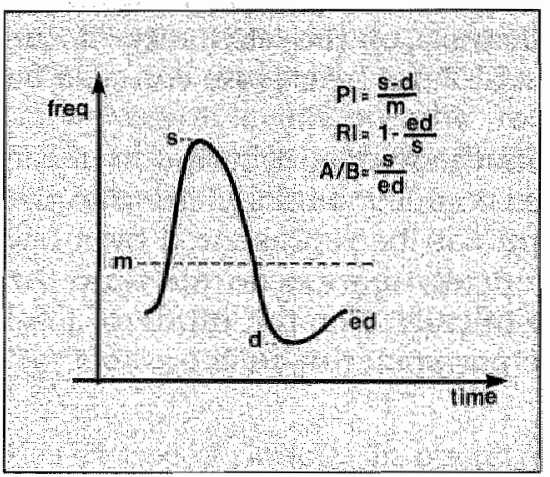

Figure 4:

Definition of the indices to describe the velocity waveform. The curve may be the mean or maximum frequency produced by a frequency estimator or by spectral analysis.

$s=$ systolic value; $d=d$ tastolic value; $\mathrm{m}=$ time average of the signal; ed=end diastolic value frequencies c.q. velocities can not be used. Parameters must relate to differences in the velocity curve itself, instead of differences between velocity curves.

Several methods have been developed to describe the main features of the velocity waveform: the Resistance Index (RI) [131] defined as one minus the end diastolic value divided by the systolic value, the $A B$ ratio [158] defined as the systolic value divided by the end diastolic value, the Pulsatility Index (PI) [59] defined as the difference between systolic and minimal diastolic value divided by the time average mean of the signal (fig. 4), and several mathematical descriptions of the waveform [153, 159].

The RI reflects the resistance of the distal vascular bed, and the $A B$ ratio Is also a reflection of distal vascular re- 
sistance, although less sensitive than the RI. The most accurate description of the hemodynamics of blood flow based on simple parameters provides the Pulsatility Index (P1) $[160,161]$. In the umbilical artery the enddiastolic value is generally also the minimal diastolic value, but this is not necessarily the case in the thoracic and abdominal aorta, nor in femoral artery investigations and other peripheral artery measurements.

This parameter has been elaborately Investigated in the adult peripheral circulation and also in the umbilical artery and fetal aorta the PI seems to describe the processes in the vascular bed well [157]. The PI is determined by various factors:

- vessel wall distensibility

- local pulse pressure

- proximal vascular impedance

- impedance of the distal vascular bed

In the umbilical circulation, the PI reflects the ratio of the umbilical cord resistance and the placental resistance. Under certain conditions, the RI and the $\mathrm{AB}$ ratio will fail to describe the velocity waveform. In the case of zero or negative endliastolic velocities, the RI will reach its theoretical maximum of one or even a meaningless value greater than one; the A/B ratio will become infinite or negative and thus become meaningless. The PI can handle these conditions; that is why the PI is to be preferred.

Additional information can be obtained from the rise and decay times of the velocity waveform. These can be defined as the time between the beginning of the curve and the moment the maximum value is reached (risetime) and the time from the maximum value to reach a certain low level (decay time) respectively. These parameters give an indication of the elasticity of the vascular bed and of the left ventricular function. Fetal heart rate can also be derived from the velocity waveforms.

A few articles have been published on the mathematical description of the velocity waveform $[29,153,159]$. A more or less complex model is fitted to the actual curve in such a way that the waveform can be represented by a few numbers. Although these methods are theoretically more accurate than the PI or RI, this benefit has yet to be proven clinically. For the study of fetal hemodynamics, the PI remains at present the parameter of cholce.

\section{CALCULATION}

The calculation of the parameters mentioned above can be performed by hand, although this is cumbersome or almost impossible for the PI and the mathematical descripters. The velocity waveform of the mean or maximum frequency can be recorded on a strip of paper and by reading the appropriate values, the $A / B$ ratio and the RI can be obtained. For calculation of the PI, numerical integration is necessary, and for the mathematical methods com- 
plex calculations must be performed. That is why the computer is used. The mean or maximum frequency waveform is fed into the computer, and the PI or other parameters are calculated by the program in the computer, and optionally printed on paper [148]. Modern spectrum analyzers can perform automatic calculation of the PI, RI, A/B ratio and other values of interest. This is done by the programs of the microcomputers incorporated in this equipment.

Sometimes a lightpen option allows the observer to trace the outline of the curve on the screen, where the observer, with his a-priorl knowledge of the signal, can select the best curve. This is important in situations where the $\mathrm{SN}$ ratio is low, and the program of the analyzer is not able to distinguish between noise and signal. The number of waveforms processed may also influence the result [155]. All kinds of cosmetic manipulations can be performed with the spectra, such as cutting the noise above a certain frequency, color coding the intensities, averaging to decrease noise and so on. A good understanding of all these operations is necessary to obtain a reliable result. Some of the aforementioned operations can be done on-line, i.e. immediately during the investigation. The signals can also be recorded on an analog taperecorder for off-line processing, i.e. after the investigation of the patient is completed. The phase relationship in the quadrature pair is very susceptive and can be easily distorted by low quality recorders, so that a good quality recorder, for example a HiFi video recorder must be used. Recording of the mean or maximum frequency signal is possible too, but also requires an expensive taperecorder because of the low frequencies in these signals. A drawback of the on-line method is that no reprocessing of the signals is possible; only a photograph taken from the screen may provide durable information.

With the presently available calculation programs in automatic spectrum analyzers it is not possible to obtain reliable figures under all conditions. Therefore, careful checking of the automatic calculation process and manual correction is necessary.

\section{CONCLUSION}

The use of doppler in obstetric investigations may be troubled by all kinds of technical problems. Nevertheless, a good understanding of the basic principles of doppler ultrasound will prevent serious errors. Reliable values for some parameters such as the PI can be obtained by proper selection of the emission frequency and measuring method. For obstetric investigations of the fetal circulation, an emission frequency of 2 to $4 \mathrm{MHz}$ is satisfactory. Lower frequencies will lead to a reduction of signal amplitude and resolution; higher frequencies will lead to problems due to attenuation. A pulsed doppler device is preferable because of the ability to measure at a selected depth, thus avoiding contamination of the signal by venous blood flow and vessel wall 
movements. The beamwidth must be in relation to the size of the vessel, in most cases 4 to $6 \mathrm{~mm}$, and the sample volume of the pulsed doppler device should not be too small $\left(50 \mathrm{~mm}^{3}\right)$.

The PI is theoretically the most specific of the simple parameters. Mathematical descriptions may provide more information, but their clinical use have not as yet been demonstrated.

Automatic calculation of parameters is time-saving but one should be aware that under obstetric doppler measurement conditions, mean and maximum frequency followers and automatic calculations will often fail.

\section{Some remarks on the safety of ultrasound}

Ultrasound has been used in medicine for at least 30 years. From the very beginning, there was concern about the possible harmful effects of ultrasound, especially in obstetric applications. Therefore, studies have been performed to prove any damage to exposed tissue [17]. Due to the way diagnostic ultrasound is used, it is theoretically impossible to prove that ultrasound is harmless. For the time being, it can only be concluded that no harmful effects of diagnostic ultrasound have been demonstrated in routine clinical applications. The safety levels, advised by the AIUM (American Institute of Ultrasound in Medicine) [7], are extrapolated from animal or tissue experiments, in which much higher ultrasound levels were used than in human diagnostic situations. Recently, some articles were published [13, 18.19 ] dedicated to the bioeffects in pregnancy of laboratory animals. The conclusions support the above statement that there are no proven harmfull effects of ultrasound itself.

The ultrasound levels of the equipment used in the experiments in this thesis, are well below the recommendations of the AIUM. The ultrasound output of the transducers was confirmed by measurements in the Ultrasound Laboratory of the department of Biophysics of the University of Limburg.

Further improvement of ultrasound equipment will lead to lower exposure levels in the future; hence, there is no contra-indication for the use of ultrasound equipment in obstetrics, as long as it is used by a physician, with a well formulated diagnostic or research goal. 
Chapter 4

REVIEW OF THE LITERATURE 


\section{Review of the literature}

\section{INTRODUCTION}

Although the investigation of blood flow velocities in peripheral arteries with doppler ultrasound was first reported by Satomura [150] as early as in 1959. it. was not until 1977 that this method was applied to fetal vessels. In that year, Fitzgerald and Drumm [48] published an article on a new noninvasive method to investigate the umbilical circulation with $\mathrm{CW}$ ultrasound. After the development of a combined two-dimensional B-mode scanner and Pulsed doppler, used by Eik-Nes et al. in 1980 [37], examination of the fetal aorta also became possible. An overwhelming number of publications has appeared ever since, reporting measurements in various fetal vessels. such as the carotid artery, the femoral artery and the liver vessels $[1,10,61,105,106,119$, $153,179]$. Because of the continuously improving image quality of the two-dimensional scanners, the application of color doppler systems with a combined echo image and two-dimensional doppler information, and signal processing power, new areas of the fetal circulation will be explored in the near future [34]. In this chapter an overview is presented of the most important applications of doppler ultrasound with respect to fetoplacental circulation. In each section only a limited number of references will be given; it is impractical and hardly possible to present all the publications. The quoted articles serve as an input to additional references. The following items will successively be discussed:

- Technological remarks

- Clinical features

- Measurement locations

- External influences

\section{TECHNOLOGICAL REMARKS}

As already mentioned, the first publications reported the use of $\mathrm{CW}$ doppler whereas in the years thereafter Pulsed Wave doppler (PD) is often used. The differences between these techniques for obstetric applications were discussed in chapter 3 and in the literature $[23,173]$. Because of these differences, comparison of the results obtained by different authors may be difficult if the exact conditions of the measurements are not known. 
The studies concerning volume flow measurements in the umbllical vein were equivocal; the calculated flow per kg estimated fetal weight varied considerably between authors, mainly due to technical and methodological shortcomings. In current clinical practice flow measurements are obsolete. It is not impossible that vollume flow measurements will become more important in the near future because of increasing accuracy and localization capabillties.

At present, waveform analysis is the method of choice. Although it is possible to use a low cost technique for the determination of the mean or maximum velocity as function of the cardiac cycle (i.e. zero crossing decoder. frequency follower), the state of the art is the application of a spectrum analyzer. In chapter 3 the features of the different techniques and parameters for the description of the waveform have been discussed.

\section{CLINICAL FEATURES}

\section{Intrauterine growth retardation}

One of the first hypotheses concerning the fetal circulation was that waveform analysis of umbilical artery blood velocities could differentiate between Appropriate for Gestational Age (AGA) and IntraUterine Growth Retardation (IUGR) or Small for Gestational Age (SGA) fetuses. Numerous reports have been published concerning this important clinical problem. These were generally retrospective studies, showing the relationship between doppler data and fetal outcome, without establishing the clinical value of this method $[20,27,28,52,70,72,92,174,177,183]$. Beattie and Dornan [20] state that there is no relationship whatsoever and van Vugt et al. [175] also showed that doppler registrations in the umbilical artery do not detect the individual IUGR fetus. This is partially due to the different definitions of the terms IUGR and SGA. These terms are not synonymous as the first one expresses a pathological condition (IUGR) and the latter a statistical statement on the basis of biometrical data [122]. Moreover, the endpoints used to define neonatal complications differ greatly between authors. A follow-up period of years is necessary to differentlate between normal and abnormal neonatal outcome [43]. Only a few prospective studies have been published e.g. Trudinger et al. [166], Reuwer et al. [136], Erskine and Ritchie [40], van Vugt et al. [175], which however, differ in methodological approach. Although there is no consensus on this subject, most investigators endorse the opinion that doppler measurements are not useful in screening for IUGR $[72,123,132]$. The sensitivity and specificity related to a post natal "gold standard" are too low to justify the examination of all pregnant women. Reported values for sensitivity range from 64 to $100 \%$ and the specificity is rarely mentioned. If IUGR 
has already been diagnosed with other clinical criteria, umbilical artery doppler measurements may still be of value in fetal monitoring. Although the physio-pathological basis is still obscure, absent end diastolic velocities (AEDV) or even reverse velocities in the umbilical artery is an ominous sign which cannot be neglected [84].

A well designed clinical trial is necessary to estabilish a set of reference values for the population and methods used in the obstetric clinic. Application of these values in the high risk patient may lead to better patient management.

\section{Fetal distress}

Doppler recordings in the umbilical artery are more promising with respect to the prediction of acute fetal compromise. Mulders et al. [119] reported on uterine and umbilical blood flow measurements in 99 patients, using doppler measurements from both sides of the placenta. They concluded that these measurements are not appropriate for the prediction of IUGR (see previous section) but have a reasonable sensitivity with respect to fetal distress (FD): $73 \%$ for the umbilical artery alone, and for the combined measurements a value of $90 \%$ is reached , both at a specificity level of $95 \%$. Brar and Platt [26] also found a significant correlation between FD and umbilical artery indices, although values for the sensitivity were not reported and the study group was highly selective. Other publications related CTG results to doppler measurements [45.51] which yielded equivocal conclusions. Although in the near future more data will become available on the clinical value of doppler measurements in compromised fetuses, it is unlikely, that this will lead to a better understanding of the pathophysiology.

\section{Hypoxia and biochemical monitoring}

The relationship between oxygenation of the fetus and the umbilical circulation has been investigated in animal fetuses $[81,86,118]$, and in man $[11,47]$. Bilardo et al. [21] described the results of blood gas values after chordocentesis in humans in relation to umbilical velocity parameters. The latter study shows serious methodological drawbacks and is too preliminary to be conclusive. It is not a longitudinal, but a cross sectional study, and the statistical analysis is questionable. Further studies of this kind will have to be performed to shed more light on this issue. Data from animal experiments support a possible relationship between biochemical parameters such as $\mathrm{pH}$ and $\mathrm{pCO}_{2}$ and the umbilical blood flow velocity parameters. In particular, extreme hypoxia will influence the PI of the umbilical artery, although the subsequently induced bradycardia is an equal important factor in the increase of the PI. 


\section{MEASUREMENT LOCATIONS}

\section{Cardiac and aortic flow}

One of the first applications of doppler ultrasound was the measurement of cardiac and aortic blood flow. Lingman especially [95] focused on the thoracic and abdominal aorta and others also $[60,176]$ established reference values of the PI in relation to gestational age. The PI values are relatively invariant with GA but show a large variation with the measurement location due to the pulsatility gradient in the fetal aorta. In the assessment of fetal condition these measurements seem to play a less important role than the umbilical artery registrations, even if sophisticated parameters such as acceleration time are applied. Only in special conditions such as fetal arrhythmia and congenital heart defects doppler can add to the information already available from the GTG and echo (see also chapter 9).

\section{Umbilical flow velocities}

Most of the doppler measurements performed to establish fetal condition are performed in the umbilical artery. Only in very special cases [65] a discrepancy between the two umbilical arteries has been found. Normally it is not important, and almost impossible, to determine in which artery the examinations are conducted. Some authors $[3,110]$ find an influence of the sampling site along the cord. Unless one measures at the extreme ends of the cord, this dependency is not relevant for routine measurements; a free floating part of the cord will give reliable results (chapter 7).

\section{Other fetal vessels}

Doppler measurements are also applied to other fetal vessels such as the carotid artery and the femoral artery. Especlally the group of Wladimiroff performed a number of studies on the cerebral circulation [182]. The "brain sparing effect", the mechanism that protects the brain from hypoxia at the expense of other tissues, that had already been demonstrated in animal experiments, could also be confirmed in the human fetus. These measurements are difficult because of localization problems and the lack of reference values. The clinical value has as yet to be proven. Further research of this kind may provide important information about the hemodynamic relations between several vascular sub-systems. 


\section{Placenta}

The changes in umbilical artery blood flow velocity waveforms have been attributed mainly to changes in peripheral resistance [126] and in particular to the placental bed. Giles et al. [55] and recently Fok et al. [50] reported a significant correlation between the umbilical artery blood flow velocity waveforms and the result of a histological examination of the placenta with respect to the number of small vessels. Their results are not conclusive because the histological changes in the SGA placentas were also found in the normal placenta, albeit to a lesser extent. In addition, the histological outcome was not compared to the fetal outcome. It may be concluded that not only the number of small arteries is important, but also other characteristics of the vascular bed such as the compliance. Erskine [38] investigated waveforms in fetuses with cardiac arrhythmias and reached the same conclusion with respect to placental compliance. In chapter 8 this will be discussed in more detail.

Localization of the placenta influences the distribution of the uterine artery blood flow $[91]$. but does not seem to be important with respect to umbilical artery waveforms. Postnatal data of placenta measurements such as weight or size. is not directly related to the prenatal doppler results.

\section{EXTERNAL INFLUENCES}

\section{Smoking}

The influence of smoking on the umbilical artery flow veloctty waveforms has been investigated $[87,152]$ and an immediate effect on the waveform parameters could not be established. The influence of smoking, therefore, is a long term effect, that posstbly affects the total circulatory system. The perinatal complications of smoking are generally recognized.

\section{Maternal exercise}

Chapter 6 is dedicated to the subject of maternal exercise. A number of publications have reported equivocal results $[31,117,130,156]$ mainly because of different starting points and experimental setup. In the normal clinical routine, maternal exercise does not need to be taken into account. 


\section{Other clinical applications}

Doppler measurements have been conducted for a number of other indications such as twin pregnancies [46,57], postterm pregnancies [140], diabetes [22], labor $[44,98,99]$, hypertension $[1,35,165,169]$, blood viscosity $[56,88]$ and immunological disease of the mother [168]. These publications mainly concern case-reports describing the use of doppler measurements in the monitoring of complicated pregnancies. The effect of these measurements lies in the reassurance of the patient and the doctor and sometimes gives a corroboration of information already obtained with other diagnostic procedures. Nevertheless, these reports may further enlarge our knowledge of the patho-physiological behavior of the fetal circulatory system. 



\section{Chapter 5}

\section{VARIABILITY OF PI CALCULATIONS}

C.J. Ruissen, J.M.G. van Vugt, J. de Haan Variability of PI calculations

Eur J Obstet Gynecol Reprod Biol 27: 213-220 (1988) 


\section{Variability of PI calculations}

\section{INTRODUCTION}

The Pulsatility Index (PI) of a blood velocity signal is defined as the difference between maximum velocity and minimum velocity divided by the timeaveraged mean: $\left(V_{\max } V_{\text {min }}\right) / V_{\text {mean }}$ [59]. The formula itself is straightforward, but the determination of the components, and therefore the final result, can be affected in several ways, such as the way in which the blood velocity signal is obtained, recorded, processed and in the way calculations are performed. Emission frequency may be a factor that affects signal-to-noise ratio; frequency estimation may be performed with zero-crossing decoders, frequency followers or spectrum analyzers. Calculation can be based on the mean frequency, the maximum frequency or from some arbitrary level below the maximum intensity of the signal $[128,143]$. Several investigators have reported on the normal range of PI values as a function of menstrual age $[128,137]$. Blood velocity waveform analysis would become more valuable if results obtained by various investigators could be compared. To obtain insight into the comparability of PI values a group of investigators collaborated in a study within the framework of the EC project on Perinatal Monitoring.

\section{MATERIALS AND METHODS}

Because differences in PI results can be caused by different types of error. a testing method should include as many as possible stages in the process of PI calculation. Extensive discussions at a meeting in Maastricht, May 1985 , revealed the following problems. Doppler phantoms, 1.e. a device which simulates blood flow that can be measured by doppler instruments, are not so widely available that all the centers have access to the same type of phantom. The size of the equipment needed to set up a doppler phantom, for example, the one available in Maastricht, makes it impractical to send such a machine to all the participating centers. Some investigators use Continuous Wave $(\mathrm{CW})$ and others pulsed doppler (PD) equipment. CW equipment measures an average velocity across the diameter of the vessel while PD systems are almed at the measurement of the center stream velocity. In fetal doppler applications, however, the vessel is small with respect to the sample volume. Theoretically the results of both techniques should be similar; nevertheless the application of a maximum frequency follower or a spectrum analyzer will 
lead to different velocity curves when compared to those obtained with a zero-crossing decoder. Due to the higher signal to noise ratio of the $\mathrm{CW}$ signal, the PI obtained in this way, may also be somewhat different in spectral analysis from the value obtained by $\mathrm{PD}$ [173].

To overcome these and other problems it was decided to use the method of analyzing a pre-recorded audio signal, thus eliminating the emitter and receiver part of the doppler system. Therefore, only the signal processing part of the equipment and the PI calculation procedures was tested.

A PD system (Pedof $2 \mathrm{MHz}$ ) was used to record signals of major fetal vessels: the umbilical artery, the thoracic and the abdominal aorta, at two points in pregnancy: $24 / 25$ weeks and $35 / 36$ weeks. Besidles these signals, two signals of the umbilical artery at 25 and 35 weeks were recorded with a CW system (DeLalande $4 \mathrm{MHz}$ ). All signals were recorded in steady state during 10 consecutive heart beats in the absence of fetal breathing or excessive fetal movements. The 10 heart beats, therefore, should have a low beat to beat variance.

The signals were of average quality with respect to signal-to-noise ratio as not only high-quality signals were recorded. The aim was to test comparability under normal daily routine conditions. All the signals were copled from a master tape (Hewlett Packard Instrumentation Recorder) to a normal-quality stereo cassette recorder, both in quadrature and separated audio (outphaser technique). This cassette was copied 10 times and sent to the participating centers.

The assignment was to analyze the tape recordings and to calculate a PI value for all the signals with the methods normally used in that center, i.e.. we did not dictate the method used. We left the centers free to use 1 or 3 or all 10 heart beats. Information was compiled about the frequency estimator, the calculation method, the equipment used by the centers with respect to emission frequency and emitted output power of the doppler and echo system. Table III gives an overview of the equipment and methods used by the different centers.

\section{RESULTS}

In Maastricht the cassette tape was analyzed with seven different techniques. Although with each method the same signal was used, different results were obtained each time. These results were evaluated as produced by different centers and indicated as M(aastricht) 1 to $M 7$ in table $\mathbb{I}$ and the figures 1 to 9 . The other participating centers are indicated by: U(trecht), H(erlev), R(otterdam), N(ijmegen) and L(ondon). When centers used different methods, the results were also considered to be obtained from different centers. Table I gives the numerical results, and figures 1-8 show the results graphically. 


\section{Thoracic aorta 23 wks}

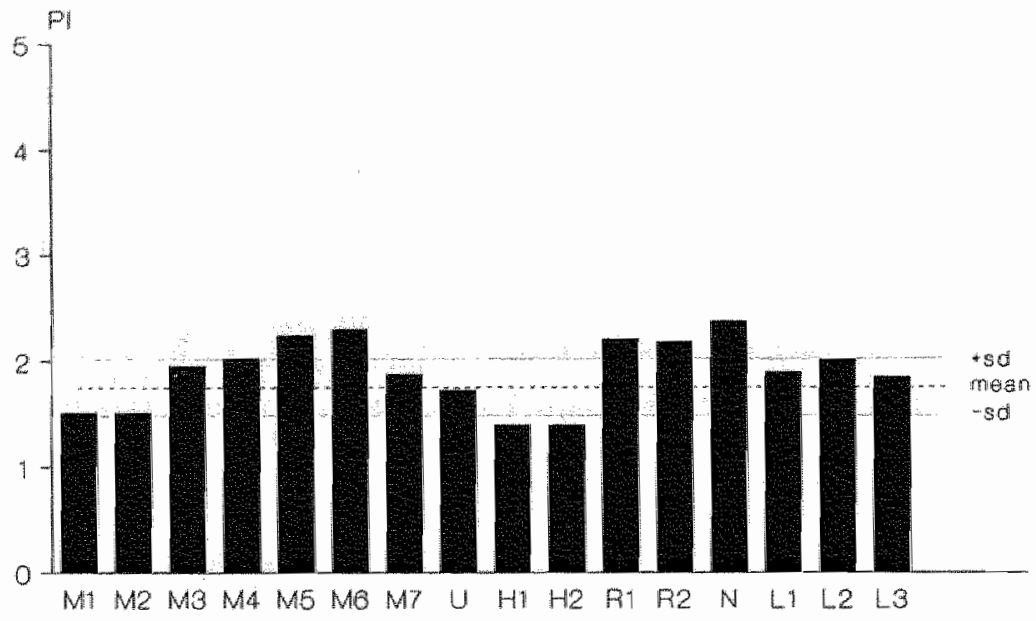

Figure 1:

PI values of the thoracic sorta at 23 weeks for the various centres. Dotted lines show the reference value

\section{Thoracic aorta 36 wks}

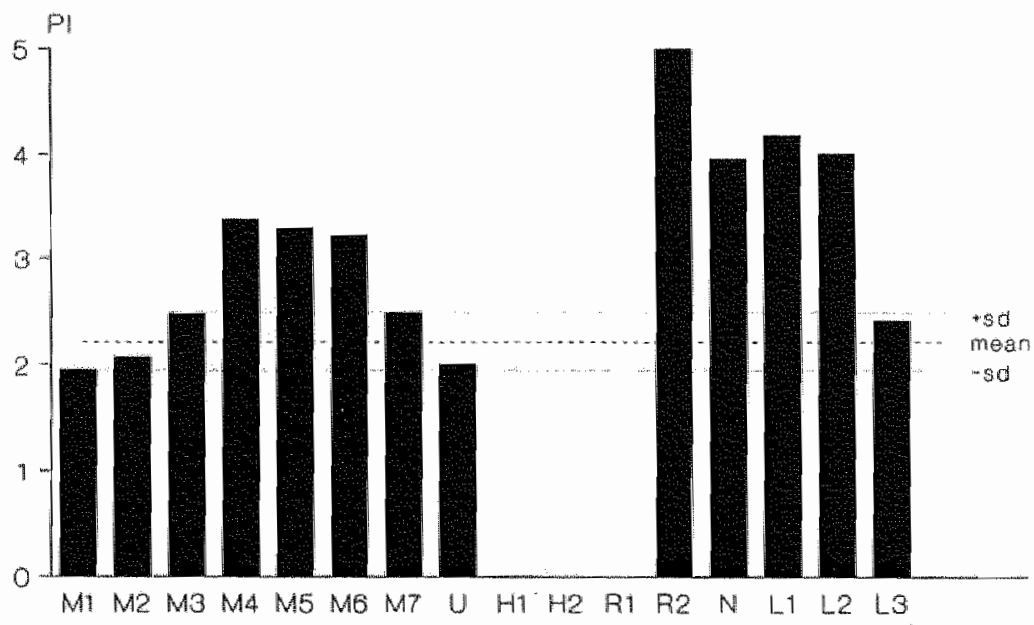

Figure 2:

PI values of the thoracle aorta at 36 weeks for the various centres. Dotted lines show the reference value 


\section{Abdominal aorta 24 wks}

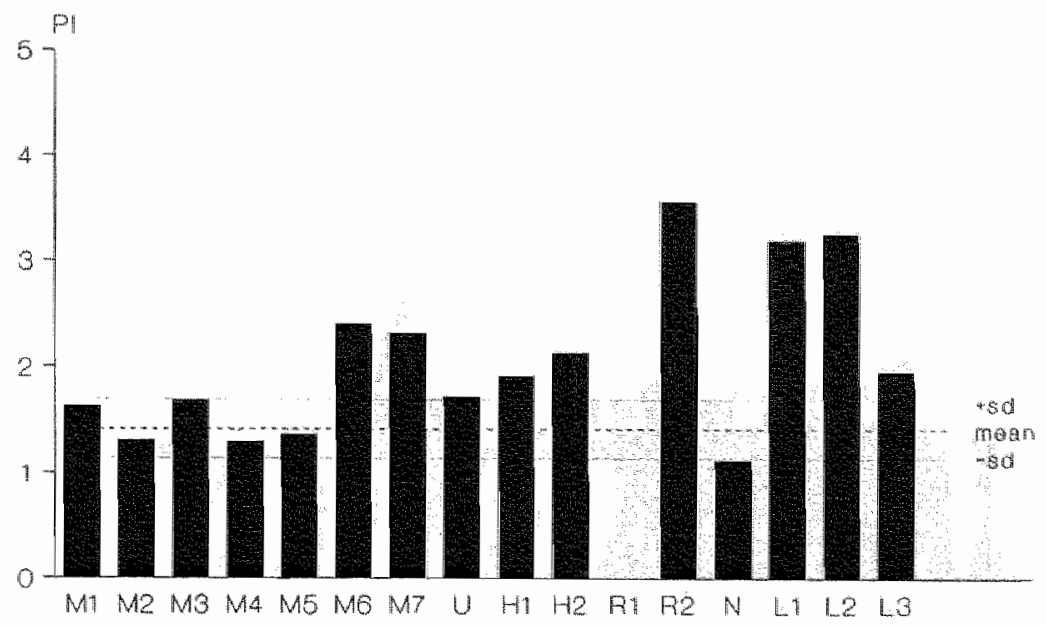

Figure 3:

PI values of the abdominal aorta at 24 weeks for the vartous centres.

Dotted lines show the reference value

\section{Abdominal aorta 33 wks}

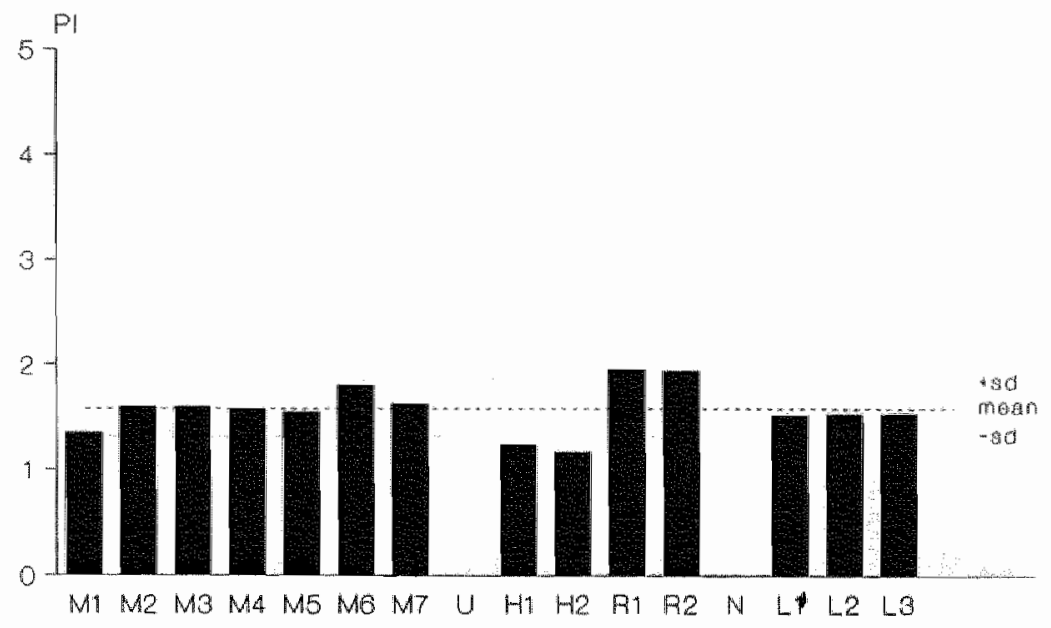

\section{Figure 4:}

PI values of the abdominal aorta at 33 weeks for the various centres.

Dotted lines show the reference value 


\section{Umbilical artery 24 wks}

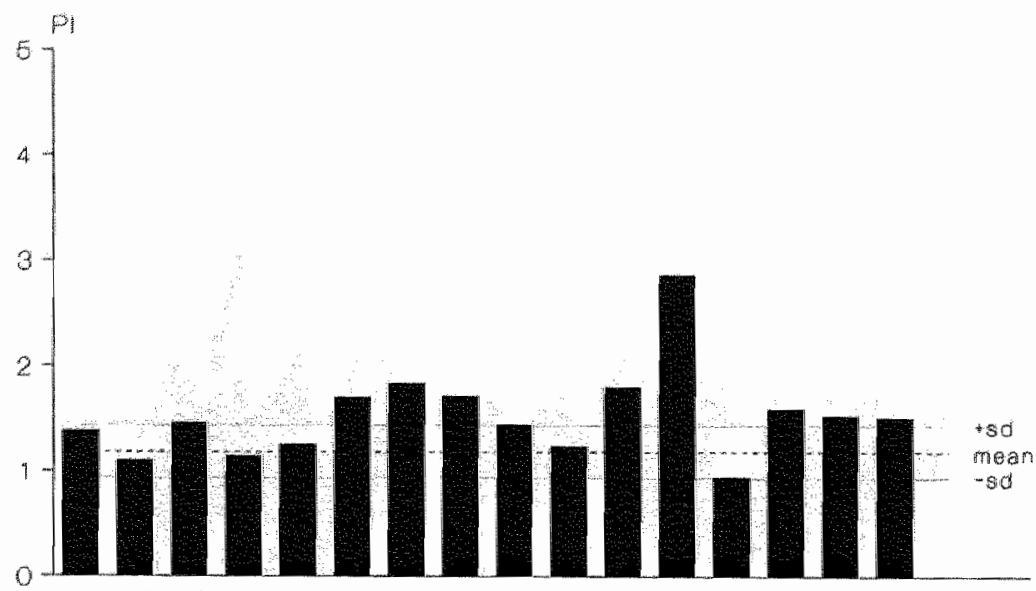

M1 M2 M3 M4 M5 ME MT U H1 H2 P1 R2 N L1 L2 LO

\section{Flgure B:}

PI values of the umblical artery at 24 weeks for the vartous centres. Dotted lines show the reference value

\section{Umbilical artery 35 wks}

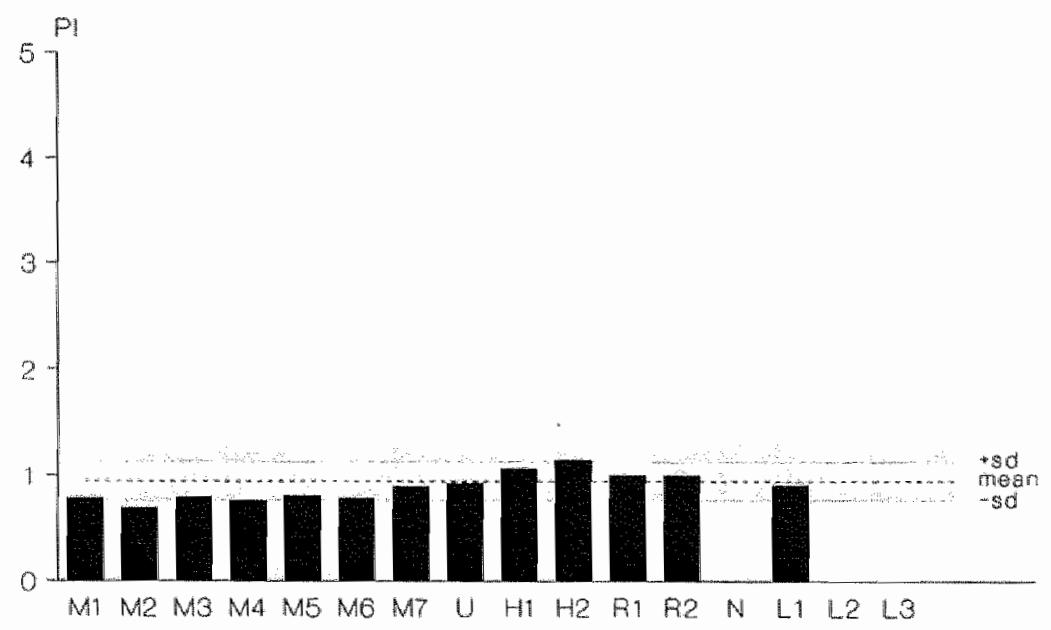

Figure 6:

PI values of the umbillcal artery at 35 weeks for the various centres. Dotted lines show the reference value 


\section{Umbilical artery 25 wks CW}

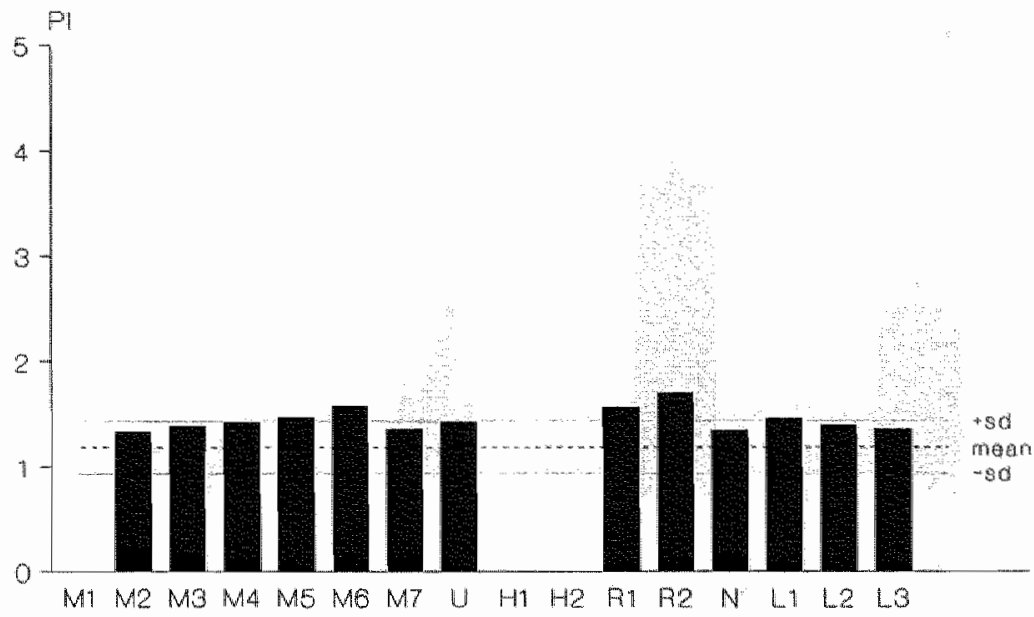

\section{Figure 7:}

PI values (CW) of the umbllical artery at 25 weeks for the various centres.

Dotted lines show the reference value

\section{Umbilical artery 35 wks CW}

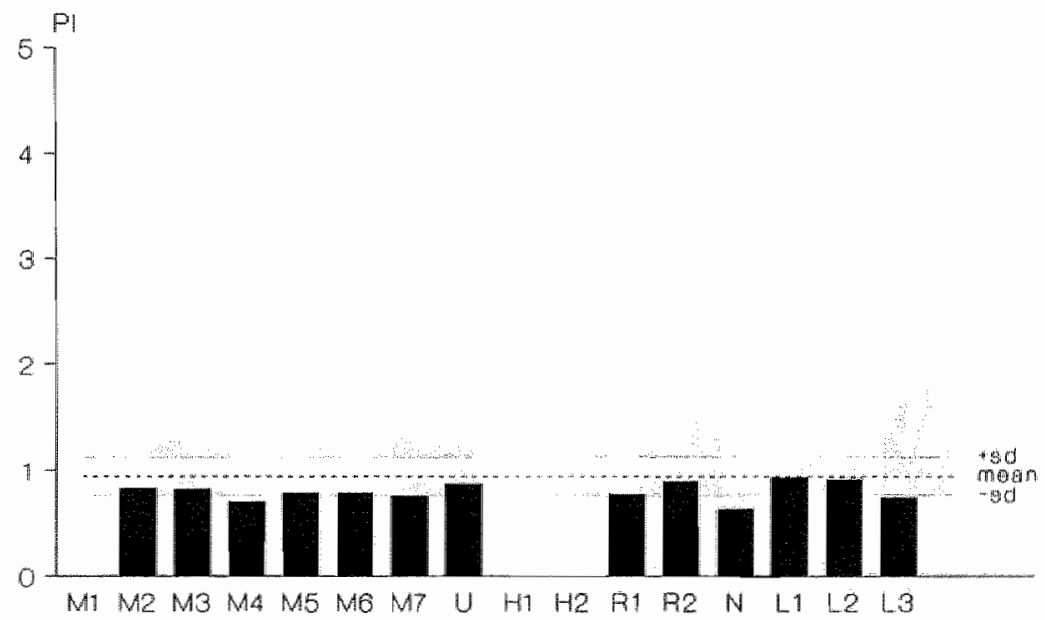

Figure 8:

PI values (CW) of the umbilical artery at 35 weeks for the various centres,

Dotted lines show the relierence value 


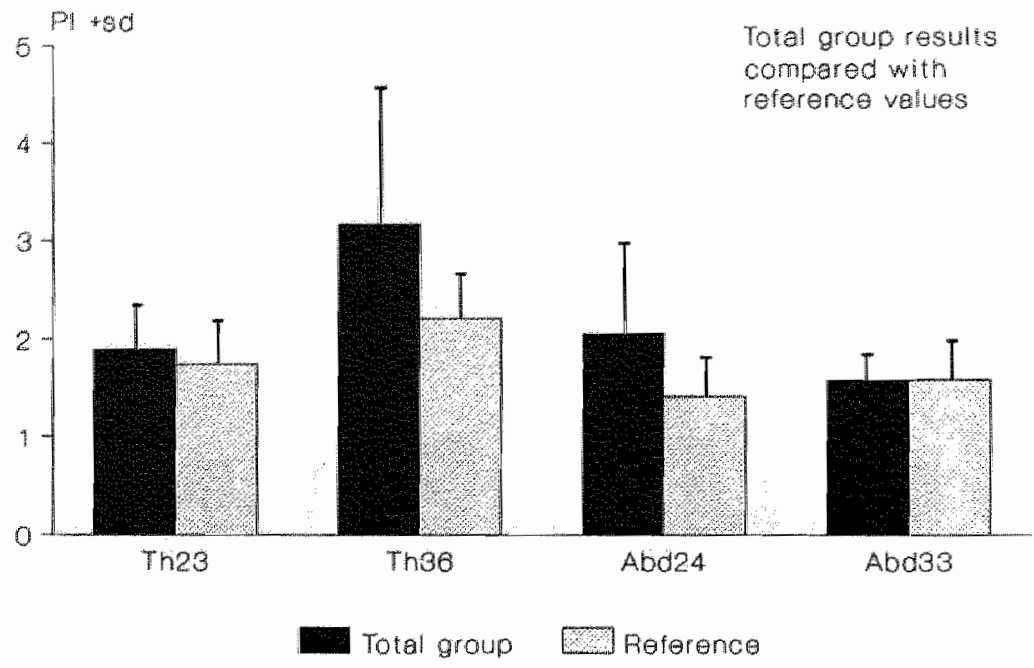

Figure 9a:

Mean PI values $+/-1$ s.d. for all the centres compared to the Maastricht reference values for the thoracic aorta at 23 weeks and the abdomunal aorta at 24 weeks

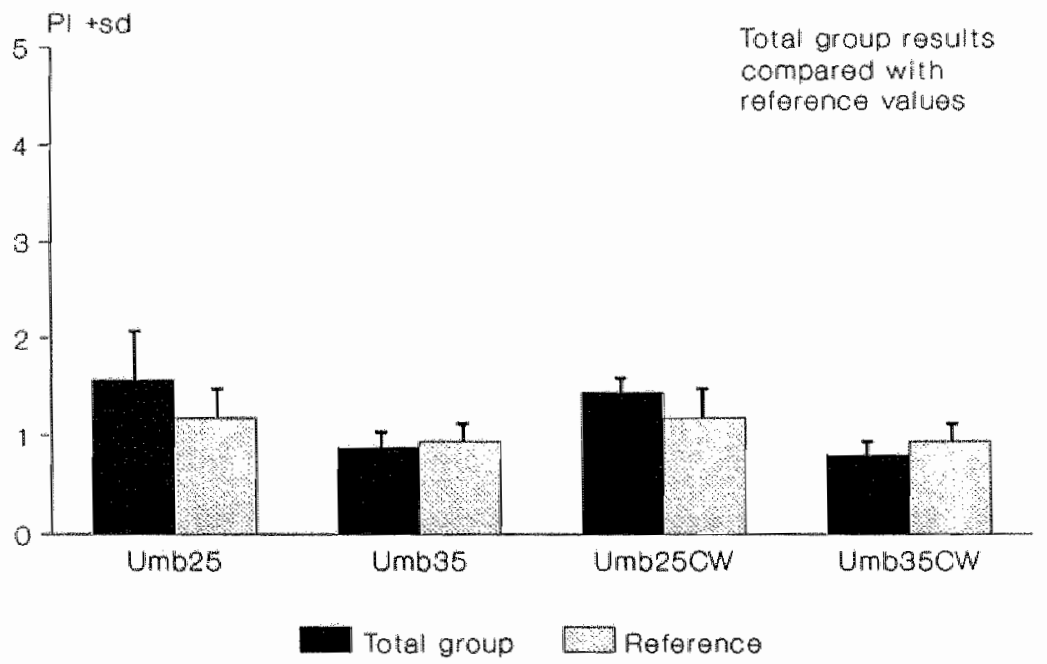

Figure 9b:

Mean PI values $+/-1$ s.d. for all the centres compared to the Maastricht reference values for the umbllical artery at 25 and 35 weeks obtained with $\mathrm{CW}$ and $\mathrm{PD}$ 
Table 1: PI values from the varlous centres

\begin{tabular}{|c|c|c|c|c|c|c|c|c|}
\hline \multirow[t]{2}{*}{ 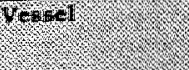 } & \multirow[t]{2}{*}{ weivits: } & \multicolumn{2}{|l|}{ Centre } & \multicolumn{2}{|r|}{$\cdots$} & \multirow[b]{2}{*}{ Habistors } & \multirow[b]{2}{*}{ Maras uno } & \multirow[b]{2}{*}{ Manaste } \\
\hline & & Maas ir 1 & Marstr2 & Malaster3 & Manas $\mathbf{r} 4$ & & & \\
\hline $87 \times 641$ & 23 & $\mathbb{1 1 . 5 1}$ & 1.51 & 1.95 & 2.02 & 2.24 & 2.30 & 1,87 \\
\hline 16. , arota & 24 & 1.62 & 1.30 & 1.68 & 1.29 & 1.36 & 2.40 & 2.311 \\
\hline 1min & 24 & 11.38 & 1.10 & 1.46 & 114 & 1.25 & 1.70 & 1.83 \\
\hline 460 orotur & 33 & 1.35 & 1.60 & 1.60 & 11.58 & 1.55 & 1.80 & 1.63 \\
\hline $41 \%$ arta & 36 & 1.95 & 2.07 & 2.48 & 3.38 & 3.30 & 324 & 2.49 \\
\hline 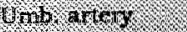 & 35 & 0.78 & 0.69 & 0.79 & 0.76 & 0.80 & 0.78 & 0.89 \\
\hline 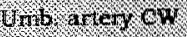 & 25 & - & 1.33 & 1.38 & 1.42 & 1.47 & 1.58 & 1,35 \\
\hline 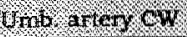 & 35 & - & 0.83 & 0.82 & 0.70 & 0.78 & 0.78 & 0.70 \\
\hline
\end{tabular}

\begin{tabular}{lllllllll}
\hline $\begin{array}{l}\text { Centre } \\
\text { Utrecht }\end{array}$ & Herlev1 & Herlev2 & Rdam1 & Rdam2 & Nifjm & Lond1 & Lond2 & Lond3 \\
\hline 1.72 & 1.39 & 1.39 & 2.20 & 2.17 & 2.37 & 1.89 & 2.00 & 1.84 \\
1.71 & 1.91 & 2.13 & - & 3.56 & 1.11 & 3.19 & 3.26 & $1.96^{*}$ \\
1.71 & 1.44 & 1.24 & 1.80 & 2.86 & 0.94 & 1.59 & 1.53 & 1.51 \\
- & 1.24 & 1.17 & 1.95 & 1.94 & - & 1.52 & 1.53 & 1.53 \\
2.00 & - & - & - & 5.67 & 3.95 & 4.17 & 4.00 & $2.41^{*}$ \\
0.92 & 1.06 & 1.14 & 1.00 & 1.00 & - & 0.90 & - & - \\
1.42 & - & - & 1.56 & 1.69 & 1.34 & 1.45 & 1.39 & 1.35 \\
0.87 & - & - & 0.77 & 0.89 & 0.63 & 0.93 & 0.91 & 0.74 \\
\hline
\end{tabular}

\begin{tabular}{llll|}
\hline Mean PI & s.d. & Ref. PI & s.d. \\
\hline 1.90 & 0.32 & 1.74 & 0.27 \\
2.05 & 0.76 & 1.41 & 0.27 \\
1.57 & 0.42 & 1.18 & 0.25 \\
1.57 & 0.22 & 1.58 & 0.27 \\
3.17 & 1.10 & 2.21 & 0.27 \\
0.88 & 0.13 & 0.94 & 0.18 \\
1.44 & 0.11 & 1.18 & 0.25 \\
0.80 & 0.08 & 0.94 & 0.18 \\
\hline
\end{tabular}

- , no value

" not reliable

The dotted lines represent the mean value (plus and minus 1 standard deviation) of the reference values for the PI based on a longitudinal study performed in Maastricht by van Vugt et al. [176,177]. For the mean PI in the umbilical artery they reported the value: $\mathrm{PI}=1.68-0.021 \cdot \mathrm{MA}$ (Menstrual Age). These values were obtained from normal pregnancies with the $2 \mathrm{MHz}$ Pedof system. The velocity tracings were digitized and the indices were calculated with a computer, similar to method M1.

We decided to compare the results of the different centers with the reference PI values for that particular gestational age, in order to see whether a center would classify a patient as normal or as abnormal. For the thoracic aorta at 23 weeks all of the sixteen methods were successful in producing a PI value 


\begin{tabular}{|c|c|c|}
\hline & Successful PI & Withln normal range \\
\hline 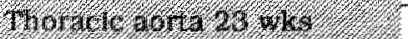 & $16[100 \%)$ & $9(56 \%)$ \\
\hline 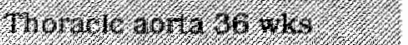 & $13(81 \%)$ & $6(46 \%)$ \\
\hline 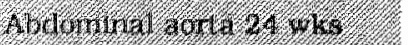 & $15(94 \%)$ & $5(33 \%)$ \\
\hline 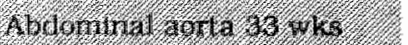 & $14(88 \%)$ & $10(71 \%)$ \\
\hline 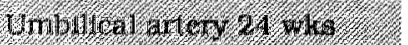 & $16(100 \%)$ & $7(44 \%)$ \\
\hline 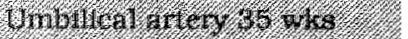 & $13(81 \%)$ & $9(69 \%)$ \\
\hline 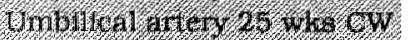 & $13(81 \%)$ & $7(54 \%)$ \\
\hline 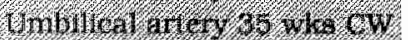 & $12(81 \%)$ & $11(84 \%)$ \\
\hline
\end{tabular}

Table 3: Equpment and methods of the various centres

\begin{tabular}{|c|c|c|c|}
\hline Contro & Tape & Procesaling & Computation \\
\hline Mor.4molu & Inst.rec. & Spectr. analyzer $A^{\alpha}$ & Digltizer/Computer \\
\hline Marastiong & Cass/sep & Spectr. analyzer $\mathrm{A}$ & Digitizer/Computer \\
\hline Marastion 1 w & Cass/quad & Spectr. analyzer A & Digitizer/Computer \\
\hline Nodrtrotst & Crass/sep & Spectr. analyzer $B^{\text {at }}$ & Automatic \\
\hline Mrastidulus & Cass/sep & Spectr. analyzer B & Digitizer/Computer \\
\hline Nows 141016 & Cass/quad & Spectr. analyzer B & Automatic \\
\hline Mrasurlebin & Cass/quad & Spectr. analyzer B & Digitlzer/Computer \\
\hline Mreoty & Cass/quad & Spectr. analyzer & Automatic \\
\hline H.trovl & Cass/quad & Max. freq. estim. & Manual \\
\hline 140162 & Cass/quad & Mean freq. estim. & Manual \\
\hline $1001 \mathrm{er} 4 \mathrm{mr}$ & Cass/quad & Spectr. analyzer & Computer/automatic \\
\hline wolterding & Cass/quad & Mean freq. estim. & Computer/automattlc \\
\hline Nyrregen & Cass/quad & Spectr. analyzer & Computer/automatic \\
\hline Kondonl & Cass/quad & Spectr analyzer & Automatic method $1 \mathrm{~b}$ \\
\hline Lradon2 & Cass/quad & Spectr. analyzer & Automatic method 2b \\
\hline Londons & Cass/quad & Spectr analyzer & Automatic method 3b \\
\hline a Spectrum & A. ATIO & B: Doptek & \\
\hline & & velope $7 / 8$ (Doptek) & \\
\hline Method: & frequenc? & lope 15/16 (Doptek) & \\
\hline Met & frequenc & ght pen (Doptek) & \\
\hline
\end{tabular}

and 9 out of 16 were within the normal range (56\%). For the thoracic aorta at 36 weeks, 6 out of 13 attempts were within the normal range $(46 \%)$. The overall results are listed in table II.

In at least $80 \%$ of the cases the methods used were able to process the signals in order to calculate a PI value, but only in about $60 \%$ of the cases the patients (signals) were classified correctly. Figure 9 shows the mean value of the reference PI and the standard deviation (+ and sd) for the week of pregnancy concerned, and the mean ( + and sd) of the overall results found by all centers (including Maastricht). 


\section{DISCUSSION}

The results show a large variation, not only between the centers, but also within the centers (M,R, H,L). A 'gold standard' to which the results can be compared is not available. A variation in the outcome of the several methods used was also observed in Maastricht. The method used for the determination of the reference values is the most reliable (but also the most laborious): spectral analysis combined with manual tracking of the maximum frequency envelope of the signal, recorded by a high quality tape recorder. Due to the application of a spectrum analyzer, no information is discarded, and the a-priori knowledge about the course of the frequency spectrum eliminates most of the errors.

The variation is largest for the thoracic and abdominal part of the aorta. In this vessel, high velocities occur in the systolic phase and, hence, high frequencies with a low amplitude over a wide frequency range, leading to poor results with spectrum analyzers, and certainly with zerocrossing decoders. In the umbilical arteries, the variation is less, due to the fact that the signal to noise ratio is higher and the bandwidth of the signals is smaller.

A major problem, however, is the testing method itself. Copying of the cassette tapes degrades the quality of the signals; the quality of the different cassette recorders is probably not the same. Most spectrum analyzers require quadrature signals; the phase relationship between the signal pair is extremely important for a reliable result. However, with a cassette recorder of the consumer type, it is very difficult to maintain a phase relation of 90 degrees within 3 degrees. Although we advised the use of separate audio signals, some centers had to use the quadrature pair.

There were no obvious systematic errors: signals obtained earlier in pregnancy did not cause more problems than signals recorded later in pregnancy. Signals from the aorta are probably harder to record, but in processing and PI calculation there was no difference, although the deviations from the reference value were much larger for the aorta than for the umbilical artery.

The poor result of this study may have several causes: the test method itself, the narrow margin for the reference values (+ and 1 SD) and/or differences in processing methods, and various other causes.

The method used in this study has several drawbacks which makes It impossible to draw detalled conclusions. The variability in the results obtained within one center are sometimes higher than the average variability between different centers, from which can be concluded that some of the methods used are unable to produce reliable results. The variation in the results shows that comparison of results between centers should be treated with reserve, although for some vessels the results are in reasonable agreement. For the umbilical artery, comparison is more likely to be allowed after careful consideration of the method applied. Comparison of the results for the thoracic aorta, however, is to be discouraged. 
Clinical decisions based upon PI values of the umbilical artery should remain preliminary as long as there are no generally accepted reference values, based upon standardized calculation methods.

\section{Acknowledgements}

We would like to thank the following persons (in alphabetical order) for their participation. Prof. S. Campbell. London; Dr. H.W. Jongsma, Nijmegen; Prof. F. Larssen, Copenhagen; Dr. P. Reuwer, Utrecht; Dr. P. Sindberg Eriksen, Herlev/Copenhagen; Prof. J.W. Wladimiroff, Rotterdam.

This study was carried out and supported by the EC study on Perinatal Monitoring. 3rd Medical Research program, 1.1.1. 


\section{Chapter 6}

\section{THE INFLUENCE OF MATERNAL EXERCISE ON THE PULSATILITY INDEX OF THE UMBILICAL ARTERY BLOOD FLOW VELOCITY WAVEFORM}

C. Ruissen, W. Jager, M. v. Drongelen and H. Hoogland The influence of maternal exercise on the pulsatility index of the umbilical artery blood flow velocity waveform Eur J Obstet Gynecol Reprod Biol, 37:1-6 (1990) 


\section{The influence of maternal exercise on the pulsatility index of the umbilical artery blood flow velocity waveform}

\section{INTRODUCTION}

The Pulsatility Index (PI) as a description of the blood flow velocity waveform in the umbilical artery $1 s$ increasingly used in the management of obstetric patients, although little is known about the way in which pathophysiology of the fetoplacental circulation affects the PI $[82,177]$. The last few years, several reports have been published on the relationship between the PI and fetal wellbeing $[136,9]$. A generally accepted item in this respect is Absent End Diastolic Flow (AEDF) in the umbilical artery which is regarded as a sign of severe fetal compromise [142]. Notwithstanding the generally accepted application of doppler techniques in obstetrics it is important to be aware that doppler ultrasound measures velocities and not flow, and that some so-called pathological findings might also be the result of, often poorly understood, physical limitations [143]. External influences can also determine the results of doppler registrations. In this respect, external factors such as smoking and alcohol intake have been studied in relationship with uterine, aorta and umbillical flow $[152,39]$. Maternal exertion on an ergometer or during jogging has been investigated $[32,73,130]$, but also normal daily strain such as climbing stairs or riding a bicycle may influence the fetal circulation. If hemodynamic changes in the maternal circulation affect the blood flow velocity in the umbilical arteries, these should be standardized for in order to obtain more reliable PI values. To investigate whether a period of rest is required before making PI measurements, we studied the changes in PI values of umbilical blood flow velocities in relation to standardized physical exercise of the mother.

\section{METHODS AND MATERIALS}

Twentythree women from the outpatient clinic were enrolled in the study voluntarily after informed consent. All had had uneventful pregnancies up until the entry into the study and were not under a specific therapy. The mean gestationall age was 28.7 weeks and varled from 14 to 37 weeks. The age of the women was between 22 and 41 years with a mean age of 28.8 years. 
After a 15 minute period of rest, the women were examined with a linear array scanner (Pie Medical 1120) combined with a $2 \mathrm{MHz}$ pulsed doppler system (Pedof, Vingmed), modified with a doppler high-pass filter of $50 \mathrm{~Hz}$. A free floating part of the umbilical cord was located and blood velocities were measured in absence of excessive fetall movements and fetal breathing. At least five stable heart beats were recorded and the site of measurement was marked on the skin. Maternal blood pressure was recorded with a standard sphygmomanometer and stethoscope with the volunteers in the supine position after 10 minutes of rest. In addition the maternal heart rate was recorded. Then the women made 20 deep knee bends alongside the examination table. Immediately after this exertion blood pressure and heart rate were measured again and in the same position as before, the umbilical artery blood flow velocity was recorded within two minutes. All signals, the doppler quadrature pair as well as the echo-Image of the location were stored on a HiFi video recorder with high quality (digitally converted) audio channels (Sony Betamax SL9). The recorded signals were analyzed off-line with a spectrum analyzer (Doptek) and the mean PI was calculated from five consecutive heartbeats using the maximum frequency envelope. The fetal heart rate was also calculated from the doppler signals. Statistic analysis was performed with the non-parametric Wilcoxon test for paired samples, used because of the low number of subjects and the not normally distributed values, with SPSSPC+ statistical software (SPSS-inc.).

\section{RESULTS}

The PI values measured before exercise were all in the normal range, as established by van Vugt et al. [177] in our hospital. No abnormal blood pressures were found before exercise (WHO limits $18.6 / 12.0 \mathrm{kPa}$ or $140 / 90$ $\mathrm{mm} \mathrm{Hgl.} \mathrm{The} \mathrm{mean} \mathrm{PI} \mathrm{before} \mathrm{exertion} \mathrm{was} 1.25$ with a standard deviation of 0.27 . The mean PI immediately after exercise was 1.23 with a standard deviation of 0.32 . Each woman was considered to be her own control subject; the differences between the PI values before and after exercise are shown in fig. $1 \mathrm{a}$ and $\mathrm{lb}$. Statistic analysis showed no significant difference before and after exercise (threshold $p=0.05$ ). The difference in fetal heart rate (FHR) in beats per minute (bpm) was small and not significant: $142.5 \mathrm{bpm}(\%-10.5)$ before and $141.9 \mathrm{bpm} \mathrm{(} \%$ 12.4) after exercise. Maternal heart rate (MHR). however, varied significantly before and after exertion: 86.1 and $112.2 \mathrm{bpm}$ with standard deviations of 11.2 and 14.3 .

Maternal blood pressure was higher after exercise, the systolic blood pressure showing a larger difference of $2.5 \mathrm{kPa}(18.8 \mathrm{~mm} \mathrm{Hg})$ than the diastolic pressure which only changed $0.27 \mathrm{kPa}(2.0 \mathrm{~mm} \mathrm{Hg})$. 


\section{PI-difference}

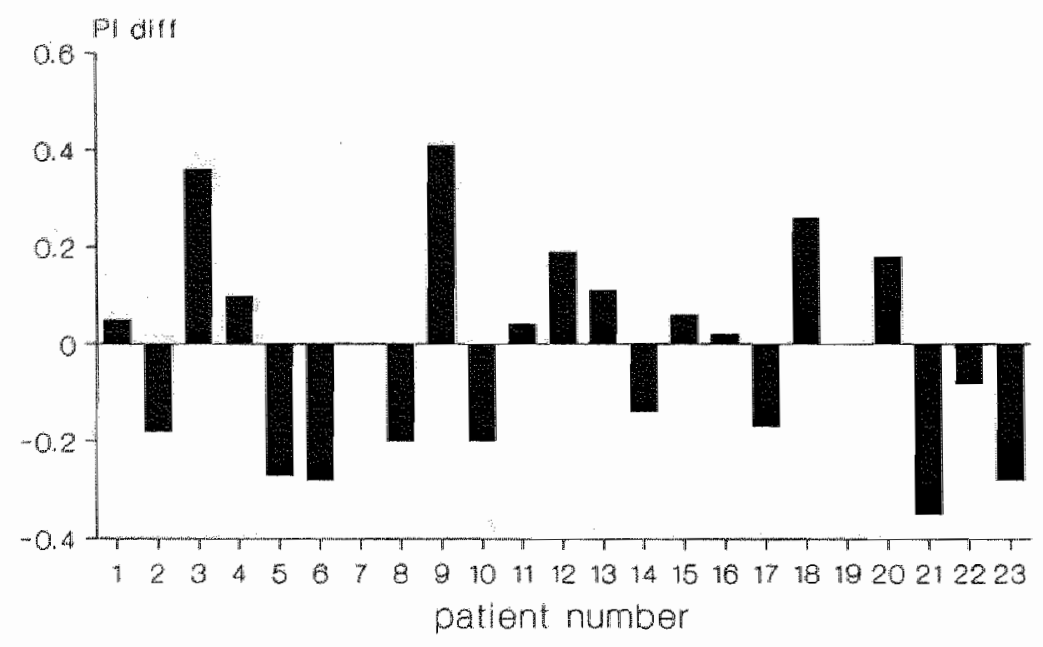

Figure 1a:

Difference In PI values after and before exercise per patient number

\section{PI-difference}

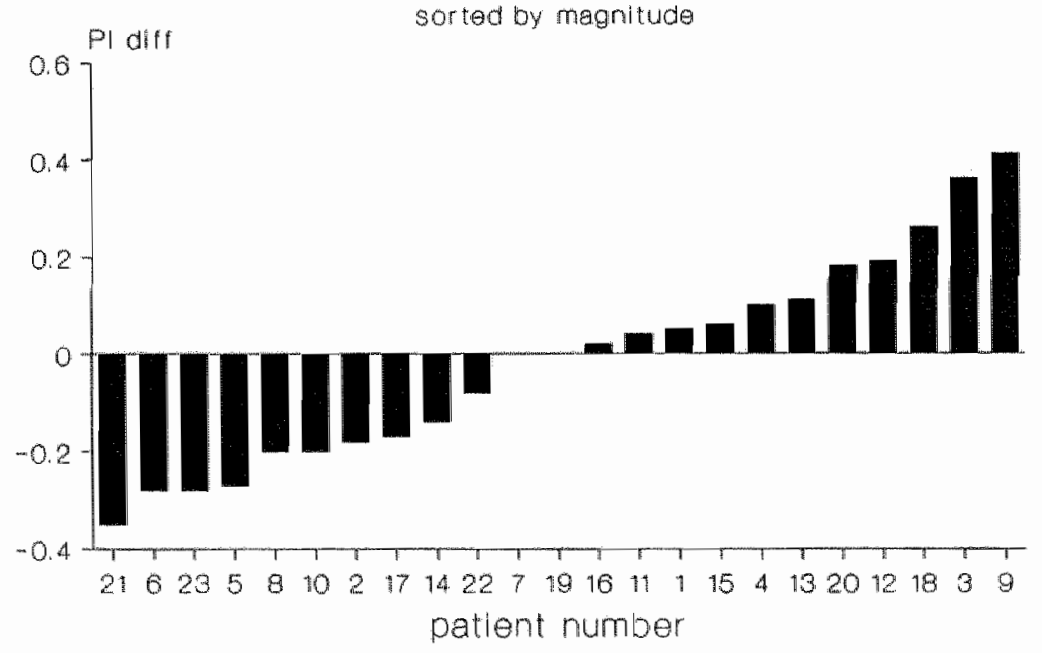

Figure 1b:

Ranked difference in PI walues after and before exercise 


\section{RE vs PI-difference}

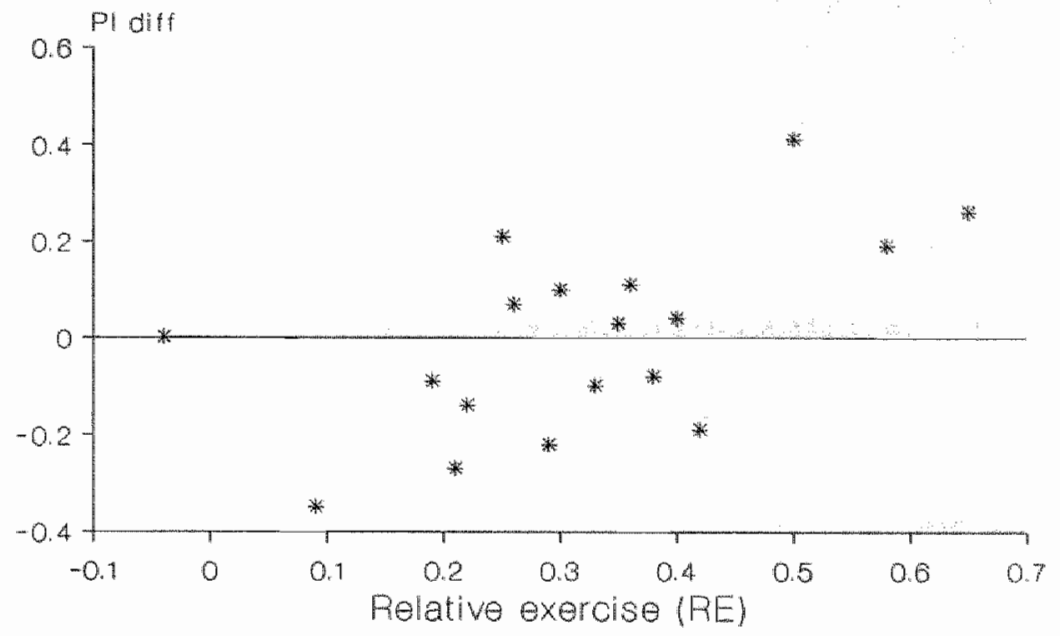

\section{Figure 2:}

Dufference in PI values as function of the Relative Exercise (RE) calculated from the increase in MHR

Because the women were not comparable with respect to physical condition and gestational age, a multiple regression analysis was performed to discriminate for the several covariables, such as increase in maternal heart rate, fetal heart rate, maternal age and gestational age. From physiological research it is known that the increase in heart rate reflects exertion. Therefore, the relative exercise factor (RE) from the increase in MHR could be calculated and plotted against the difference in PI before and after exertion (fig. 2). A linear correlation analysis showed no significant linear relationship between the two variables. Introduction of this $\mathrm{RE}$ in the multiple regression analysis did not change significance. None of the covarlables were found to alter the nonsignificance of the difference in PI values.

\section{DISCUSSION}

In this study no significant difference was found in the PI values before and after exercise. Knowledge of externally induced effects on fetal hemodynamics are of major importance with regard to standardization procedures in doppler research in order to guarantee the fetal origin of data. Sindberg-Eriksen and Marsal [152] found an effect of smoking on the end-diastolic velocities in the umbilical artery and hence an effect on the PI, which disappeared after 10-20 minutes. Erskin and Ritchie [39] found no effect of alcohol intake on umbilical 
artery blood flow. However, it is assumed that there are substances produced by the mother that affect the umbilical circulation. With respect to exercise, circulating catecholamines following stress or an increase in maternal and possibly fetal temperature may be considered of influence. Collings and Curet [32] investigated fetal heart rate response to maternal exercise. They found a significant increase in FHR after exertion. However, the study group differed completely from our group. Their volunteers participated in an aerobic exercise program early in pregnancy and she used much higher exercise levels, with an increase in MHR to $140 \mathrm{bpm}$, than in our study.

Hauth et al. [73] also found an increase in FHR after jogging, again at a higher level of strain than in our study, and they used only 7 volunteers who were well trained. Pijpers et al. [130] reported no cardiovascular signs of fetal stress immediately after moderate short term maternal exercise. However they did not calculate the PI and admitted only subjects in late pregnancy, where the cardiovascular response is likely to be different from that early in pregnancy. Moore et al. [116] also suggested that non-exhaustive maternal exercise does not compromise the uterine circulation, which is one of the mechanisms by which the fetal cardiovascular circulation could be affected.

Our study design was focussed on the question whether or not one should standardize for moderate daily exercise or a moderate increase in maternal heart rate in routine outpatient clinic PI studies. The PI values before exercise found in the examination group were in accordance with previous findings by van Vugt et al [177]. The relationship between the PI and gestational age was also in agreement with his findings: $\mathrm{PI}=1.68-0.021 \cdot \mathrm{GA}$. The multiple regression analysis performed to investigate the effect of gestational and maternal age showed no change in significance.

A drawback of our approach is the lack of quantification of the exercise used. The different methods in use have the disadvantage that they are either invasive or impractical in a outpatient situation. In order to correct for this we introduced the relative exercise (RE) factor which, however, did not alter the results of the statistical analysis.

\section{CONCLUSION}

No difference in PI values of the umbilical artery blood flow velocity was found after moderate exercise of the mother, irrespective of maternal and gestational age or maternal condition. The amount of exercise was comparable with normal daily strain such as climbing stairs. We may, therefore, conclude that it is not necessary to precede an echo-doppler investigation by a period of rest. However, the group investigated had uneventful pregnancies with a normal outcome and only a moderate level of exercise was used. One may not conclude, therefore, that the umbilical circulation in severely compromised fetuses is not influenced by strain. 


\section{Chapter 7}

\section{SOME CHARACTERISTICS OF THE UMBILICAL ARTERY BLOOD FLOW VELOCITY WAVEFORM AS FUNCTION OF MEASUREMENT SITE}

C.J. Ruissen, M.M.H.P. v. Drongelen, H.J. Hoogland, A.P.G. Hoeks

Characteristics of the umbilical artery blood flow velocity waveform as function of measurement site Gynecol Obstet Invest: in press (1990) 


\section{Some characteristics of the umbilical artery blood flow velocity waveform as function of measurement site}

\section{INTRODUCTION}

Optimal fetoplacental circulation is required to supply the unborn child adequately with oxygen and nutrients and remove waste products, thereby providing optimal conditions for an undisturbed development. Until recently it was impossible to assess this essential part of the fetal circulation as a means of determining fetal condition.

Doppler techniques made it possible to obtain information on this circulatory system. Within little more than one decade these techniques have swiftly advanced into a possible meaningful tool in obstetric management [167], particulary after the introduction of several angle-independent parameters, such as the Pulsatility Index (PI) [59], the Resistance Index (RI) [13I] and the $A / B$ ratio [158], to qualitatively describe the velocity signal. This, despite the strongly diverging values for sensitivity, specificity and post-test probability in the various studies $[136,167,175]$. Several factors can be held responsible for the poor agreement, such as research design, variability of the parameters due to physiological variations, measurement inaccuracies and other yet unknown factors [125, 144,173].

The PI is the most widely used parameter for the evaluation of the fetoplacental circulation. Although it is generally considered to reflect placental vascular resistance, the PI in the umbilical artery depends on three main factors: the pressure pulse at the input of the umbilical artery, peripheral impedance and vessel wall characteristics. If the umbilical cord only has a transport function, the PI should, therefore, not change substantially with increasing distance from the source, i.e. the point of branching from the internal iliac arterles. Furthermore, an almost constant flow velocity distribution (flow profile) allong the umbilical artery may be expected. At the origin of the umbilical blood flow, which is in the abdominal aorta, the pulsatility is high (PI in the range of 2 to 4). At the entrance of the umbilical cord the PI is in the range of 1.2 to 2.0 , depending on MA. From that point the pulsatility of the blood velocity should remain constant from fetus to placenta. The accompanying velocity distribution across the artery can be characterized by the Frequency Distribution Index (FDI), defined as $F_{\max } / F_{\text {mean. }}$. The velocity profile in the aorta is plug-shaped. For an umbilical artery diameter of $3 \mathrm{~mm}$ and a length of the cord of 300 to $500 \mathrm{~mm}$. it can be expected that despite the 
pulsatility, the velocity profile in the umbilical artery is more parabolic $[108,162]$. In a plug-shaped velocity profile, the FDI is more or less one, as virtually all velocities are similar over the cross section of the vessel (fig. 3). The FDI is 2 for a parabolic flow profile, where the maximum velocity is twice the mean. In the umbilical artery, a value between 1 and 2 can be expected. The FDI will change during the heart cycle reflecting the driving force of the left ventricle. Thus peak systole should be selected to calculate the FDI because this point in the heart cycle can be determined unambiguously as the profile is hemodynamically stable because acceleration has ceased. If a significant site dependency would be present, it is important to standardize for measurement location in ordler to obtain comparable results, to reduce the variance in PI values found in normal pregnancies and thus to increase clinical value. The present study was designed to investigate whether there is an influence of sampling site by measuring doppler signals at several standardized locations along the umbilical artery.

\section{MATERIALS AND METHODS}

The population studied consisted of 30 women from the outpatient clinic (22 to 41 years of age, with a mean age of 31.2), who were enrolled in the study voluntarily. At informed consent they all had uneventful singleton pregnancies with fetal growth appropriate for Menstrual Age (MA), and normal blood pressure. Menstrual age, determined by accurate menstrual history and early sonographic assessment of fetal biometry, varied from 23 to 40 weeks (with a mean of 30.0). The lower limit of 23 weeks was chosen in advance, since localization of the doppler sampling sites at an earlier age is unreliable or even impossible. The women were examined in a semi-recumbent position. Depending on the ease with which a reliable signal could be obtained, the duration of the examination ranged from 20 to 45 minutes.

Using real-time ultrasonography with a $3 \mathrm{MHz}$ linear array transducer (Ple Medical 900) four, predefined, representative locations in the course of the umbilical artery were visualized in the following order:

- within the fetal abdomen (location 0)

- 0 to $5 \mathrm{~cm}$ from the abdominal origin of the umbilical cord (location 1]

- in a free-floating part (location 2)

- 0 to $5 \mathrm{~cm}$ before the insertion of the umbilical cord into the placenta (lacation 3)

These locations were brought serially within reach of a $2 \mathrm{MHz}$ pulsed doppler transducer (Pedof), mechanically coupled to the linear array transducer. Evaluation by ear and visual inspection of the signal by means of a spectrum analyzer (Doptek) were used to obtain optimal signals. Low frequency signals from vessel wall movements were eliminated by a $50 \mathrm{~Hz}$ 
high-pass filter, thereby preserving minimal diastolic frequencies. During the doppler recording, the site of measurement was repeatedly verified with respect to the preset conditions. The doppler-shifted signals, and the matching echo images, were recorded on a high quality video tape recorder (Sony Betamax SL 9) for detailed off-line spectral analysis. A signal was defined appropriate for analysis if recorded in a steady-state, defined as the absence of fetal breathing and excessive fetal body movements during a period of at least five successive heart beats. The course of the maximum frequency shift was displayed on the screen of the spectrum analyzer and traced with a lightpen. Mean PI and fetal heart rate (FHR) were calculated by averaging the values obtained from five consecutive heart cycles.

Because a change in PI with sampling site is likely to be accompanied by a change in flow velocity distribution across the vessel, and, hence, in the recorded frequency distribution, the Frequency Distribution Index (FDI), defined as the maximum frequency divided by the mean frequency at peak systole, was calculated.

Only women in whom a high quality signal could be obtained at two or more locations, were included in the statistical analysis, which was performed with the non-parametric Wilcoxon test and the Student $t$-test for paired values. using SPSS-PC statistical software.

\section{RESULTS}

Figure 1 displays a scattergram of the individual PI values at the varlous sampling sites. In 25 of the 30 women (83.3\%) an appropriate signal could be obtained at all four locations. In one case $(3.3 \%)$ only three valid registrations were obtained and in two cases $(6.7 \%)$ two or only one location yielded a useful signal. Reasons for these missing values were fetal breathing, body movements and obscured localization with advanced pregnancy ( $\geq 37$ weeks) due to a decrease in amniotic fluid and in one case due to adiposity.

The PI values at the various locations, in the women included in the statistical analysis, were all within the normal range according to the reference values established by van Vugt et al. [177]. Table 1 shows the mean PI values and the standard deviations at the four measuring locations and the results are graphically presented in figure 2 . To enable comparison, all the values presented are mean values calculated from individual vallues which were corrected for menstrual age (mean menstrual age $=30 \mathrm{wks}$ ). The statistical analysis, however, was performed per patient as our main interest lay in the course of the PI within each individual. Using a threshold of $p=0.05$, the paired Student's $t$-test showed no significant difference in PI values for any of the six different combinations of locations. The same was true for the non- 


\section{PI vs LOCATION}

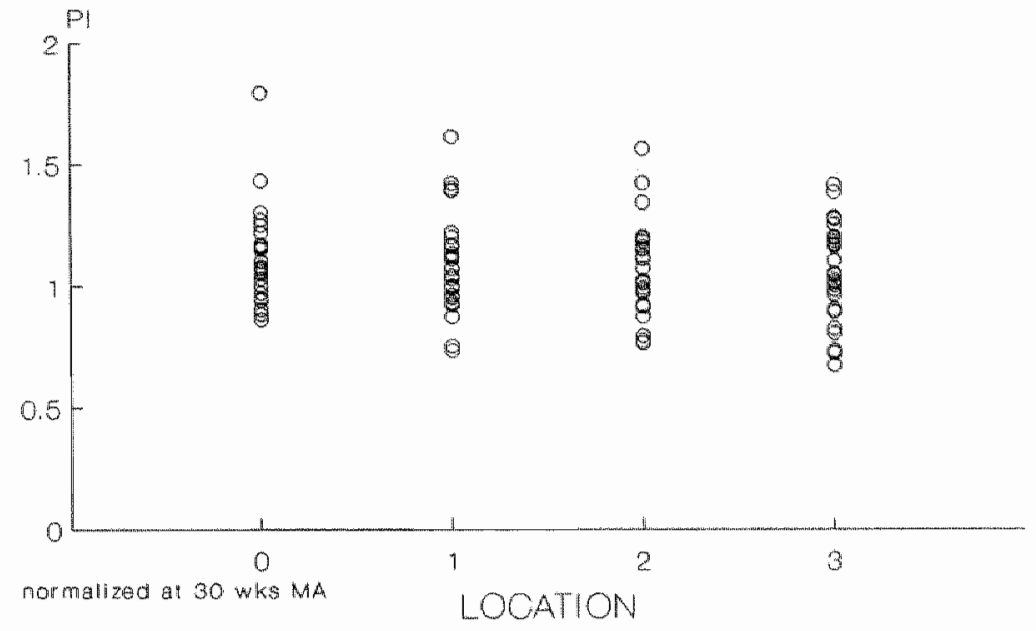

Figure 1:

Individual PI vahes as function of location, norrnallzed at 30 weeks menstrual age.

Table 1: PI values, normalized at 30 weeks menstrual age and the F(requency D(istribution I(ndex) at the varlous locations.

\begin{tabular}{|c|c|c|c|c|}
\hline 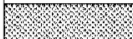 & LOCO & LOC1 & LOC2 & LOC \\
\hline Plorm & 1.095 & 1.098 & 1.071 & 1.052 \\
\hline s.d. & 0.200 & 0.202 & 0.191 & 0.202 \\
\hline nol & 1.381 & 1.384 & 1.384 & 1.387 \\
\hline 80 & 0.107 & 0.146 & 0.153 & 0.142 \\
\hline
\end{tabular}

parametric Wilcoxon test, performed to check whether the low number of cases or the lack of a normal distribution of the values could be an explanation for this absence of significant differences (table 2).

Moreover, the total group was subdivided into 4 classes with respect to menstrual age $(<27$ weeks $(n=8)$, from 27 to 30 weeks $(n=7)$, from 30 to 35 weeks $(n=8)$ and $\geq 35$ weeks $(n=7)]$ to verify whether a hemodynamic gradient could be demonstrated during a particular gestational period. Each group consisted of almost equal numbers of patients. A significant dependency of the PI value on measurement site could not be demonstrated in any of the groups.

To investigate the impact of interindivldual physiological differences within the population studied, a multiple regression analysis was performed. Maternal age, menstrual age and fetal heart rate (FHR) were introduced as the most relevant covariables. Due to the relatively short time-span between measure- 
Trble 2: Means of the difference of the PI values and signincance of the difference of PI and FDr between the stx possible combinations $(\mathrm{p}=0.05)$

\begin{tabular}{|c|c|c|c|c|c|}
\hline \multirow[t]{2}{*}{ 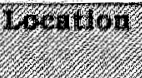 } & \multicolumn{2}{|l|}{ T-test PT } & \multicolumn{3}{|c|}{ Significance* } \\
\hline & Diff mean & s.d. & $T$-test & PI Willcox & PI Willcox FDI \\
\hline 6. & -0.029 & 0,227 & n. & n.s. & n.s \\
\hline 6. 2 & -0.030 & 0.215 & $\mathrm{n}, \mathrm{s}$. & n.s. & n.s. \\
\hline 0. & $-0.07 \%$ & 0.290 & n.s. & n.s. & n.s. \\
\hline 12 & 0.007 & 0.1186 & n.s. & n.s. & n.s. \\
\hline 1.96 & 0.047 & 0.207 & n.. $s$ & n.s. & n.s. \\
\hline 2. & 0.036 & 0.195 & n.s. & n.s. & n.s. \\
\hline
\end{tabular}

\section{PI vs LOCATION}

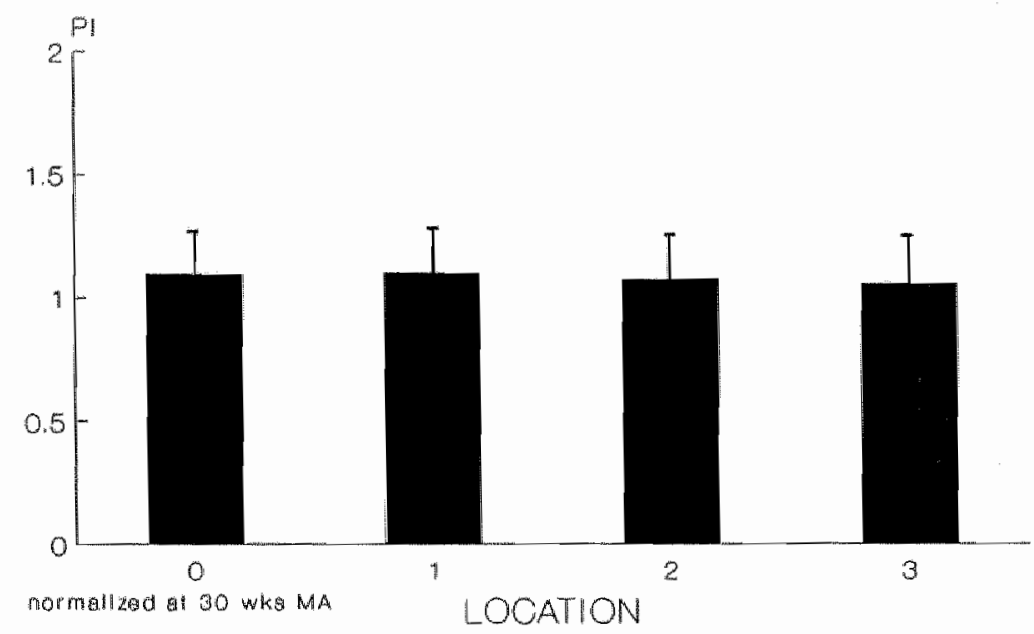

\section{Thüe 2:}

Mean PI values ( +1 s.d.) as function of location, normallzed at 30 weeks menstrual age.

ments, the FHR did not differ significantly between the four locations. Therefore, the value of the mean fetal heart rate at location 0 , measured in the intra-abdominal part of the umbilical artery, was used in the analysis. None of the covariables was found to have a significant influence on a possible difference in the PI value per location. The values for the FDI are also listed in table 1 . Statistical analysis did not demonstrate a significant dependency of the FDI on the position along the umbilical cord. 


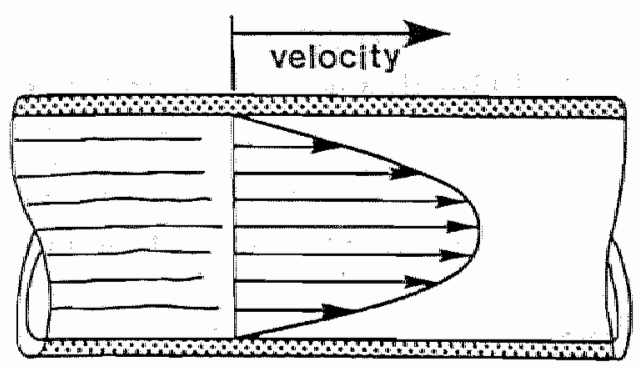

a

Parabolic profile FDI $=2$

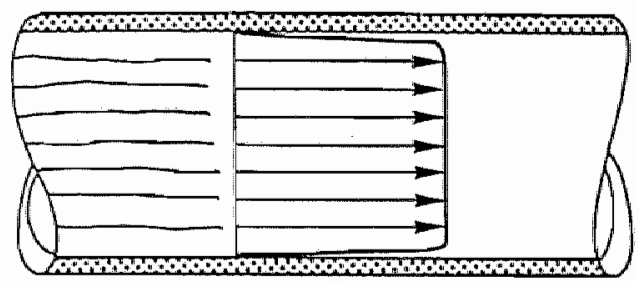

b
Figure 3:

Velocity distribution in a vessel with $F$ (requency) D(istribution) I(ndex):

a. Parabolic profule, $F D l=2$;

b. Plug profile, $\mathrm{FDl}=1$

\section{DISCUSSION}

The main goal of this study was to investigate whether it is necessary to standardize for measurement location in doppler investigations of the umbilical artery. There were no significant differences between the PI values at the selected measurement locations and no clear trend in PI values could be established from the fetal origin to the placental end of the umbilical cord.

This is in accordance with the findings of Trudinger et al. [167], who did not observe a difference in umbilical artery signals recorded at two different locations on opposite ends of the umbilical artery in 8 subjects. Other investigators, however, did find a significant difference between indices at the fetal and placental end of the umbilical artery. This might partially be explained by inaccuracies in the determination of the enddiastolic frequency caused by a too high cut-off frequency of the highpass filter in combination with an unfavorable angle of investigation. Mehalek et al. [110], in a pulsed doppler study in 58 uncomplicated pregnancies, found significantly higher values for PI, RI and A/B ratio at the fetal insertion of the umbilical cord. However, the figures presented in this study, showed a surprising difference in the variation-coefficient between the PI, RI and A/B ratio and between the two measurement locations, although the same waveforms were used for the calculations. It is unclear what the influence of this varlation is on the statistical analysis. 
Abramowicz et al. [3] combined the results of Continuous Wave doppler and Pulsed doppler in the statistical analysis. Due to the different variation-coefficients of $\mathrm{CW}$ and $\mathrm{PD}$, this is debatable. In addition, they used the S/D ratio which is known to be highly non-linear as function of peripheral impedance. In an abstract on the influence of measurement location on PI values, Maulik et al. [101] reported a statistical significant difference between the fetal and placental end of the umbillical artery. As detailed information on their study design was not provided, it is unclear if the t-test used in the evaluation of the differences in the PI data (1.14 \pm 0.24 and $0.93 \pm 0.23)$ was justified.

One of the reasons for the absence of a clear gradient in our study may be the inaccuracy in the location of the predetermined positions. The selected sites were carefully located and anatomical landmarks were used where possible. However, complete certainty with regard to the correct location cannot be achieved with grayscale scanning equipment. The use of color doppler Imaging could improve rellability. Nevertheless, if indeed a gradient in PI would exist in the umbilical artery, the difference should be greatest between origin and end of the umbilical artery. Neither for the PI nor for the FDI could such a gradient be demonstrated.

It is likely that a gradient would be menstrual age dependent, but even by dividing the study group into sub-populations according to MA, the possible relationship was not apparent. The absence of a gradient could also be attributed to methodological factors such as the restricted number of subjects and the limitations of the gray-scale equipment. Further research, preferably with Color doppler imaging, is needed to reveal the contribution of the umbilical cord to the hemodynamic behavior of the fetoplacental circulation.

\section{CONCLUSION}

From our results it can be concluded that there is no significant dependency of the PI value on the site of measurement in the umbilical cord. As the umbilical arteries are rich in muscular fibers, they are likely to have a low compliance [121]. The damping effect of the umbilical arteries on the pulsatility of the blood flow velocity can be neglected. The main damping of the pulsatility occurs in the placenta itself. Because of the uniform distribution along the course of the umbilical cord. there is no PI and FDI gradient, so it is not necessary to standardize for sampling site when performing routine doppler studies in pregnancy. Although the umbilical cord does not seem to play an important role in damping of the pulsatile umbilical blood flow, other hemodynamic functions need to be investigated. The availability of CDI systems may be a great asset in the study of unknown mechanisms in the fetoplacental circulation. 
Chapter 8

\section{UMBILICAL BLOOD FLOW VELOCITY PI AND PLACENTAL IMPEDANCE}




\section{Umbilical blood flow velocity PI and placental impedance: a study in fetal lambs}

\section{INTRODUCTION}

As has already been mentioned in the previous chapters, the feto-placental circulation can be approximated by a simple network with an umbilical artery resistance $R_{1}$ and a placental resistance $R_{2}$ in parallel with the placental compliance $C$. From this network, it can be inferred that the pulsatility of blood flow is determined by the ratio of the two resistors, and by the capacitor C. Several authors $[50,55]$ associate placental pathology with an increase in resistance [107]. The chief function of the placenta is fetomaternal exchange and it is a matter of debate whether its transfer function is influenced by the resistance of the placenta, the compliance of the placenta or a combination of both. In a steady state condition, which is comparable to a direct current (DC) in an electrical network, diffusion is promoted by the contact time of the red blood cells with the vessel wall. On the other hand, in larger capillaries, only the outer cells near the vessel wall have the possibility to transfer oxygen and metabolites. Mixdng of blood is facilitated by a certain pulsatility in blood flow, in electrical terms an alternating current $(\mathrm{AC})$, in such a way that all cells take part in the exchange process. From the electric network it can be derived that the compliance, 1.e. the capacitor $C$, does not play a role in DC situation (continuous flow), because the impedance of a capacitor $\mathrm{X}_{\mathrm{c}}$ is proportional to the reciprocal of the applied frequency $\left(X_{C}=1 /(2 \cdot \pi \cdot f \cdot C)\right.$, and hence is infinite for a DC flow. In case of AC flow, the compliance also determines the behavior of the network $[94,124]$.

In instrumented animal experiments, such as fetal sheep models, the resistance of the placenta is generally calculated from the time averaged flow. divided by the time averaged pressure. This means that the AC component of blood flow is neglected, and only the static resistance is calculated. It can be imagined that the compliance varies in certain experimental and pathological conditions, whereas the resistance remains the same (fig. 1). Thompson and Stevens [163] indicated that the $\omega R \mathrm{RC}$-product should be much greater than 1 , which means that the compliance of the placental bed must be large with respect to the input frequency of the system, i.e. the fetall heart rate, normally approximately $2.5 \mathrm{~Hz}$. If the compliance decreases to very low values. the PI may become dependent on the compliance. 

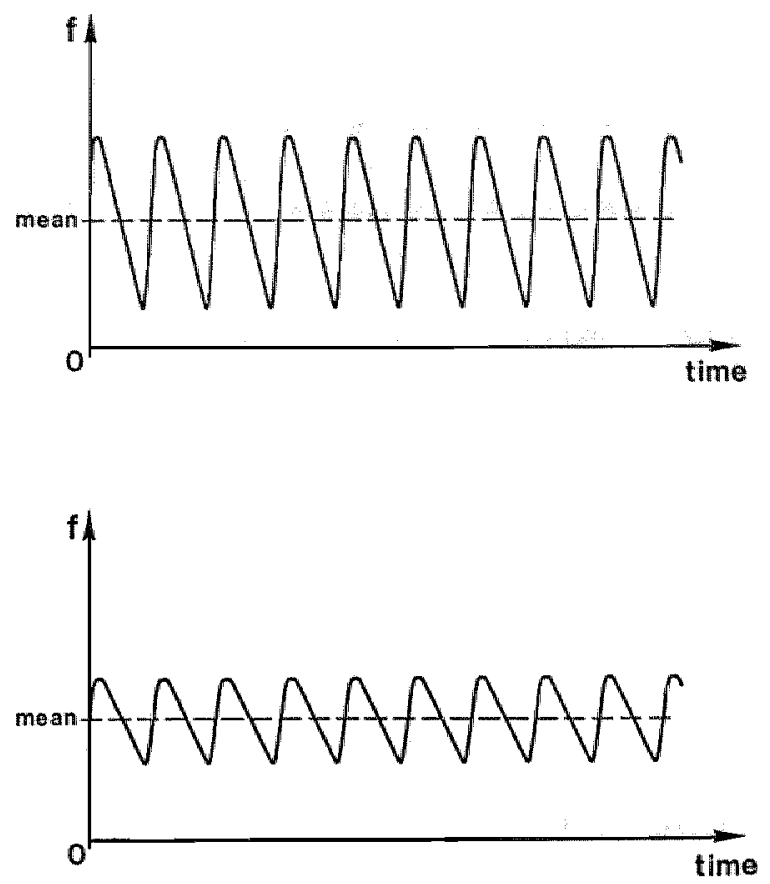

\section{Figure 1:}

The dependency of the pulsatility on the compliance. The upper panel shows a high pulsat1ity in case of a high compliance, with a certain mean value averaged over time. The lower panel shows a lower pulsatillty with the same time averaged mean, in case of a low compliance. As a result, the PI in the upper situation will be higher than in the lower case.

In physiological terms it means that the diameter of the total vascular bed does not change, whereas the elasticity does change. This situation will not be recognized by the before mentioned time average calculation method, whereas the pulsatility, and hence the PI, will be affected. The goal of this study was to investigate whether a change in placental compliance could be induced, irrespective of the mechanism, and whether this change in compliance is associated with a change in PI of the umbillical bllood flow velocity waveform. The analysis of the impedance, however, can not fully explain the behavior of the PI because the pulsatillity index does not take into account the frequency content of the local pressure pulse, but only regards the velocity waveform. 
The determination of the impedance requires the measurement of the frequency dependent behavior of a system. This can only be performed with at measurement system that allows high frequency resolution measurements. Because frequency is reciprocally proportional with time $(f=1 / t)$, a high speed measurement system for pressure and flow is required. To this end, flow was measured with an electromagnetic flow meter and pressure with a external mernbrane pressure sensor connected through a water filled catheter. The experiments were carried out in 3 ewes of the Dutch Texel breed. between 100 and 130 days of gestation. The sheep were instrumented under aseptic conditions and general anesthesia, induced with pentobarbital and maintained with $5 \%$ halothane. The abdomen of the ewe was opened with a paramedian incision, and the fetal lamb was approached by hysterotomy. An electromagnetic flow transducer was placed around the common umbilical artery, and a catheter was advanced through the fetal femoral artery to a point close to the fetal abdominal aorta. In this way it was possible to measure the instantaneous flow and pressure curves of blood entering the umbilical artertes. Doppler signals were measured in the common umbilical artery by an implanted doppler transducer of a $20 \mathrm{MHz}$ system. The electrical signals of pressure and flow, as well as the doppler audio signals were recorded on an analog instrumentation recorder for further off-line analysis. The experiments were part of a more elaborate study to investigate the circulatory changes in fetall lambs after the application of vasoactive drugs and embolization of the placental vessels. The following interventions were made to change the fetoplacental impedance: noradrenaline, angiotensin II and stepwise embolization of the placenta by sephadex microspheres injection in the umbilical arteries. In each experiment the instantaneous pressure and flow curves were recorded to estimate the change in impedance and the doppler signals were used to calculate the associated Pulsatility Index. All experimental conditions were preceded by a steady state period of 10 minutes to enable comparison. PI values were calculated with a Doptek spectrum analyzer, by tracing the maximum frequency curve, and pressure and flow signals were digitized with a $500 \mathrm{~Hz}$ sample frequency to preserve sufficient time resolution, and were stored on a personal computer. Estimation of the change in impedance was performed in the frequency domain by fast. Fourler transformation of flow and pressure signals. Comparisons were made between the zero frequency DC component ( $\left.\mathrm{f}_{\mathrm{O}}\right)$ and the first, second, third and fourth harmonic $\left(f_{1}, f_{2}, f_{3}, f_{4}\right)$ of the impedance. 


\section{RESULTS}

The hypothesis is, that an increase in resistance of the placenta, can be estimated by the fo (DC) component, whereas the value of the higher harmonics in relation to the $\mathrm{DC}$ component gives an estimation of the compliance. A decrease of the compliance alone by a substance reducing the elasticity of the vascular bed, will lead to a constant ratio for the DC $\left(f_{0}\right)$ and an increased ratio for the higher frequency components with respect to the steady state. The results of part of the calculations are listed in table 1, which shows the ratios of the various frequency components in steady state and experimental conditions. A ratio of less than 1 means that that particular frequency component of the impedance is smaller than the DC component. The associated PI values are listed in the last column. In the first column, the various experiments are grouped, where StSt means the steady state situation. NA are the noradrenaline experiments, AT indicates the angiotensin II experiments and EM stands for embolization.

\begin{tabular}{|c|c|c|c|c|c|c|}
\hline & fo & $f_{1} / f_{0}$ & $f_{2} / f_{0}$ & $\mathrm{f}_{3} / \mathrm{fo}_{\mathrm{O}}$ & $f_{4} / f_{0}$ & PI \\
\hline stst & 1.62 & 0.63 & 0.78 & 0.49 & 0.28 & 0.78 \\
\hline $\mathrm{NA}$ & 2.43 & 0.80 & 0.87 & 0.57 & 0.26 & 0.67 \\
\hline $4 r$ & 4.42 & 0.76 & 0.71 & 0.33 & 0.10 & 1.30 \\
\hline EIX & 9.91 & 0.52 & 0.55 & 0.48 & 0.41 & 4.35 \\
\hline
\end{tabular}

\section{DISCUSSION}

The results shown in the table, do not allow a consistent explanation of all the experimental conditions. In the steady state situation, there is a gradual decrease in the higher frequency components, and a PI value in the normal range. In the NA experiments, the pure resistive component has increased, suggesting a higher resistance, but the ratios of the higher frequency components did not change considerably, indicating that the time constant of the circuit did not alter. The increase in resistance, however, is not reflected in the PI value. In the AT experiments, the resistance also increased, paralleled

by an increase in PI. The course of the higher frequency components remained comparable to the other experimental conditions. The PI after embolization shows values as would be expected from the increase in blood flow resistance indicated by the marked increase in the DC component. The higher frequency components, however, do not show the gradual decrease present in the other experimental conditions. This suggests that the compliance of the remaining vascular bed is reduced. 
Adamson et al. in their publication [6] described the influence of drugs, as used in this study, on the umbilical cord resistance and the placental resistance. Angiotensin II appeared to have little effect on the cotyledonary resistance but mainly affected the umbilical artery resistance. The same was true, although to a different degree, for noradrenalin, which appeared to have a marginal effect on the cotyledonary resistance. These drugs seem to act mainly on the vascular systems proximal and distal to the placenta, whereas the placental resistance itself was relatively unaffected. The measurement location used in the present experiment, comprises the total vascular reaction, the placenta as well as the supplying and draining vessels. It is, therefore, not possible to distinguish between the effects at the various vascular levels. The main interest. however, was to investigate whether changes in compliance occur in the fetoplacental circulation and whether these isolated changes in compliance influence the umbilical artery blood velocity waveform PI, irrespective of the pure resistance changes. The measured PI values did increase parallel to the $\mathrm{DC}$ component, but the ratios of the higher frequency components of the impedance did not show significant changes, except in the case of embolization. This suggest that it is not feasible to alter the placental compliance with the drugs used. In addition, technical problems did not allow measurement of the total placental impedance alone, due to the smallness of the vessels involved. Measurement results, therefore, are obscured by larger influences from other vessels. The results of Adamson et al. [6] have not been corroborated by other authors, but there could well be a certain independence of the placental impedance to external influences. Up until now, there is no known vasoactive drug which affects the compliance alone, although in peripheral vascular studies, substances are being tested that may affect mainly the vascular compliance. In further studies these new drugs could be applied in fetal sheep experiments. Moreover, signal processing and impedance analysis might need further improvement to differentiate between the small experimentally induced effects and background noise.

\section{CONCLUSION}

The results of the experiments do not allow definite conclusions to be drawn. There are various sources of error which may contribute to the poor results. The model studies of Thompson et al [163] suggest. however, that it is unlikely, that changes in the placental compliance will affect the umbilical velocity waveform PI in normal and pathological situations. Further studies have to be performed to support this opinion. In experimental conditions, the frequency dependency of the impedance might be an explanation for some of the unexpected results in the investigation of the relationship between PI and placental resistance in animals. 
Chapter 9

\section{DIAMETER CHANGES IN FETAL VESSELS}




\section{Diameter changes in fetal vessels}

\section{INTRODUCTION}

The vessels of both the arterial and venous systems are elastic tubes, enabling them to vary in diameter depending on their anatomical location. physiological function and vessel wall characteristics. In this way, they can adapt to changing situations and play a role in the regulation of local volume blood flow under changing conditions such as cardiac activity and respiratory movements. By studying the adaptation process, it is possible to obtain information about the adaption stimulus, and to learn more about the characteristics of the adapting system.

Because the pulsatility index of the blood flow velocity waveform is determined by the volume ejected by the left ventricle, the local vessel wall properties and the distal impedance, knowledge of all these parameters is essential to properly assess the velocity waveform recorded. In all the PI studies, the role of the left ventricle ejection has been neglected, mainly because this parameter can not be measured noninvasively.

In our working hypothesis, it was assumed that the umbilical cord has mainly a transport function. As a result, the compliance should be low, and the diameter change as function of the heart cycle. will be small. In this chapter, the application of a new method is described to assess arterial wall displacement, to obtain more insight into the fetal circulation related to the heart cycle. This might enhance the clinical value of velocity waveform analysis.

\section{ARTERIAL DIAMETER CHANGE}

Although the venous system is as important as the arterial system, hemodynamic aspects of the great arteries are interesting because the diameter changes as function of cardiac activity contain information on the vessel as well as on the local distension force.

The local pressure increase, generated by the outflow of blood from the left ventricle, causes the vessel to dilate until a new equilibrium between the forces acting on the vessel walls have been established. The compliance of a vessel, which is equivalent to a capacitor in electric networks (fig. 1), is defined as the ratio of the volume increase $\Delta V$ of a segment of that vessel due to a change in local pressure $\Delta \mathrm{P}$. 


$$
C=\frac{\Delta V}{\Delta P}
$$

Therefore, the compliance coefficient $\mathrm{CC}$, being the compliance per unit of length, can be expressed as:

$$
C C=\frac{\Delta A}{\Delta P}=\frac{2 \cdot \pi \cdot r \cdot \Delta r}{\Delta P}=\frac{0.5 \cdot \pi \cdot D \cdot \Delta D}{\Delta P}
$$

where D is the diameter [135]. In an elastic vessel the $\mathrm{CC}$ will be high whereas in a rigid vessel, the $\mathrm{CC}$ will be low. The $\mathrm{CC}$ is governed fully by the elastic characteristics of the vessel wall [109]. In arterial segments, close to the heart especially, the $\mathrm{CC}$ should be high since these segments need to rapidly absorb the flow pulse generated by the heart, thereby reducing the afterload of the heart. As stated before, the $\mathrm{CC}$ is a material parameter and will therefore be independent on heart action and heart rate. It follows from the expression of the $\mathrm{CC}$, that for a large initial diameter, only a minor increase in diameter is needed to achieve a given $\mathrm{CC}$. The fractional increase in diameter, i.e. the ratio of the increase in diameter and the initial diameter, is low. This is expressed by the distensibility coefficient DC (again per unit of length), defined as:

$$
D C=\frac{\Delta A / A}{\Delta P}=\frac{2 \cdot \Delta D / D}{\Delta P}
$$

The distensibility (the fractional increase in diameter normalized with respect to the pressure pulse) is a measure for the adaption of the circulatory system to the pressure pulses present. It can be argued that for a developing fetus both $\triangle D$ and $D$ will increase at the same rate $(C C$ will be almost

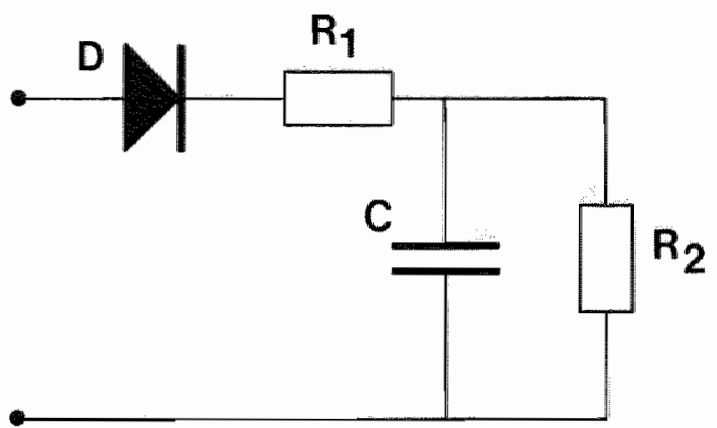

Figure 1:

Approximation of the fetal aorta with a simple RC.

network.

$D=$ diode, $R_{1}=$ inflow resistance, $R_{2}=0$ ut flow $r e$ -

sistance, $\mathrm{C}=$ compliance 
constant), in order to keep the circulatory system balanced. Since at the

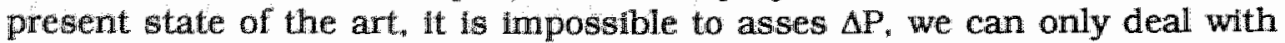
$\triangle \mathrm{D} / \mathrm{D}$. Thus a low distensibility is indicative of a reduced pulse pressure and/or a low compliance. The expression shows the relationship between the driving force in the form of the pressure, and the reaction of the system, expressed by the diameter change, governed by the characteristics of the system, the compliance.

\section{MEASUREMENTS}

With a high resolution diameter measurement system, the diameter change of the fetal aorta and the umbilical artery were studied throughout pregnancy. These diameter changes were related to simultaneously measured Pulsatility Indices (PI) of the blood flow velocities in both arteries. Because the measurement system has been documented in an other publication [77!. only a short description is given here. The vessels of interest are localized with a standard 3.5 or $5.0 \mathrm{MHz}$ duplex system (depending on the depth) with a mechanical sector scanner. The system is provided with a dedicated radiofrequency (RF) output, which makes it possible to transfer the amplified high-frequency echo signals from the transducer directly into the Diameter Measuring System (DMS), together with the necessary timing signals. It is important that no other signal processing, except for depth dependent amplification, has been performed. The DMS itself, consists of a high speed data acquisition system with a large solid state memory to store the echo data ${ }_{\text {" }}$ and a fast personal computer to perform the calculations. With the vessel brought in view, a marker line is set across the vessel and the duplex system is switched to the Time Motion (TM) mode, by which information over that single line only is acquired, at a high repetition frequency. Depending on the depth of investigation, the emission frequency and the selected resolution, it is possible to store local echo information of five to eight heart beats and to calculate the distension curve with an accuracy of more than $10^{-6}$ meter. With the doppler section of the duplex system, blood flow velocities in the vessels were measured and an off-line calculation of the PI with a spectrum analyzer, using the maximum frequency envelope, was performed.

In 40 healthy pregnant subjects with MA ranging from 23 to 33 weeks, one or both vessels were recorded. In one volunteer, measurements were repeated throughout pregnancy to investigate the influence of gestational age. Before discussing the results of the measurements it should be emphasized that the investigated group is too small to draw definite conclusions from. The measurement technique itself is very susceptible to sudden changes in position of the fetus as a stable signal over a period of at least three seconds is essential. In addition, the positioning of the markers at the very small umbilical artery is difficult, leading to a large inaccuracy in the initial diameter. The calcula- 
tion process takes about 1 minute, which means that the procedure is not real time. Because of these limitations, only $50 \%$ of the measurements were found to be of use. The complete investigation is time consuming and certainly not applicable as routine measurement. The results are presented only as a feasibility study for the introduction of the DMS in obstetrics. For the determination of the correlation between various parameters, a linear regression analysis with Pearsons correlation coefficient was used.

\section{RESULTS}

The diameter of the fetal aorta is dependent on MA. As the investigated group was small and only comprised pregnancies from 23 to 33 weeks, it was not possible to establish a statistically significant relationship between MA and fetal aorta diameter although a clear tendency between these two parameters could be observed. At 23 weeks the values ranged from 3.0 to $4.5 \mathrm{~mm}$ and at 33 weeks from 5.0 to $7.0 \mathrm{~mm}$. Figure 2 shows a typical distension curve of the fetal aorta during the cardiac cycle; in the upper and middle tracing the displacement of the anterior and posterior wall respectively are displayed as function of time. The lower tracing shows the difference between the curves and consequently the diameter change of the vessel during the cardiac cycle. The computer program calculates the relative diameter change with respect to the initial diameter and displays a table with the individual and averaged values.

In all the investigated subjects, there was no correlation between the relative diameter change of the aorta and gestational age; the overall relative diameter change in the aorta was $16.2 \%$. However, in the one subject followed longitudinally, there appeared to be a small increase in diameter change with MA. The mean Pulsatility Index (PI) in the fetal aorta was 2.43 without dependency on the MA, which is in accordance with findings in the literature [176].

In the umbilical artery, the diameter changes were only small. Without an obvious dependency on MA, the mean distension was $3.61 \%$ with a large standard deviation of 1.89 . The PI's of the velocity registrations were within the normal limits established by van Vugt et al. [177] (see table 1), according the relationship $\mathrm{PI}=1.68-0.021 \mathrm{MA}$, which indicates a normal cardiovascular development.

\section{Table 1}

\begin{tabular}{|lllll|}
\hline & Diam. change & (s.d.) & PI & (s.d.) \\
\hline fetal gorta) & $16.2 \%$ & $(3.30)$ & 2.43 & $(0.31)$ \\
Vmblical anter) & $3.6 \%$ & $(1.89)$ & range 1.18-0.97 & \\
\hline
\end{tabular}




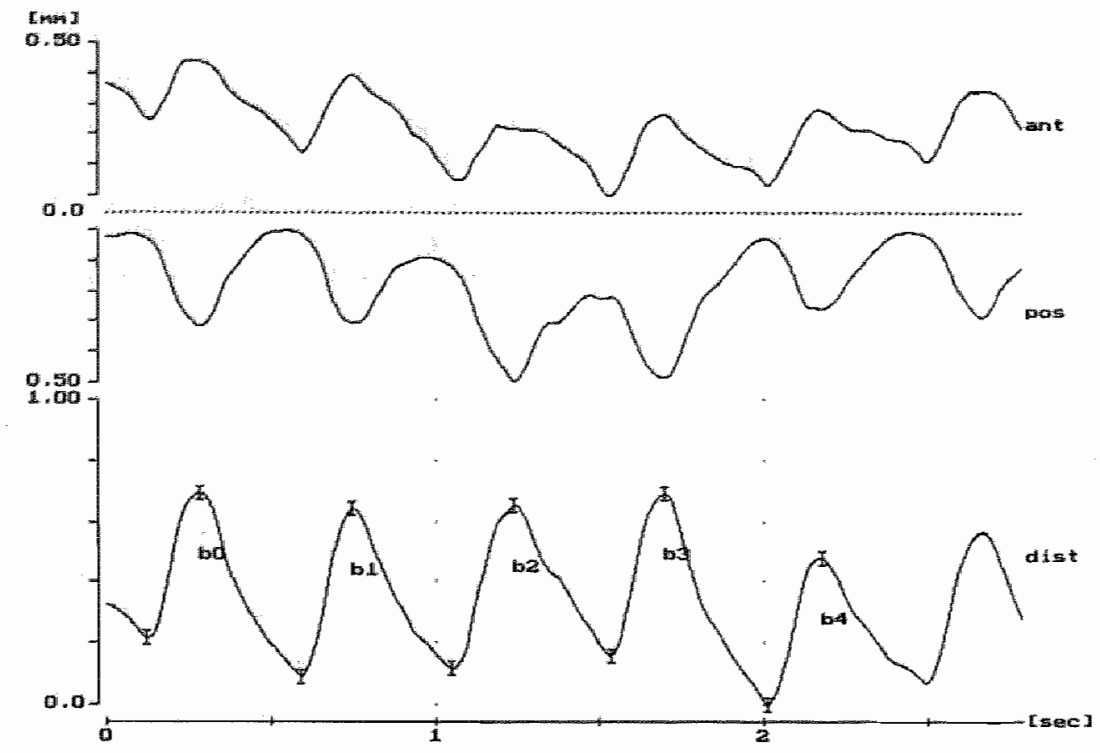

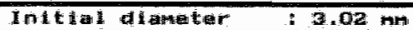

Data from file :

.034

Site of neasurament? porte 27 कs

$\begin{array}{rrrrrc}\text { beat } & \begin{array}{c}\text { dist } \\ (\mu \mathrm{m})\end{array} & \begin{array}{c}\text { diam } \\ (\mathrm{mm})\end{array} & \begin{array}{c}\text { dist } \\ (\mathrm{q})\end{array} & \begin{array}{c}\text { RR-int } \\ (\mathrm{ms})\end{array} & \begin{array}{c}\text { rise-time } \\ (\mathrm{ms})\end{array} \\ 0 & 473 & 2.92 & 16.16 & 468 & 81 \\ 1 & 545 & 2.80 & 19.46 & 459 & 95 \\ 2 & 537 & 2.83 & 18.96 & 481 & 106 \\ 3 & 529 & 2.86 & 18.49 & 478 & 92 \\ 4 & 479 & 2.71 & 17.70 & 481 & 92 \\ & & & & & \\ \text { mean } & 513 & 2.83 & 18.15 & 472 & 93 \\ \text { stdev } & 34 & 0.08 & 1.29 & 10 & 9\end{array}$

\section{Figure 2:}

Distension curve of the fetal aorta

Upper trace: anterior wall

Middle trace: posterior wall

Bottom trace: distension curve (dufference)

In the investigated group, there was no correlation between the relative distension of the fetal aorta and the umbilical artery, which means that a large distension in the aorta was not associated with a large distension in the umbilical artery. Neither could a significant correlation be demonstrated between the PI in the aorta and the PI in the umbilical artery (see fig. 3). 


\section{Correlation PI a vs PI u \\ * significant $p=0.01$}

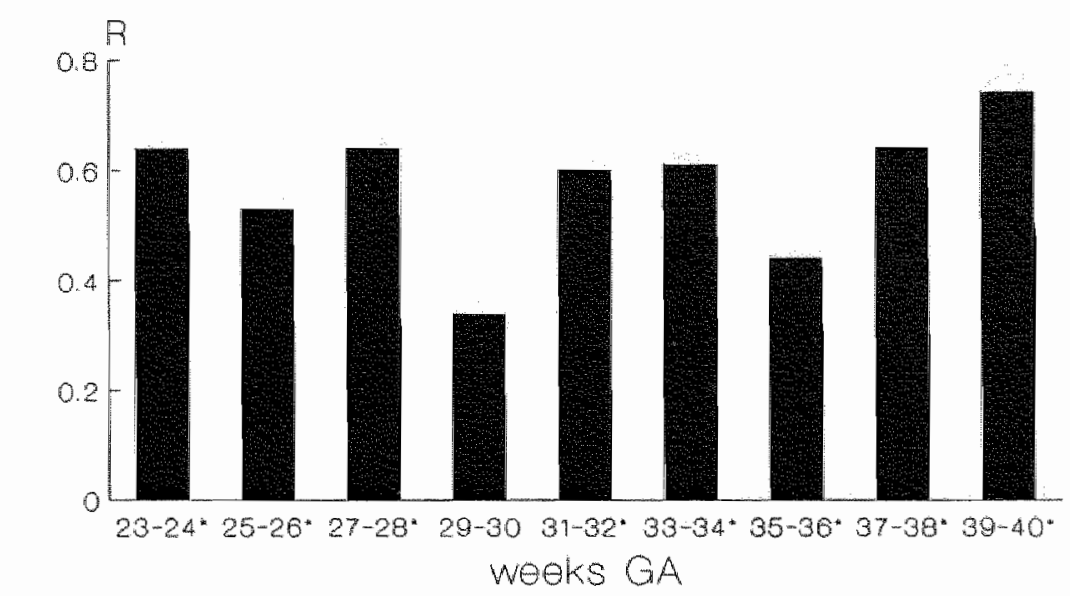

varn Vut 1988

Figure 3:

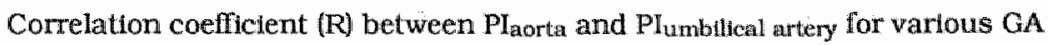

There was, however, a very weak and negative correlation between the umbilical artery PI and the relative distension in the aorta, a large distension in the aorta being associated with a lower PI in the umbilical artery.

The measured distension curve in the fetal aorta can be considered to represent the pressure curve in the aorta (see discussion). A first order approximation of the hemodynamic processes in the fetal aorta is a simple RC network as depicted in figure 1 . This assumes the distension curve to be part of an exponential curve. The diode is a replacement of the aortic valve, which prevents blood from flowing in the reverse direction. Resistor $1\left(R_{1}\right)$ is the inflow resistance of the fetal aorta; $R_{2}$ is the lumped peripheral resistance and $\mathrm{C}_{\text {n }}$ is the compliance of the aorta reflecting its capacity to temporarily store energy. During systole this capacitor is charged through the diode and $R_{1}$. and during diastole $\mathrm{C}$ is discharged through $\mathbb{R}_{2}$. The pressure being analogous to electrical voltage, the distension curve reflects the charging and discharging time constants of the circuit, being $\mathrm{R}_{1} \mathrm{C}$ and $\mathrm{R}_{2} \mathrm{C}$. The time constants can be extracted from the distension curve. This is done by an approximation procedure in the frequency domain which is more robust than curve fitting in the time domain. The time constants are called TcS (systolic time constant) and $\mathrm{TcD}$ (diastolic time constant). The ratio of the time constants represents the ratio of $R_{2}$ and $R_{1}$. In 19 subjects, the curves were sufficiently consistent to calculate these time constants from. The TcS was $67.6 \mathrm{~ms}$ with a standard deviation of 4.9 and the TCD was 131.2 with a s.d. of 16.5 (see fig. 4). The TeS was not dependent on the duration of the heart 


\section{Time constants}

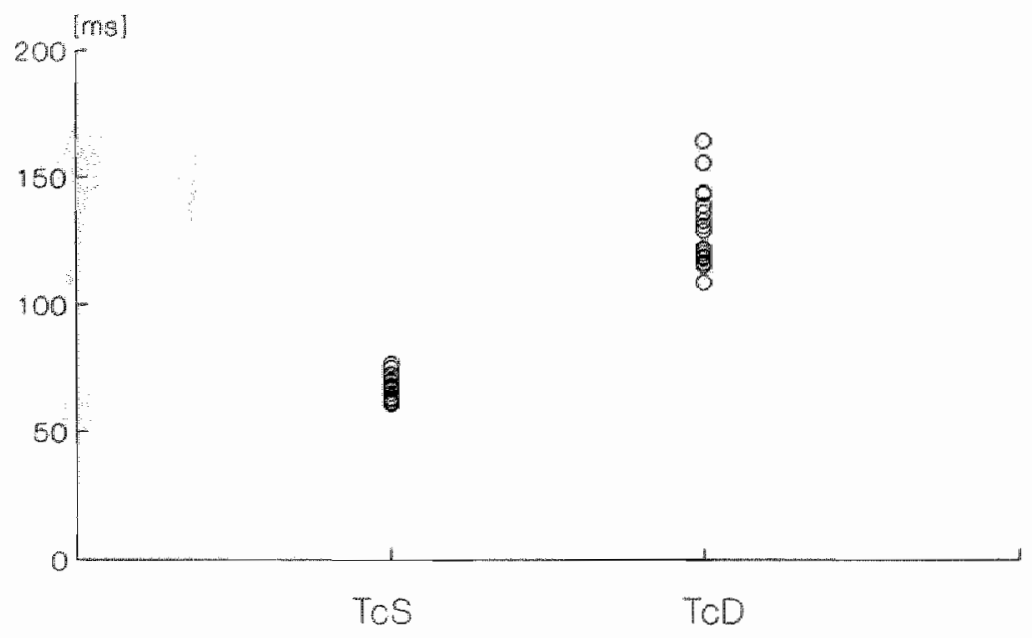

Flgure 4:

Time-constants of the fetal aorta for systolle and diastole

cycle, while the TCD showed a positive correlation of 0.68 with the beat interval. No dependency of TCS or TCD on the MA could be found, and no coherence between TcS and TcD could be demonstrated.

\section{DISCUSSION}

The aim of this study was to investigate the distensibility of fetal vessels and the association with doppler parameters. The diameter change of the fetal aorta as function of the cardlac cycle is approximately $16 \%$, whereas the umbilical artery varies only approximately $4 \%$ in diameter. However, the investigated group is too small, and concerns only MA of between 23 and 33 weeks, to allow definite conclusions to be drawn.

At present, little data is available on the diameter changes of fetal vessels. Gustafsson et al. [64] dedicated part of the discussion of their publication on the results obtained in the human fetus, but they presented only qualitative data. The relationship between aortic diameter and MA is due to growth of the fetus and consequently of the fetal aorta. Because the fetal aorta is a vessel that has to store energy, this storage capacity should increase with fetal weight, probably in an exponential way, to account for the increase in body volume. With a constant change in the diameter of the fetal aorta of $15 \%$, which means growing from $3 \mathrm{~mm}$ diameter to $6 \mathrm{~mm}$, there is an increase in 
storage capacity per unit length of approximately $2.3 \mathrm{~mm}^{3}$ to $9.1 \mathrm{~mm}^{3}$, which is an almost 4- fold increase. If the length of the aorta is also taken into consideration, the capacity increase is even larger. In one subject, a slight increase in the relative distension with MA was found, which has an additional effect on the storage capacity.

From this data it can be concluded that there is a remarkable drop in distension from the fetal aorta to the umbillical artery. The umbillical artery is known to be a muscular vessel [121] while the aorta is an elastic vessel. Vascular studies in children [113] have shown that the distensibility of the carotid artery is about $12 \%$ and in adult studies $[114,75]$ the distensibility in the arterial tree gradually decreases distally from the heart, while the PI increases [59]. This reflects a stiffening of the more peripheral vessels, where the increased amount of muscle fibers enables local regulation of blood pressure. The umbilical arteries can be considered to belong to the greater arteries, and because they branch off from the abdominal aorta one would expect a distensibility comparable with, for instance, that of the femoral artery, which has a value of approximately $7 \%$. The value for the umbilical artery, however, a value of only $3.6 \%$ was found. This may be due to measurement errors (note the large s.d. due to the error in the initial diameter) which means that the value can be explained from the normal gradual decay of distensibility along the arterial tree. Further investigations should reveal if there is an abrupt transition in distensibility from the aorta to the umbilical arteries. What remains, however, is that the distensibility of the umbilical arteries is small, and that hemodynamic influence on the pulsatility of umbilicall blood flow can only be marginal (see chapter 7). One would, therefore, expect a correlation between the aortic PI and the umbilical PI, which was, however, found not to be statistically significant $(r=0.39)$. This is probably due to the low number of cases. In the data of van Vugt [178], however, which comprised more than 100 subjects and some 2000 measurements, this correlation was statistically significant (fig. 4 ; overall $\mathrm{R}=0.68$ ). The very low value in the period of 29 and 30 weeks of MA demands an explanation as it is strongly marked. In that period a high PI in the aorta does not coincide with a high PI in the umbilical artery. This is likely to be due to important hemodynamic changes which temporarily disturb the normal flow distribution. An explanation can only be speculative as it is a purely empirical finding. After the 6 th month ( 28 weeks) the fetus starts to gain weight rapidly, while up until that moment body weight had only gradually increased to below 500 grams. This rapid increase in body mass demands a rapid increase in blood volume, and may disturb cardiovascular regulating mechanisms, until new setpoints are achieved. This might be the reason for this temporarily change in hemodynamic balance.

The low value of distensibility can be explained from the hemodynamic point of view, because the umbilical arteries mainly have a transport function and do not need to absorb energy. The high pulsatility of the pressure may be essential for the venous return (see chapter 3). 
When the distensibility figures are translated to storage capacity of the various vessels, the following results can be found. For an umbilical artery diameter of $3 \mathrm{~mm}$ and a distension of $3.3 \%$, the increase in volume of both the umbilical arteries is

$$
2 \cdot\left[1 / 4 \cdot \pi \cdot l \cdot\left(D_{s}^{2}-D_{d}^{2}\right)\right] \text {. which is } 1 / 2 \cdot \pi \cdot l \cdot\left(3 \cdot 1^{2}-3.0^{2}\right) \cdot 10^{-6}\left[\mathrm{~m}^{3}\right]
$$

For a length of the umbilical cord of $500 \mathrm{~mm}$, the total storage capacity of the arterial part of the cord is $0.5 \mathrm{ml}$. The same calculation for the fetal thoracic aorta, with an assumed length of $50 \mathrm{~mm}$, an initial diameter of $6 \mathrm{~mm}$ and a distension of $16 \%$, also yields a storage capacity of $0.5 \mathrm{ml}$. Comparing an umbilical artery with the fetal aorta, assuming the pulse pressure at the input of the cord to be about half that of the pulse pressure of the aorta, and taking into account the length of the segments involved, the compliance of an umbilical artery can be assumed to be 10 times less than that of the aorta. The stroke volume of the fetal left ventricle can be estimated from venous flow measurements. A flow of $100 \mathrm{ml} / \mathrm{kg} / \mathrm{min}$ yields a venous volume flow of 150 $\mathrm{ml} / \mathrm{min}$ in a fetus of $1.5 \mathrm{~kg}$. If about $50 \%$ of the cardiac output (CO) is directed to the umbilical cord, then for a total $\mathrm{CO}$ of $300 \mathrm{ml} / \mathrm{min}$, and a FHR of 150 bpm, a stroke volume of $2 \mathrm{ml} /$ beat is provided. It can be concluded that approximately $25 \%$ of the stroke volume (SV) can be stored in the aorta. These estimations are comparable to the situation in young adults, in which the SV can be measured non-invasively, and shows an average value of $80 \mathrm{ml} / \mathrm{beat}$. If a body weight of $60 \mathrm{~kg}$ is assumed for the adult, the SV of a fetus of $1.5 \mathrm{~kg}$ is comparable to the SV of the adult Calculation of the storage capacity of the adult aorta shows approximately the same figures in relation to the body weight. The compliance of the cord can be estimated from fetal lamb data on the pulse pressure at the input of the cord, which is in the range of $1.3 \mathrm{kPa}$ (10 $\mathrm{mm} \mathrm{Hg}$ ). The compliance of the cord is then $0.5 / 1.3=0.38 \mathrm{ml} / \mathrm{kPa}$. Compared to the estimated compliance of the placenta of $11.3 \mathrm{ml} / \mathrm{kPa}(1.5$ $\mathrm{ml} / \mathrm{mm} \mathrm{Hg}$ [172,85], this is very low and supports the hypothesis that the cord has only a marginal effect on the damping of the pulsatility. These inferences illustrate the hemodynamic relations in the fetus, but are partially speculative, because the exact pressure relations in the human fetus are still unknown.

From cardiovascular research 178, unpublished data Hoeks et al.] it is known that the shape of the distensibility curve accurately resembles the local pressure curve, under the assumption that there is a linear relationship between pressure and compliance, which is the case at physiological pressure levels. This implicates that the distensibility curve is a measure for the local pressure pulse, although the absolute systemic pressure level remains unknown.

The time constant calculations show that the outflow resistance is approximately twice the inflow resistance. The outflow resistance $R_{2}$ is the lumped resistance of the distal body vessels and the umbilico-placental resistance. A change in the latter will thus be partially reflected in the TcD. Also, a change 
in the resistance of the peripheral vessels, induced for instance by redistribution on the basis of the brain sparing mechanism, will be reflected by TcD. Further investigations will have to show if this method can discriminate between normal and abnormal pregnancies. The relatively low standard deviation of the TcS and the invariability with MA indicate that this method of quantification of the cardiovascular performance is promising. The same approach of the time constant calculation can be applied to the blood velocity waveform. Whereas the distension curve yields information about the pres sure, the velocity curve contains information about the flow in relation to the diameter of the vessel; together they may provide more accurate data on the distribution of impedance.

The time constant calculation combined with the pulse-pressure information of the distension curve may be helpful in the quantification of cardiac abnormalities such as valve defects or coarctatio aortae.

\section{CONCLUSION}

A new ultrasound application has been presented which utilizes the diameter change of a vessel as measure of the local pulse pressure. A correlation between the relative diameter change of the aorta and the umbilical blood flow velocity PI was found. The distension of the aorta is high and serves as a capacity vessel for the storage of kinetic blood energy. The relative distension of the umbilical artery is low, mainly due to its vessel wall characteristics. Therefore, the hemodynamic influence on the pulsatility of blood flow is small, and the pulsatility in the cord is mainly determined by the aorta and the placental impedance. The transition point within the fetal abdomen where the high distension changes to a low one, has yet to be established. The time constant calculations on basis of a first order electrical approximation, show that the output resistance is twice the input resistance in normal pregnancies, and that the variance in these parameters is relatively low. In pathological situations, in placental pathology as well as in cardiac abnormalities, a change in this ratio can be expected.

The complexity of the measurement procedure itself reduces its applicability to selected groups of patients. Further research has to examine its clinical value. 
$\therefore$ 


\section{Chapter 10}

\section{THE INFLUENCE OF \\ BRADYCARDIA ON THE PI OF THE UMBILICAL ARTERY BLOOD FLOW VELOCITY WAVEFORM}

Hemodynamic surveillance of fetal congenital heart block with doppler ultrasound

C.J. Ruissen, H.J. Hoogland, M.M.H.P. v. Drongelen, S.J. Nienhuis

Hemodynamic surveillance of fetal congenital heart block with doppler ultrasound: a case report Submitted for publication 


\section{The influence of bradycardia on the PI of the umbilical artery blood flow velocity waveform:}

Hemodynamic surveillance of fetal congenital heart block with doppler ultrasound: a case report

\section{INTRODUCTION}

In chapter 4, some applications of the PI of the umbilical artery blood velocity waveform were presented. It was mentioned there that in specific situations, such as cardiac pathology, blood velocity waveform analysis might provide additional diagnostic information. In addition, the PI value is affected by variations in the fetal heart rate (FHR), which often occur in cardiac pathology. Several authors have reported on the dependency of the PI on FHR $[80,120]$, so that in cases of severe bradycardia, it is necessary to correct for FHR. Because the PI in the umbilical artery may also depend on the pulsatility of blood flow in the aorta, the values may yield information on the condition of the left ventricle. In addition, due to the large beat-to-beat interval in persistent bradycardia, the compliance of the placenta has to ensure sufficient exchange of oxygen and nutritients. The cardiac output of the fetus must be maintained by an increase in stroke volume.

Persistent fetal bradycardia is a symptom with several underlying causes such as maternal cardiovascular insufficiency, antihypertensive medication, chronic fetal distress or congenital heart block (CHB) [53,89]. When persistent fetall bradycardia is found, whatever the etiology. it is of the utmost importance to estimate fetal condition and determine the prognosis with appropriate diagnostic tools before clinical decisions are made. In these rare cases. new diagnostic tools such as doppler ultrasound might be a valuable clinical asset to the routine diagnostic procedures.

The aim of this study is to investigate some characteristics of the umbilical artery blood velocity waveform in persistent bradycardia, and whether hemodynamic monitoring is appropriate in the assessment of the fetal condition in this special case. 


\section{CASE REPORT}

A 28 year old primigravid patient was under routine observation at the out-patient obstetric department. At a menstrual age (MA) of 18 weeks ultrasound evaluation revealed a normal fetal heart and no congenital malformations. At 28 weeks a persistent fetal bradycardia (48-50 bpm) was found on the ultrasound scan which was confirmed by cardiotocography (CTG). There were no maternal complications such as (pre-existing) hypertension or pre-eclampsia.

A level II ultrasound examination was performed to elucidate the origin of the bradycardia. Again no congenital malformations, and more specifically no cardiac malformations were found. Neither were there signs of fetal cardiac decompensation. A time motion (TM) recording through the fetal atrium and ventricle (fig. 1) showed a congenital heart block (CHB), with a normal atrial contraction rate of $140 \mathrm{bpm}$ and a ventricular contraction rate of 48 to 50 bpm.

In the maternal blood anti-rho antibodies were found which seemed the most probable cause of the CHB [41].

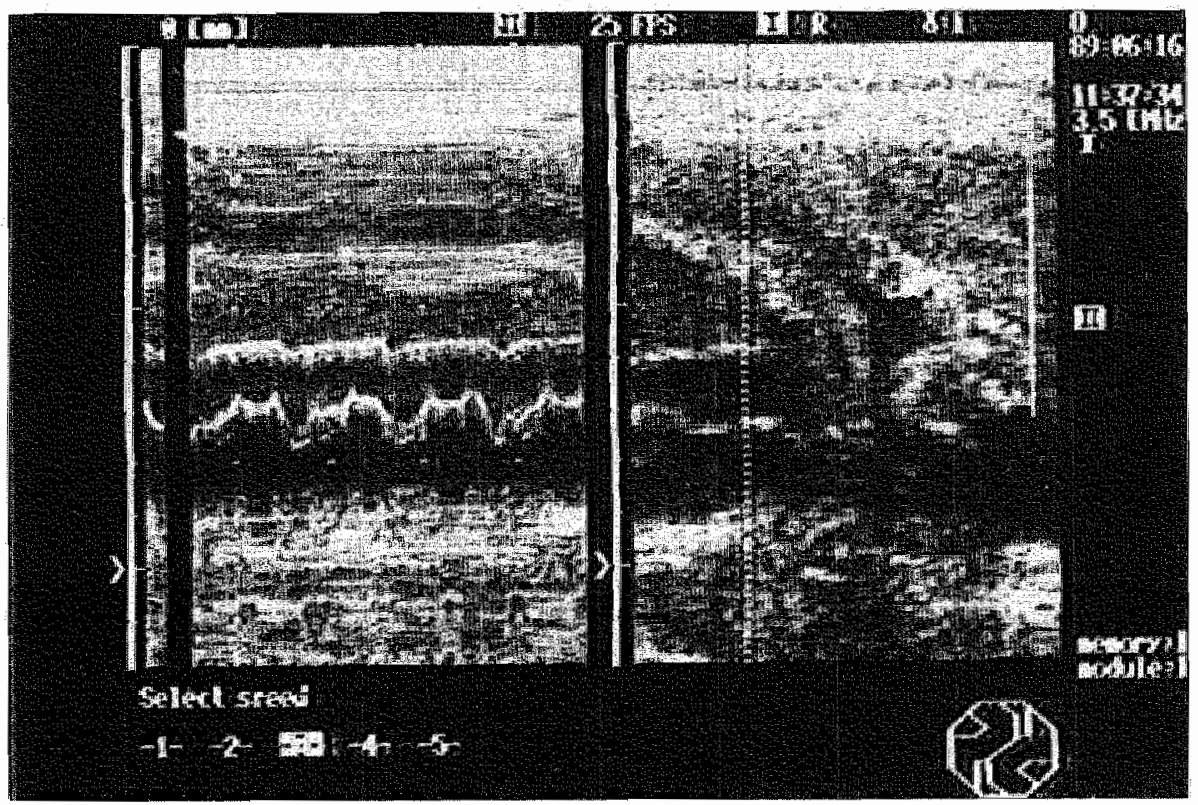

Figure 1:

Time-Motion recording through left atrium and left ventricle demonstrating dissociation 
In close cooperation with the pediatric cardiologist, the decision was made to await the natural course of pregnancy. Once a week the mother had a routine check-up and twice a week a two dimensional echo and doppler ultrasound evaluation of the fetal condition was performed in which the following functional and anatomical aspects were scored:

- presence of pericardial effusion, ascites and other signs of hydrops

- ventricular contraction frequency

- atrial contraction frequency

- thickness of the ventricular walls

- diameter of the umbilical vein

- fetal movements

Fetoplacental circulation was evaluated with both Continuous Wave (CW) (Ple Medical 1120 scanner) and Pulsed doppler (PD) (Pedof 2 Mhz), by recording the blood flow velocity in the umbilical artery, the umbilical vein and the fetal aorta. For both vessels, the PI [59] was calculated as the mean value of 4 consecutive heartbeats (Doptek spectrum analyzer). The rise time of the umbilical artery signal was measured to obtain an impression of ventricular function. From the velocity curves, fetal ventricular heart rate was calculated, while the atrial rhythm was frequently checked with CTG. In addition to these parameters of cardiac dysfunction, the course of the umbilical vein diameter was measured throughout pregnancy under the assumption that venous storage due to deteriorating right ventricle function might lead to dilatation of the umbilical vein. This hypothesis could not be confirmed as heart failure did not develop in this case. Throughout pregnancy, no pericardial effusion or other signs of backward failure were visualized. Atrial contraction frequency and ventricle wall diameter remained within physiological limits. No abnormal changes in fetal movements were recorded. The course of the hemodymamic parameters is displayed in figures 2 to 4 .

At a menstrual age of 39 weeks the patient came into labor spontaneously. In order to check fetal condition during labor, atrial contraction frequency was recorded with the ultrasound section of the CTG equipment [97] and ventricular heart rate by means of a scalp electrode (fig. 5).

To facilitate labor, epidural anaesthesia was given and eventually a girl of 3500 grams was born with Apgar scores of 8 and 9 over 10 after 1 and 5 minutes, respectively. There was no apparent cyanosis. The $\mathrm{pH}$ of the umbilical arterial and venous blood were 7.19 and 7.36 respectively. Neonatal heart rate was stable at $48 \mathrm{bpm}$. The baby was transferred to the neonatal high care unit for intensive monitoring. The neonatal ECG (fig. 6) confirmed the complete heart block. The baby remained hemodynamically stable without signs of respiratory or cardiac distress, and within a few days she was transferred to the medium care unit under respiratory and cardiac monitoring. After ten days she was discharged from the hospital under frequent survellance of the 


\section{Fetal parameters}

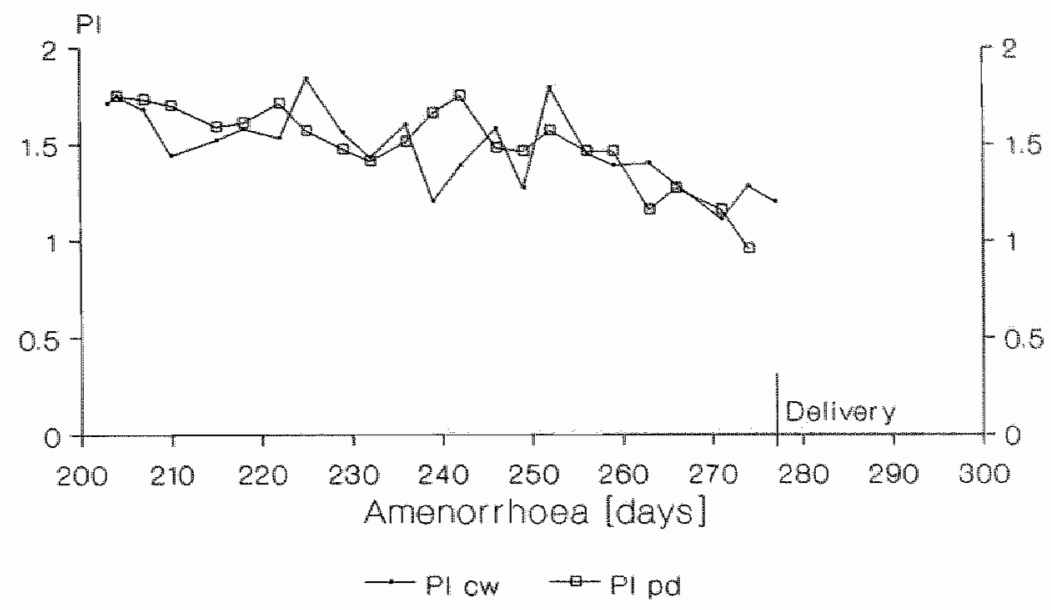

\section{Figure 2:}

Pulsatility Indices (PI) of the umbillcal artery blood velocity waveform measured with Continuous Wave (cw) and Pulsed Doppler (pd) as function of menstrual age

\section{Fetal parameters}

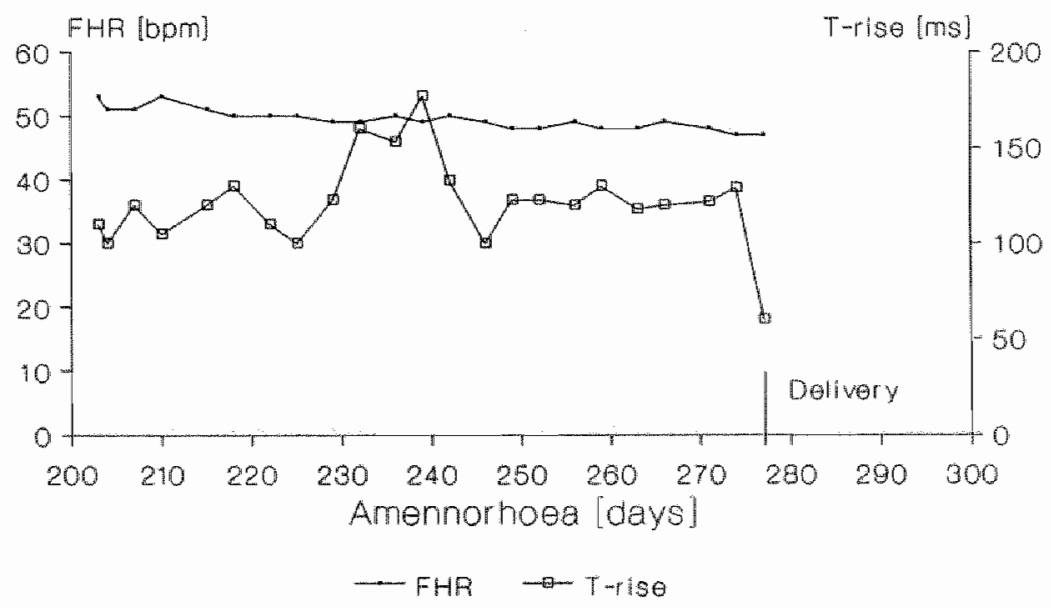

\section{Figure 3:}

Fetal heart rate (FHR) (ventricular rate) and the rising time (T-rise) of the umbillical blood flow velocity waveform as function of menstrual age 


\section{Fetal parameters}

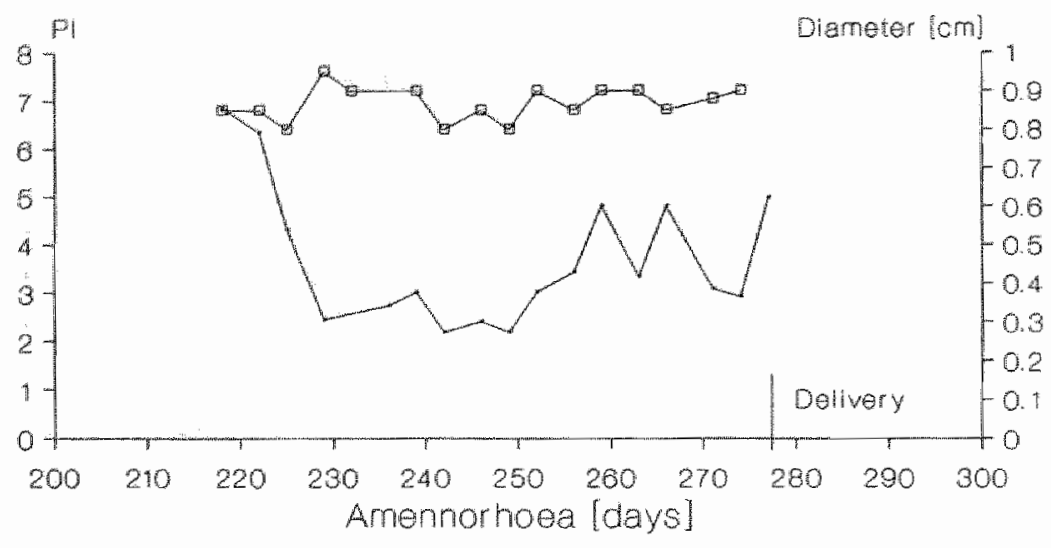

- Pl-morta Dlameter

\section{FIgure 4:}

Pulsatuly Index (PI) of the blood flow vellocity waveform of the aorta and the diameter of the umbillcal vein as function of menstrual age

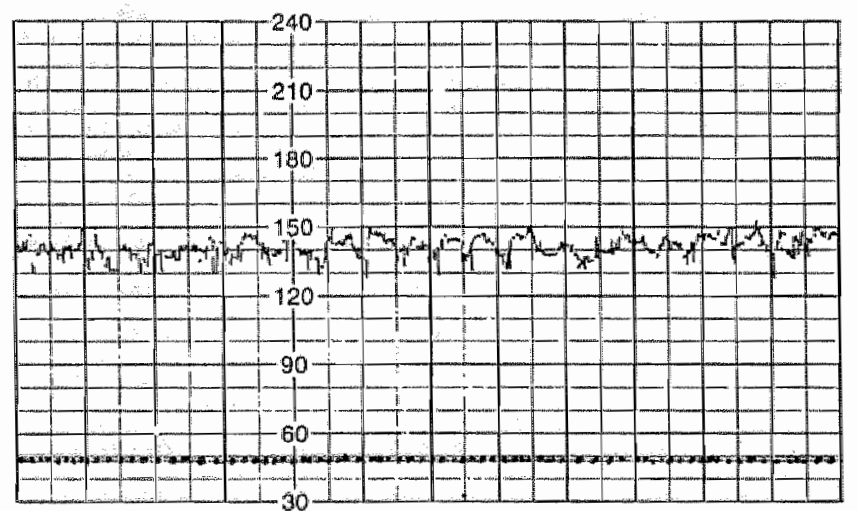

ultrasound FHR [bpm]

scalp electrode FHR [bpm]

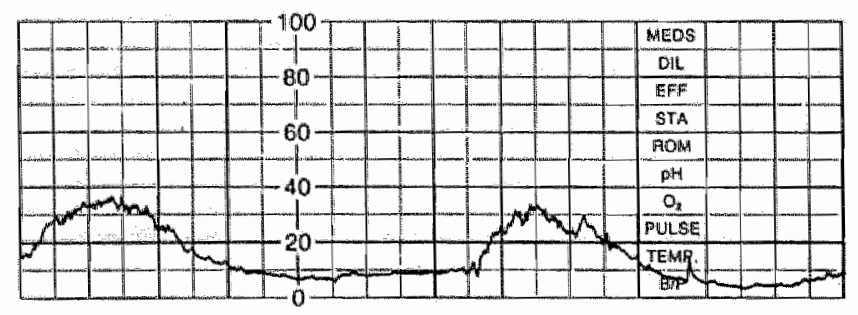

uterine activity

Figure 5:

Atrial heart rate (ultrasound FHR), ventricular heart rate (scalp electrode FHR) and uterine contractions during labor as function of time 

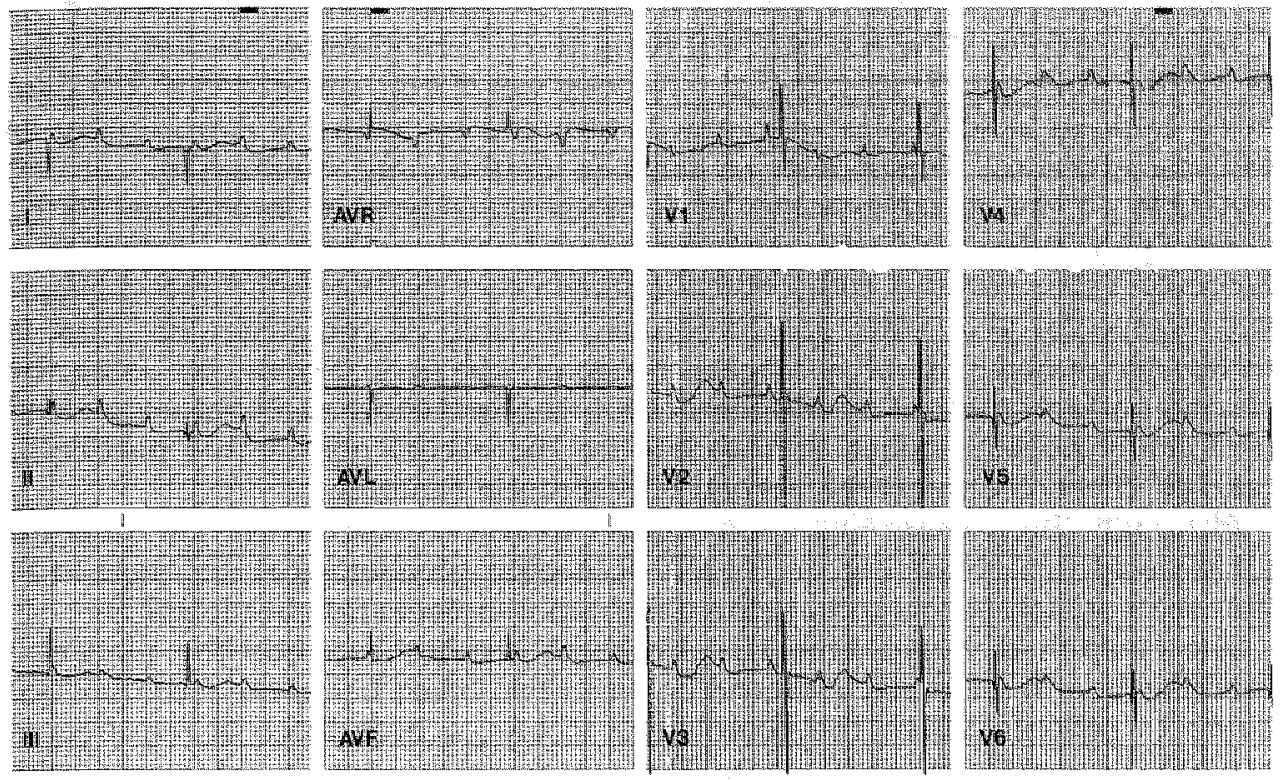

\section{Figure 6:}

Neonatal electrocardiogram

pediatric cardiologist. Because of subsequent decreased skin circulation, liver enlargement and restricted growth, a pacemaker was installed 6 weeks after birth.

\section{DISCUSSION}

The most reliable way to achieve the diagnosis of complete heart block during pregnancy is by a Time-Motion recording through the fetal atrium and ventricle. In this way it is possible to demonstrate the functional dissociation between these cardiac structures $[104,164,53,133]$. However, due to fetal movements it is almost impossible to obtain a sufficiently extended recording to be able to differentiate between an incomplete and a complete block. The ultimate differentiation should be made by post partum ECG recording.

In order to predict the prognosis of a fetus with a complete heart block, it is of great importance to exclude structural cardiac malformations. Signs of possible cardiac decompensation such as fetal hydrops, ascites, pericardial effusion, hypertrophic ventricular walls, incomplete contraction of the ventricles and other signs of backward failure of the heart should be checked. 
Left ventricular function is the driving force behind fetoplacental circulation. Therefore, the PI of blood flow velocity waveforms measured in the fetal aorta and the umbilical artery, are determined by ventricle contractility as well as placental impedance. In case of diminishing function of the left ventricle. PI values are expected to decrease considerably, in contrast to the slight fall in value with advancing gestational age in uneventful pregnancies. Several studies $[80,120,180,186]$ have shown that the PI is heart rate dependent, particularly in extreme conditions, so that PI correction for FHR is necessary outside the physiological range of 130 to $170 \mathrm{bpm}$. By using the correction factor found by Mulders [120], the recalculated PI values yielded completely normal values appropriate for menstrual age in this particular case [8]. This also indicates normal left ventricle function.

Although there were slight differences in the course of the $\mathrm{CW}$ and $\mathrm{PD}$ ultrasound recordings (fig. 2) [111,173], a clear physiological decrease in PI was seen, which seems to indicate a normal fetoplacental circulation.

The ejection of blood from the umbilical arteries expands the placental vascular bed to a certain level and between two heart beats the vascular bed tends to collaps. When the compliance is low, a high force is required to expand the vessels in the placenta and consequently a low blood flow velocity PI in the umbilical artery can be expected. While the compliance is high, a lower force is sufficient, resulting in a high PI of the umbilical artery velocity waveform. When the compliance of the placenta in the present case is comparable to the compliance in a normal pregnancy, which means that the cardiac abnormality is assumed not to be associated with placental dysfunction, the diastolic downward slope of the velocity waveform is the same compared to the normal situation. That means that the exponential curve, of which the diastolic decay is a part, is the same; only a larger part of the curve is utilized in bradycardia (fig. 7). When the exponents of the decay curves are comparable or even larger, it can be concluded that the high PI values in bradycardia are not due to the an increased placental resistance and that abnormal PI values after correction for FHR indicate a deteriorated left ventricle function. Preliminary analysis show that in normal pregnancies, the time constant of the decay curve is approximately $270 \mathrm{~ms}$. In this bradycardia case the time constant was $580 \mathrm{~ms}$, which indicates a reduced placental resistance. For comparison, the time constant in a typical case of AEDV is approximately $160 \mathrm{~ms}$.

The variance in fetal aorta PI as seen in figure 4 is probably due to restrictions in the standardization of measurement location [125]. The considerable blood flow velocity decline in the descent of the thoracic and abdominal aorta might lead to a wide variation of values even if localization errors are only slight.

The rising time of the umbilical artery blood velocity curve also reflects left ventricular contractility. So, a decrease in rising time may be an early sign of decreasing ventricle function. The results were not conclusive because in this case the cardiac function remained stable. 


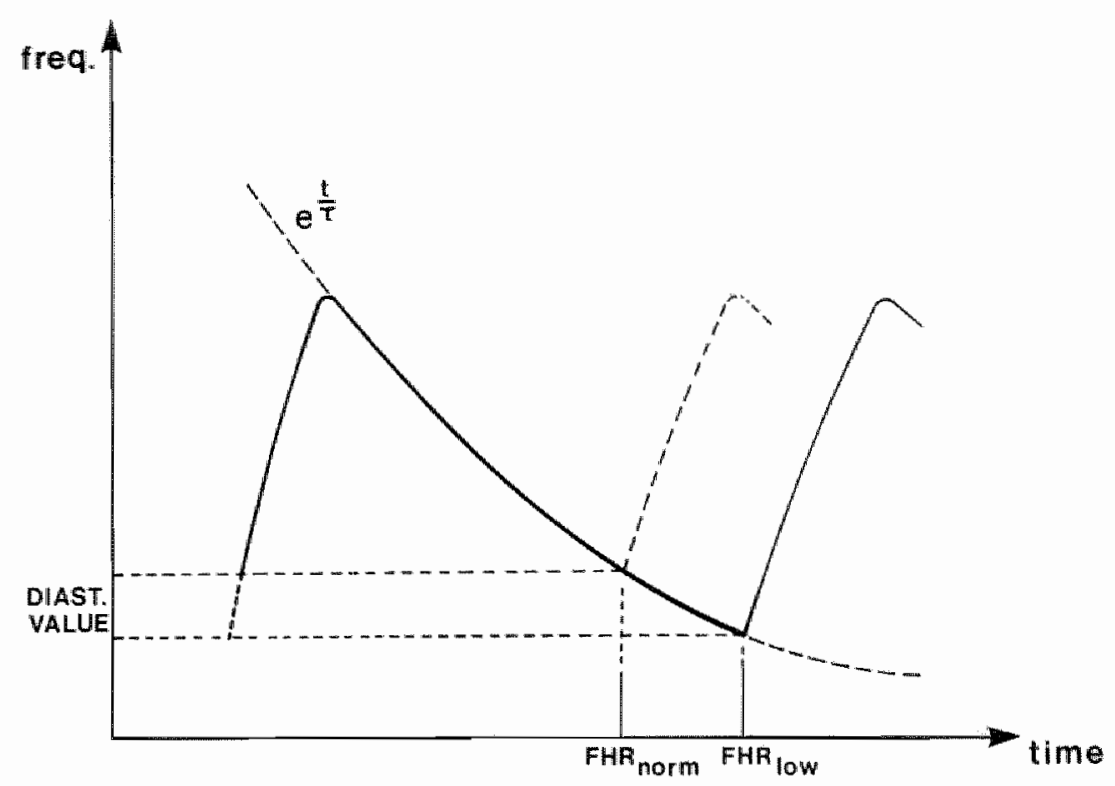

Figure 7:

Exponential downward slope of the diastolic part of the velocity waveform at high and low FHR

\section{CONCLUSION}

In a 28 year primigravid patient a complete fetal heart block was diagnosed antenatally. Throughout pregnancy, fetal cardiac function was monitored by repeated ultrasound examinations combined with doppler measurements. No signs of intrauterine decompensation were encountered and eventually the baby was delivered spontaneously without immediate post delivery complications.

Because this fetus was hemodynamically stable during pregnancy it was not possible to elucidate if doppler recordings provide relevant information about cardiac condition in cases of CHB with cardiac decompensation. In this case the doppler information confirmed the conventionally obtained data and provided a more reliable FHR measurement of the upper as well the lower heart. Moreover, the low FHR made the comparison of normal exponential decay of the velocity waveform and the decay in this pathological situation possible. It can be concluded that an exponential decay of the velocity waveform comparable to the decay in normal FHR fetuses, indicate normal hemodynamic relations. 

Chapter 11

\section{POST DELIVERY UMBILICAL CORD BLOOD FLOW VELOCITY WAVEFORMS}




\section{Post delivery umbilical cord blood flow velocity waveforms}

\section{INTRODUCTION}

Animal models in the study of the human fetal circulation have certain limitations. For obvious reasons it is not possible to alter placental function in man. There are only a very limited number of conditions in which the umbilical artery blood flow velocity waveform can be studied in direct relation to known hemodynamic placenta function. There have been abundant publications about the umbilical blood flow velocity waveforms (BVWF) in relation to intrauterine growth retardation (IUGR) $[72,91,151]$, which is, however, not only caused by insufficient placental function. Besides that, the clinical value of umbilical BVWF's in IUGR has never been convincingly demonstrated (see also chapter 4). Other pathological causes are placenta infarction and placenta abruption but these are rare disorders and of limited value with respect to the study of physiological processes. Therefore. it was decided to study the behavior of the blood flow velocity waveform in the umbilical vessels after the child had been delivered, delaying the immediate clamping of the cord after birth. In this way it might be possible to study the normal course of hemodynamic processes after labor, and in addition. the uterine contractions compressing the placenta after birth, might be a model in the investigation of blood flow velocity waveform indices in relation to an increased placental impedance. In the literature [93] data is provided on the closing time of the umbilical cord. The reported values range from a few seconds to a few minutes, so it was by no means certain in advance that there would be sufficient time to perform measurements.

\section{MATERIALS AND METHODS}

Six pregnant women were asked to join the study. They had uneventful pregnancles up until delivery, and with respect to labor, no complications. such as breech presentation were expected. After informed consent, a transabdominal reference measurement was performed between two contractions at a cervix dilation of about 2 centimeters. In all women the membranes were already ruptured at that time. After the delivery of the baby, the cord was left intact and the child was placed on the mothers abdomen and covered to prevent cooling. Blood velocities in the umbilical arteries and if possible in the 
umbilical vein were measured and stored on a tape recorder for off-line analysis. The signals were recorded continuously until the circulation through the cord ceased. Within the first three minutes the doppler signals were sampled at various locations in the umbilical cord: from the origin at the baby's abdomen and as far as possible to the placental side in steps of $5 \mathrm{~cm}$. After the flow in the cord had stopped, the cord was clamped and the routine examinations on the baby were performed. The doppler equipment for both the transabdominal and the direct cord measurements was an $8 \mathrm{MHz} \mathrm{CW}$ doppler device (Medasonics) with separated forward and reverse audio channels. The analysis was carried out off-line with a spectrum analyzer (Doptek). The Pulsatility Index (PI) was calculated and plotted against time.

\section{RESULTS}

The average PI values for the various patients are depieted in the figure. Calculations were performed each 30 seconds after the delivery of the baby. The range of PI values was wide and the time available to perform measurements varied considerably. Already during the recordings it became clear that the umbilical cord is very susceptible to mechanical stimuli, and although it was tried to "handle the cord with care", in some cases the arteries showed local spastic contractions from the very beginning of the measurement period. These contractions are assumed to be a protective reaction to prevent blood

\section{Post natal PI vs time}

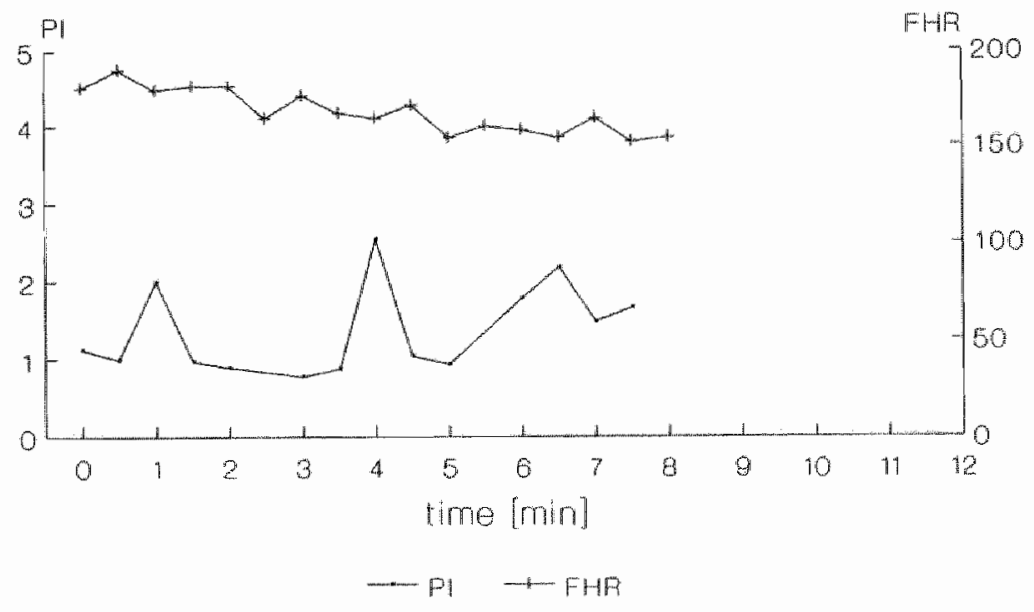

Figure 1:

PI and FHR as function of time after birth 
loss. Due to the reduction of the arterial diameter, very high blood flow velocties occur, and sometimes even reverse flow during diastole. This leads to hilgh PI values, and is the reason why the results for the PI as function of measurement site could not be presented. The variability of the PI values is likely to be caused by these contractions more than by a possible distance dependency. These local contractions are also likely to be a reason for the wide range of PI's as function of time, because these contractions were sometimes reversible.

\section{DISCUSSION}

In the literature, a number of articles describe the influence of labor on the blood flow velocity indices in the umbilical artery $[44,98,49,25]$. The measurements we performed in other studies, also demonstrate that in general, there is no influence of labor on the umbilical artery PI. No data are available as yet on the normal course of these indices after birth up until the moment the circulation stops in a natural way, because the cord is routinely clamped direct after birth. Apart from whether this is advantageous for the newborn, it causes a gap in our knowledge about the very last moments of the natural course of hemodynamics in labor. The inttial idea to use the hemodynamic changes in this period as a model for a physiological increase in impedance of the placenta, has to be abandoned. The measurement system used, does not fulfill the basic criterium which is, that the system does not affect the circulation to be measured. Partially due to the manipulations with the doppler transducer, and also because of the inevitable movements of the newborn, the cord receives mechanical stimuli that causes the arteries to contract. The reason why in some cases the circulation stops almost immediately, and in other cases this takes up to 10 minutes, is unknown. Biochemical studies for circulating vasoactive substances (see chapter 8) could provide more data, although the sampling of blood from the arteries is likely to cause contractions as well. The hemodynamic changes in the cord obscure the impedance changes in the placenta itself. As a result, the latter can not be measured in the umbilical cord. In addition, the hemodynamic conditions in the newborn are different from those of the fetal situation due to the aeration of the lungs and the changed circulatory pathways.

From the data obtained, it may be speculated, that the cessation of the circulation through the umbilical cord is not due to an increase in impedance in the placenta, but primarily the result of spastic contractions of the umbilical arteries. 
Chapter 12

GENERAL CONCLUSIONS 


\section{General conclusions}

The kind of research discussed in this thesis raises more questlons than it answers. It is comparable to the classical examination, still used in routine pregnancy checkups, of trying to see with your hands what is inside the woman's abdomen. Your hands are not equipped to see and you can only feel the outside reflections of something that happens inside. Although ultrasound has been a tremendous step forward in the investigation of pregnancy. the function of certain systems, such as the circulatory system, needs further study. The use of doppler ultrasound enables the follow-up of certain circulatory parameters, however, the patho-physiological bases is still poor. The aim of this thesis was to add some pieces to the complex jigsaw puzzle of the fetal circulation.

The first objective was to assess the validity of PI measurements under certain conditions. It can be concluded that a good understanding of the basic principles of doppler ultrasound is necessary. It is only less than 5 years ago, that, due to an inappropriate application of the equipment, reference PI values were presented for normal pregnancies, which at present would be classified as extremely abnormal. Although each clinic should use its own set of reference values, comparison of the results of various recent publications show a good agreement of the PI values in the last trimester. irrespective of the method used. Reference values that deviate strongly from those in the literature should, therefore, raise suspicion. The influence of maternal shape and exercise, prior to umbilical artery blood flow velocity PI measurements, can be neglected.

The second objective was to develop a working hypothesis, which describes the hemodynamic processes in the fetoplacental circulation and explains the PI values found at the various locations. In the following chapters, it was tried to substantiate the various parts of this hypothesis. It can be concluded that the umbilical blood flow velocity PI is relatively independent of the measurement site. The umbilical cord appears mainly to have a transport function of the blood towards the placenta; its role in damping the pulsatility is limited. The results of the presented localization study support the working hypothesis, although they are in contradiction to other publications.

The influence of the compliance of the placenta on the PI of the umbilical artery blood velocity waveforms could not be established due to experimental problems. The results of other investigators suggest that it is unlikely that variance in this compliance is important in the determination of the umbilical artery PI. Inferences from the persistent bradycardia case support the idea. that the placental compliance has such a high value in relation to the FHR, that the effect of variance in compliance can be neglected. 
Although the influence of left ventricle contraction on the umbilical artery is certainly important, this effect is generally neglected due to the impossibillity to quantify this influence. A new method was presented tt measure the diameter change of fetal vessels in relation to the simultaneously measured PIs. The results seem promising, although the number of the investigated patients was small. A weak but significant correlation between the distension of the fetal aorta and the PI measured in the umbilical artery was found. Further research on the reduction of the variance in umbilical artery blood velocity waveform PI values have to be performed. Particularly in cardiovascular highrisk fetuses, this method could also be used for the quantification of cardiac performance.

The application of color doppler imaging, that enables simultaneous display of two dimensional echo and doppler information, will facillitate localization and will enable measurements of vessels unreachable for investigation until now. In particular, measurements in the placental vessels and the umbilical vessels inside the abdomen of the fetus may provide more information on the course of the PI in the umbilical system. A better understanding of the pathophysiological bases of the PI will lead to a better use of the PI in patient management. Diameter change measurements should be performed along the course of the total vascular system of the fetus, in both normal and complycated pregnancies. The measurement procedure itself can be optimized to reduce examination time. Other experimental procedures should be developed to confirm the statement that the placental compliance can be neglected in the assessment of the PI in the umbilical artery.

Despite all the technical possibilities and scientific questions, the patient should remain in the center of all these efforts. Some aspects of the management of the patient do not only require a scientific doctor, but also a humane doctor. 



\section{SUMMARY}

With doppler ultrasound measurements, characteristics of blood flow velocities in fetal vessels can be obtained. These characteristics appear to be associated with fetal pathology. although the patho-physlological mechanisms are only poorly understood. This thesis describes some of the studies performed to increase our knowledge of physiological and pathological factors that may contribute to the behavior of the blood flow velocity waveform and it explores some of the conditions under which blood flow velocity waveform analysis can be used. In chapter 2 the physical backgrounds of the fetoplacental circulation are discussed, such as pressure-flow relations, vessel characteristics and the typical anatomy of the umbilical cord. A working hypothesis is developed to describe the hemodynamic features of the fetoplacental circulation and its effect on the Pulsatility Index (PI) of the blood flow velocity waveform in the umbilical artery. Chapter 3 deals with some physical and technical aspects of doppler measurements in general, and specific problems with respect to obstetric measurements. Knowledge of the peculiarities of different systems and technologies is essential for the appropriate application of doppler ultrasound. Chapter 4 gives an overview of the current applications of doppler ultrasound in obstetrics. Doppler techniques are not applicable as screening instrument for intrauterine growth retardation, because the sensitivity and predictive value are low. In selected high risk pregnancies, it may be used to obtain additional information and for followup.

One of the most frequently used parameters for the characterization of the umbilical blood flow velocity waveform is the PI (Pulsatillty Index). The variability and comparability of PI calculations between various centers are described in chapter 5 . It can be concluded that each clinic should develop its own set of reference values, based on a well designed longitudinal trial, as techniques of measurement and analysis differ significantly. Review of the recent literature shows that especially in the last trimester. most investigators arrive at the same range of reference PI values.

External factors, such as maternal exertion may influence the PI value of the fetal circulation. Chapter 6 concludes that normal maternal exercise does not affect the PI of the umbilical blood flow velocity, and that it is not necessary to precede a doppler investigation with a perlod of rest.

Chapter $\mathbf{7}$ is dedicated to some characteristics of the umbllical blood flow velocity waveform with respect to the sampling site. No significant dependency on measurement location of the PI or the frequency distribution of the doppler signals of the umbilical arteries could be found. The umbilical arteries seem not to be hemodynamically important for the damping of the pulsatility.

It is therefore, not necessary to standardize for sampling site. The pulsatility of the umbilical artery blood flow is determined by various factors, of which the compliance of the placenta in combination with the local resistance could 
be important. Chapter 8 describes an experimental setup to investigate whether the placental compliance can be altered, and what the influence is on the resulting PI of the umbilical artery velocity waveform. Unfortunately this setup proved to be inappropriate to demonstrate a direct dependency of the PI on the placental compliance, partially due to the impossibility to affect the placental impedance in a reproducible way.

A new method to characterize the cardiovascular system in the fetus is presented in chapter $\mathbf{9}$. With a high resolution ultrasound system the diameter changes of the fetal aorta and umbilical arteries were studied throughout pregnancy. These diameter changes were related to the simultaneously measured PI. Further studies have to be performed to explore the possible clinical value.

From the literature, the PI is known to be dependent on fetal heart rate (FHR). This necessitates the correction of the PI at extreme FHR's, but also allows inferences with respect to placental compliance. Chapter 10 describes a case study of a fetus with a persistent bradycardia due to a congenital heart block, in which the cardiovascular system remained competent. In this condition, the influence of persistent bradycardia on the PI could be studied.

Little or no possibilities exist to study the human fetoplacental circulation in vivo directly. In chapter 11 a method is described where in the umbilical blood flow velocities are measured just after delivery of the baby, and before clamping of the cord. The uterine contractions after delivery lead to an increase in placental impedance, which might be quantified by simultaneous doppler registrations in the cord. However, as the cord itself also showed contractile reactions to touching, the results are not conclusive.

Chapter 12 presents some general conclusions on the results of the various chapters and gives some suggestions for further research. 


\section{REFERENCES}

1 Abitbol M.M., LaGamma E.F., Demeter E. Cipollina C.M. Umbilical flow in the normal and pre-eclamptic placenta

Acta Obstet Gynecol Scand 66". 689-694 (1987)

2 Abitbol M.M., Monhelt A.G., Rocheison B.I., stern W., Blyalkher L., Saraf V. The use of an tndwelling Doppler probe to study acute changes in umbilical artery waveforms in the fetal sheep

Am J Obstet Gynecol 161: 1324-1331 [1989]

3 Abramowicz J.S., Warsof S.L., Arrington J., Levy D.L.

Doppler analysis of the umbilical artery; the importance of choosing the placental end of the cord

$J$ Ultrasound Med 8: $219-221$ (1989)

4 Adamson S.L, Morrow R.J., Bascom P.A.J., Mo L.Y.L., Ritchle J.W.K.

Effect of placental resistance, arterial diameter, and blood pressure on the uterine artertal veloctty waveform: A computer modelling approach

Ultrasound Med Biol 15(5): 437-442 (1989)

5 Adamson S.L., Morrow R.J., Langhlle B.L., Bull S.B., Ritchle J.W.K.

Site-dependent effects of increases in placental vascular resistance on the umbllical arterial velocity waveform in fetal sheep

Ultrasound Med Biol 16(1): 19-27 (1990)

6 Adamson S.L., Morrow R.J., Bull S.B., Langille B.L.

Vasomotor responses of the umbilical circulation in fetal sheep

Am J Physiol 256: 1056-1062 (1989)

7 ArUM

Bioeflects considerations for the safety of diagnostic ultrasound

J Ultrasound Medicine 7(9) (1988)

8 Al-Gazall W., Chapman M.G., Chita S.K., Crawford D.C., Allan L.D.

Doppler assessment of umbilical artery blood flow for the prediction of outcome in fetal cardiac abnormality

Br J Obstet Gynaecol 94(8): 742-745 (1987)

9 Arabin B., Slebert M., Jimenez, Salling E.

Obstetrical characteristics of a loss of end-dliastolic velocities in the fetal aorta and/or umbillcal artery using Doppler ultrasound

Gynecol Obstet Invest 25: 173-180 (1988)

10 Arbellle Ph., Asquller E., Moxhon E, Magnin M., Pourcelot $\mathrm{L}_{*}$, Berger Ch., Lansac $\mathrm{J}$. Lietude de la ctrculation foetal et placentalre par ultrasons

J Gyn Obst Biol Repr 12: 851 -859 (1983)

11 Arduini D., Rizzo G. Romanini C., Mancuso S.

Are blood flow velocity waveforms related to umbilical cord acid-base status in the human fetus?

Gynecol Obstet Inwest 27: 183-187 (1989)

12 Armstrom K., Eliasson A., Harelde J.H., Marsal K.

Fetal blood velocity waveforms in normal pregnancies

Acta Obstet Gynecol Scan 68: 171-178 (1989)

13 Atkinson D.E., Slbley C.P., Williams A.R.

Effects of ultrasound on placental transfer during the last third of gestation in the rat

Ultrasonics 28: 171-1.78 
14 Avloll A.P.

Mult-branched model of the human arterial system

Med \& Btol Eng \& Cornputing 18: 709-718 (1980)

15 Backe B., Brodtkorb C.J., Givedt J., Krernes S., Brubakk A.O.

Fetal and maternal aortic flow in two diferent maternal positions

Vitrasound Med Eiol 9(6): 587-593 (1983)

16 Bake* D.W. Forster F.K., Dalgle R.E.

Doppler principles and technique

In: Ultrasound. Its application in Medicine and Blology Part 1. Ed. Fry, F.J. Elsevier, Amsterdam (1978)

17 Burnett S.B. Kosisoff $\mathrm{G}$.

Utrasonic exposure in static and real time echography

Ultrassound Med Biol 8(3): 273-276 (1982)

18 Barnett S.B., Williams A.R.

Identfication of mechanisms responsible for fetal weight reduction in mice following ultrasound exposure

Ultrasonles 28: $159-165$ (1990)

19 Barnett 5.B., Walsh D.A., Angles J.A.

Novel approach to evaluate the Interaction of pulsed uitrasound with embryonic development

Ultrasonics 28: 166-170 (1990)

20 Beattie R.B., Dornan J.C.

Antenatal screening for intrauterine growth retardation with umbllical artery Doppler ultrasonography

Br Med Journal 298: 195-199 (1989)

21 Bilardo C.M. Nicolaldes K.H., Campbell s.

Doppler measurements of fetal and uteroplacental circulations:

Relationship wtth umbllical venous blood gases measured at cordocentesis

Am J Obstet Gynecol 162: 115-120 (1990)

22 Bracero L., Schulman H., Fleischer A., et al.

Umbilical artery velocimetry in diabetes and pregnancy

Obstet Gynecol 68: 654-658 (1986)

23 Brar H.S., Medearis A.L.. DeVore G.R., Platt L.D.

Fetal umbilical velocimetry using continuous-wave and pulsed-wave Doppler ultrasound. In high-risk pregnancles. a comparison of systolic to diastolic ratios

Obstet Gynecol 72(4): 607-610 (1988)

24 Brar H.S., Medearls A.L., DeVore G.R., Platt L.D.

A comparative study of fetal umbilical velocimetry with continuous- and pulsed wave Doppler ultrasonography in high-risk pregnancies: relatlonship to outcome

Am J Obstet Gynecol 160(2): 375-378 (1989)

25 Brar H.S., Platt L.D., DeVore G.R., Horenstein J., Medearls A.L.

Qualitative assessment of maternal utertne and fetal umbilical artery blood flow resistance In laboring patients by Doppler velocimetry

Am J Obstet Gynecol 158(4): 952-956 [1988]

26 Brar H.S., Platt L.D.

Placental vascular resistance using umbilical velocinetry in patients undergoing cesarean section for fetal distress

J Ultrasound Med 8: $211-214$ (1989) 
27 Brar H.S.

The use of Doppler ultrasound to assess intrauterine growth retarclation in the fetus Semin Perinatol 12: 40-51 [1988]

28 Brulnse H.W., Siljmons E.A., Reuwer P.J.H.M.

Clinical value of screening for fetal growth retardation by Doppler Ultrasound

J Ultrasound Med 8: 207-209 (1989)

29 Campbell $\mathbf{S}_{*, \mid}$ Diaz-Recasens $J_{*}$ Griffin D.R., Cohen-Overbeek T.E., Pearce J.M.; Willson K., Teague M.J.

New Doppler technique for assessing uteroplacental bloodflow

Lancet 1: 675-677 (1983)

30 Caro C.G.. Pedley T.J., Schroter R.C., Seed W.A.

The mechanics of the circulation

Oxford University Press, Oxford [1978)

31 Carpenter M.W.. Sady S.P., Hoegsberg B., Sady M.A., Haydon B., Cullinance E.M., Coustan D.R., Thompson P.D.

Fetal heart rate response to maternal exertion

JAMA 259(20): 3006-3009 (1988)

32 Collings C., Curet L.B.

Fetal heart rate response to maternal exercise

Am J Obstet Gynecol 151: 498-501 (1985)

33 Cousin A.J., Rapoport I., Campbell K., Patrick J.E.

A tracking system for pulsed ultrasound images: Application to quantification of fetal breathing movements

IEEE Transactions on Blomed Eng Vol BME-30, 9: 577-583 (1983)

34 DeVore G.R., Brar H.S., Platt L.D.

Doppler ultrasound in the fetus: a review of current applications

J Clin Ultrasound 15(9): 687-703 (1987)

35 Ducey J., Schulman H., Farmakides G. et al.

A classification of hypertension in pregnancy based on Doppler velocimetry

Am J Obstet Gynecol 157: 680-685 (1987)

36 Edmonds H.W.

The spiral twist of the normal umbllical cord in twins and singletons

Am J Obstet Gynecol 67: 102-120 (1954)

37 Elk-Nes S,H., Brubakk A.O., Ulstein M.K.

Measurements of human fetal blood flow

Br Med Journal I: 283-284 (1980)

38 Erskine L.

Placental compliance-inferences from Doppler studies of umbllical blood flow during cardlac arrhythmia

Acta Obstet Gynecol Scand 66: 301-304 (1987)

39 Erskine R.L., Ritchie J.W.

The effect of maternal consumption of alcohol on human umbilical artery blood flow Am J Obstet Gynecol 154(2): 318-321 (1986)

40 Erskine R.L.A. Ritchie J.w.K. Umblical artery blood flow characteristics in normal and growth retarded fetuses Br J Obstet Gynaecol 92: 605-610 (1985) 


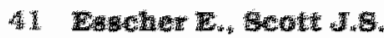

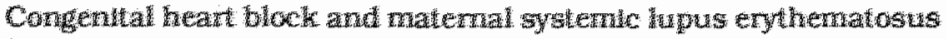

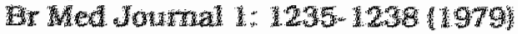

42 2.

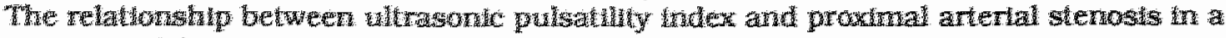

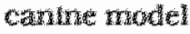

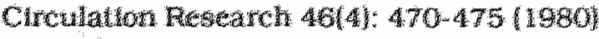

40 Evers-Enden

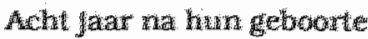

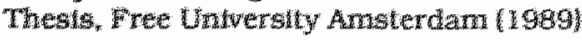

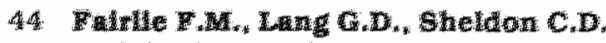

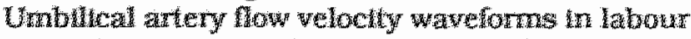

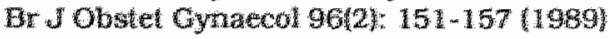

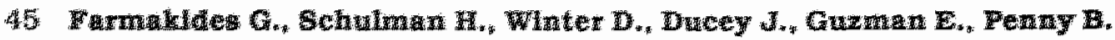

Prenatal survellatioe using nonstress testing ard Doppler welochenty

Obste Gynecol 712): $184-187$ (1)

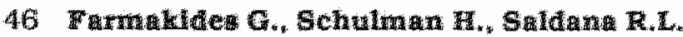

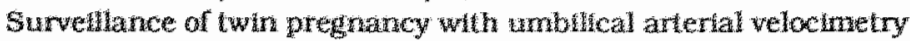

An abste Gynecol 153: 789-792 1985)

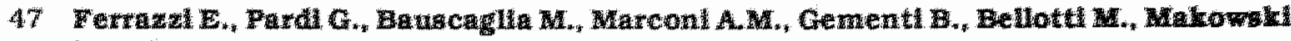

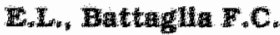

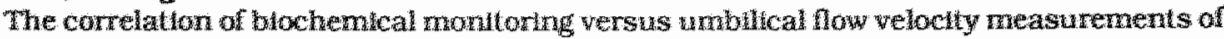
the human fetus

Am I Obstel Gynecol 159: 1081-1087/1988:

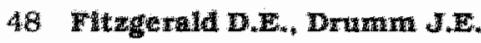

Non-inwaswereasurements of tetal chentaton using whasound: a new method

Br Med Journal it: $450-1451$ (1977)

49 Flelscher A. Anyagbunam A.A., Schuman H, Farmakles G. Randolph $G_{\text {. }}$

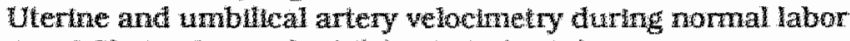

An J Obstet Gynecol $57(1): 40-43(1987)$

50 Fok R.Y., Pavlowa $Z_{\text {, }}$ Benirschke T., Paul R. Platt L.D.

The corredaton of arterial lesions wh umbilical artery Doppler velocinetry in the placentas of smatu-for-dates pregnancies

Obster Gynecol 75: 578-583 (1990)

51. Friedman D.M., Rutkowskl M., Snyder J.R., Lustig-Glliman I., Young B.K.

Doppler blood veloctty waveforms in the umbillcal artery as an indicator of fetal well-being J Clin Ultrasound 13: 161-165 (1985)

52 Gazlano E., Knox G.E., Wager G.P., Bendel R.P., Boyce D.J., Olson J.

The predictability of the small-for-gestational-age infant by real-time ultrasound-derved measurements combined with pulsed Doppler umbilical artery velocimetry

Am J Obstet Gynecol 158: 1431-1439 (1988)

53 Gembruch U., Hansman M., Redel D.A., Bald R., Knopfle G.

Fetal complete heart block: antenatal dagnosis, signiflcance and management

Eur J Obstet Gynecol Reprod Biol 31: 9-32 (1989)

54 Gibert W.M., Nicolaides K.H., Sel Y., Campbell S.

Comparison of umbilical artery flow veloctly waveform indices as measured by continuous wave Doppler ultrasound

J Ultrasound Med 7(10): 549-551 (1988) 
55 Glles W.B., Trudinger B.J., Baird P.J.

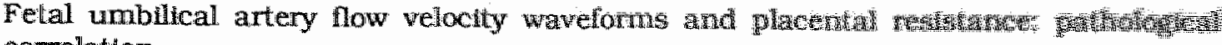
correlation

Br J Obstet Gynaecol 92: $31-38$ (1985)

56 Glles W.B., Tradinger B.J.

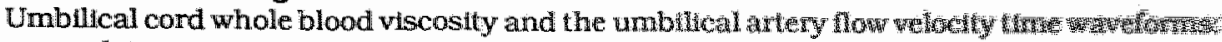

a correlation

Br J Obstet Gynaecol 93: 466-470 (1986)

57 Glles W.B., Trudinger B.J., Cook C.M.

Fetal umbilical artery flow velocity-time waveforms in twit pregraneles

Br J Obstet Gynaecol 92: 490-497 (1985)

58 Gill R.W.

Measurement of blood flow by ultrasound: acouracy and sowces of erwit

Ultrasound Med Biol 11(4): 625-641 (1985)

59 Gosling R.G., King D.H.

Processing arterial Doppler signals for clinical data

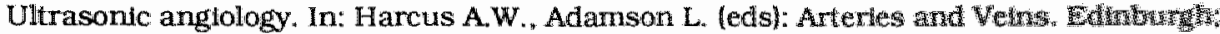
Churchill Lwilngstone 1975

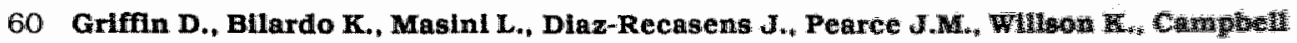
S.

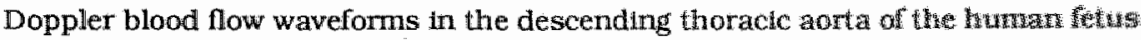

Br J Obstet Gynaecol 91: 997-1006 (1984)

61 Gudmundsson S., Marsal K.

Umbilical artery and uteroplacental blood flow velocity waveforms wamal now a cross-sectional study

Acta Obstet Gynecol Scand 67: 347-353 (1988)

62 Gudmundsson S., Marsal K.

Ultrasound Doppler evaluation of uteroplacental and fetoplacental ctreulatent in preeclampsia

Arch Gynecol Obstet 243: 199-206 (1988)

63 Guler W.H.

A hemodynamic model for relating phasic pressure and flow ln large antertes

IEEE transactions on Biomed Eng Vol BME-27, 8: 479-482 (1980)

64 Gustafsson D.. Stale H., Bjorkman J-A., Gennser G.

Dertvation of haemodymamic information from ultrasontc recondings of aortic diameter changes

Ultrasound Med Biol 15(3): 189-199 (1989)

65 Harper M.A., Murnaghan G.A.

Discordant umbilical artery flow velocity wavefonns and pregriancy outcome

Br J Obstet Gynaecol 96: 1449-1452 [1989]

66 Hasaart T.M.H. Haan J. de

Depression of uterine blood flow during total umbiltcal cord occlusion in sheep

Eur J Obstet Gynec Reprod Biol 19: 125-131 (1985)

67 Hasaart T.H.M., Haan J. de, Horiguchl T.

Effect of selective occlusion of the umbilical arteries and/ar vetins on uterine blood flow in sheep

Eur J Obstet Gymecol Reprad Biol 21: 53-60 (1986) 
Haseart T.M.M. Haan J. de Effects of fetal breathing movements on umbilical venous blood flow in fetal lambs Eur J Obstet Gynec Reprod Biol 20: 121-129 (1985)

69 Hasaart T.H.M. Haan J. de, Horlguchl $T$.

Uterine vascular resistance during compression of the umblical arterial and/or venous circulation in sheep

Eur J Obstet Gynecol Reprod Blol 33:39-47 (1989)

70 Hastle S.J., Howle C.A., Whittle M.J., Flemming J.E.E., Rubln P.C.

Umblical artery blood veloctty waveform analysis in predicting the small-for-dates fetus

Eur J Obstet Gynecol Reprod Blol 35: 35-39 (1990)

71 Hastle S.J., Howle C.A., Whilt ler M.J., Rubin P.C.

Dally variability of umbilical and lateral uterine wall artery blood velocity waveform measurements

Br J Obstet Gynaecol 95(6): $571-574$ (1988)

72 Hata K., Katoh S., Senoh D., Aokd S., Takamlya O., Hata T., Kitao M.

Umbilical artery velocity waveforms are not valid indices for assessing growth retardation In utero

Int J Gyruecol Obstet 29: 25-29 (1989)

73 Hath J.C., Glistrap L.C., Widmer K.

Fetal heart rate reactivity before and after maternal jogging during the third trmester

Am J Obstet Gynecol 142: 545 (1982)

74 Haynes R.H., Rodbard s.

Biophysical princtples of arterlal systems

In: Blood Vessels and Lymphatics, Chapter II, Abrahamson (1967)

75 Hoeks A.P.G., Rulssen C.J., Hick P., Reneman R.S.

Transcutaneous detection of relative changes in artery diameter

Uitrasound Med Blol 11(1): 51-59 (1985)

76 Hoeks A.P.G., Ruissen C.J., Hick P., Reneman R.S.

Methods to evaluate the sample volume of pulsed Doppler systems

Ultrasound Med Blol 10: 427-434 (1984)

77 Hoeks A.P.G., Brands P.J., Smeets F.A.M., Reneman R.S.

Assessment of the distensibllity of superficlal arterles

Ultrasound Med Blol 16: 121-128 (1990)

78 Hokanson D.E., Mozersky D.J., Sumner D.S., Strandness Jr D.E.

A phase-locked echo tracking system for recording arterial diameter changes in vivo

I Applled Physlology 32: 728-733 (1972)

79 HoskIns P.R., Haddad N.G., Johnstone F.D., Chambers S.E., McDlcken W.N.

The choice of index for unbilical artery Doppler waveforms

Ultrasound Med Blol 15(2): 107-111 (1989)

80 Hoskins P.R., Haddad N.G., Johnstone F.D., Chambers S.E., McDlcken W.N. Heartrate vartation of umbillical artery Doppler waveforms

Ultrasound Med Biol 15(2): $101-105$ (1989)

81 Hulsseling H. van, Hasaart T.H.M., Ruissen C.J., Muljsers G.J.J, Haan J. de Umbulical artery flow velocity waveforms during acute hypoxemia and the relationship with hemodynamic changes in the fetal lamb

Am J Obstet Gynecol: 1061-1064 (1989) 
82 Jauniaux E., Campbell $\mathrm{S}_{\text {., }}$ Vyas $\mathrm{S}$.

The use of color Doppler imaging for prenatal diagnosis of umblical cond anomalles: Report of three cases

Am J Obstet Gynecol 161:1195-1197 (1989)

83 Jauniaux E., Campbell s.

Fetal growth retardation with abnormal blood flows and placental sonographic leslons

J Clin Ultrasound 18: $210-214$ (1990)

84 Johnstone F.D., Haddad N.G., Hoskins P., McDicken W. Chambers S., Muir B.

Umbillical artery Doppler flow velocity waveform: the outeome of pregnanctes with absent end diastolic flow

Eur J Obstet Gynecol Reprod Biol 28: 171-178 (1988)

85 Jongsma H.W., Evers J.H.L., Hulkeshovem F.J.M., Hain J. de, Martin C.B.

Compliance and fow resistance of the umbillcal circulation $\| n$ vivo in sheep and effects on circulatory parameters

SGI abstract nr. 45 (1979)

86 Joupplia P., Kirkinen P.

Umbillical vein blood flow as an indicator of fetal hypoxia

Br J Obstet Gynaecol 91: 107-110 (1984)

87 Joupplla P., Kirkinen P., Eik Nes S.

Acute effect of maternal smoking on the human fetal blood flow

Br J Obstet Gynaecol 90: 7-10 (1983)

88 Jouppila P., Kirkinen P., Puukka R.

Correlattion between umbilical vein blood flow and umbllical blood viscosity in normal and complicated pregnancles

Arch Gynecol 237: $191-197$ (1986)

89 Kachaner $J_{\text {.. }}$ Fermont L., vilain E., Pedroni E.

Evaluation clinique et traitement des troubles du rythme et de la conduction chez le foetus Pediatr Med Chir 9(5): 527-534 (1987)

90 Kilkinen P., Joupplla

Umbillical vein blood flow in rhesus-isoimmunization

Br J Obstet Gynaecol 90: 640-643 (1983)

91 Kofinas A.D., Penry M., Greiss F.C., Meis P.J., Nelson L.F.

The effect of placental location on uterine artery flow velocity waveform

Am $J$ Obstet Gynecol 159: 1504-1508 (1988)

92 Laurin J., Lingman G., Marsal K., Persson P-H.

Fetal blood fow in pregnancles complicated by intrauterine growth retardation

Obstet Gymecol 69: 895-902 (1987)

93 Lavery J.P.

The human placenta: clinical perspectives

Aspen Publishers, Inc. (1987)

94 Legarth $\mathbf{J}_{*,}$ Thorup $\mathbf{E}$.

Characteristics of Doppler blood-velocity waveforms in a cardlovascular in vitro model. I.

The model and the influence of pulse rate

Scand $\mathrm{J}$ Clin Lab Invest 49: 451-457 (1989)

95 Lingman G.

Human fetal hemodynamics

Thests 1985, Malmo, Sweden 
96 Lunt M.

Accuracy and Imutatlons of the ultrasondc Doppler blood welocimeter and the zero crassing detector

Ultrasound Med Blol 2: 1-10 (1975)

97 Manning G.K., Dripps J.H.

Comparison of correlation and modulus difference processing algorithms for the determsnation of fetal heart rate from ultrasonic Doppler signals

Med \& Blol Eng \& Comput 24: 121-129 (1986)

98 Mansourl H., Gagnon R., Hunse C.

Relationship between fetal heart rate and umbillcal blood flow velocity in the human fetuses during labor

Am J Obstet Gynecol 160(4): $1007-1012$ (1988)

99 Marc Q.F. Patel S., Berman J.A. Farmakldes G., Schulman H.

Umbllical blood flow velocity waveforms in different maternal positions and with epidural analgesla

Obstet Gynecol 68(1): 61-64 (1986)

100 Maullk D., SalnI V.D., Nanda N.C., Rosenzweig M.S.

Doppler evaluation of fetal hemodynamics

Ultrasound Med Blol 8(6): 705-710 (1982)

101 Maullk D., Yarlaggdda P., Blest S., Ciston P.

The influence of measurement location on umbilical artertal Doppler indices

I Ultrasound Med 7: \$39-5283 (1988) (Abstract \#0813)

102 Maullk D., Yarlagadda P., Nathianielsz P.W., Figueroa J.P.

Hemodynamic validation of Doppler assessment of fetoplacental circulation in a sheep model system

J Ultraisound Med 8(4): 177-181.(1989)

103 Maullk D., Yarlagadda A. Youngblood J.P., Willoughby L.

Components of varlablity of umbillical arterial Doppler velocimetry-A prospective analysis Am J Obstet Gynecol 160: 1406-1412 (1989)

104 Maullik D., Nanda N.C.. Sainl V.D.

Fetal Doppler echocardiography: Methods and charactertzation of normal and abnormal hemodynamilcs

Am J Cardlol 53: $572-578$ (1984)

105 McCallum W.D., Olson R.F., Dalgle R.E., Baker D.W.

Real-tIme analysis of Doppler signals obtained from the feto-placental circulation

In: Ultrasound in Medicine, 3B. Eds. White D. \& Brown RE. p. 1361 (1977)

106 McCallum W.D., WIIlams C.S., Napel S., Daigle R.E.

Fetal blood low velocity waveform

Ain J Obstet Gynec 132: 425-429 (1978)

107 MoCowran L.M., Mullen B.M., Ritchle K.

Umbilical artery flow velocity waveforms and the placental vascular bed

Am J Obstet Gynecol 157(4): 900-902 (1987)

108 MoDonald D.A.

Blood flow in arteries

Camelot Press Ltd. Southampton [1974]

109 Megerman J., Hasson J.E., Warnock D.F., L'Itallen G.J., Abbott W.M. Noninvasive measurement of nonlinear arterlal elasticity

Am J Physiol 250: $181-188$ (1986) 
110 Mehalek K.E., Rosenberg J., Berkowitz G.S., Chitkara U., Berkowite R.L.

Umbilical and uterine artery flow velocity waveforms; effect of the sampling site on Doppler ratios

J Ultrasound Med 8: 171-176 (1989)

111 Mehalek K.E., Berkowitz F.S., Chitkara U., Rosenberg J., Berkowitz R.L. Comparison of continuous-wave and pulsed Doppler S/D ratios of umbillical and uterine arteries

Obstet Gynecol 72(4): 603-606 (1988)

112 Merode T. van, Lodder J., Smeets F.A.M., Hoeks A.P.G. Reneman R.S. An accurate non-Invastve method to diagnose minor atherosclerotic lesions in the carotid artery bulb

Stroke 20: 1336-1341 (1989)

113 Merode T. van, Hlck P.J.J., Hoeks A.P.G., Reneman R.S.

Non-Invastve assessment of artery wall properties in chlldren aged 4-19 years

Pediatric Research 25: 94-96 (1989)

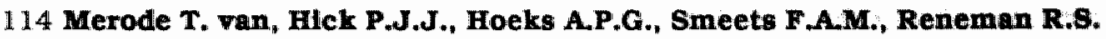

Differences in carotid artery wall properties between presumed healthy men and women Ultrasound Med Bilol 14: 571-574

115 Milnor W.R.

Pulsatile blood flow

New Eng J Med 287(1): 27 (1972)

116 Moore D.H., Jarrett II J.C., Bendick P.J.

Exercise-Induced changes in uterine artery blood flow, as measured by Doppler ultrasound. In pregnant subjects

Am J Perinatology 5(2): 94-97 (1988)

117 Morrow R.J., Ritchie J.W., Bull S.B.

Fetal and maternal hemodymamic responses to exercise in pregnancy assessed by Doppler ultrasonography

Am J Obstet Gynecol 160(1): 138-140 (1989)

118 Morrow R.J., Adamson L., Bull S., Ritchle J.W.K.

Acute hypoxemla does not affect the umbllical artery flow velocity waveform in fetal sheep Obstet Gynecoll 75: 590-593 (1990)

119 Mulders L.G.M., Jongsma H.W., Heln P.R.

Uterine and umbillical artery blood now velocity waveforms and their validity in the prediction of fetal compromise

Eur J Obstet Gynecol Reprod Blol 31: 143-154 (1989)

120 Mulders L.G.M., Muijsers G.J.J.M., Jongsma H.W., NIjhuis J.G., Heln P.R.

The umbllical artery blood llow velocity waveform in relation to fetal breathing movements, fetal heart rate and fetal behavioral states in normal pregnancy at 37 to 39 weeks

Early Human Development 14: 283-293 (1986)

121 Nadasy G.I., Mohacs» E., Monos E., Lear J.C., Kovach A.G.B.

A simple model describing the elastic properties of human umbllical arterial smooth muscle

Acta Physlologica Hungarica 70(1): 75-85 (1987)

122 Nellson J.P., Whittle M.J.

Doppler Blood Flow Studies in Fetal Growth Retardation

In: Fetal and Neonatal growth. Ed. F. Cockburn John Wiley \& Sons Ltd (1988) 


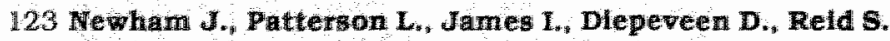

Doppler flow welocity waveform analysls: a prospective double-bilnd evaluation of its efficacy as a screening test in pregrancy

Abstract SGI 431 (1988)

124 Newman D.L, Sipkema P., Greenwald $S . E_{\text {, }}$ Westerhof $N$.

Wigh frequency characteristics of the artertal system

$J$ Biomechantes $19(10): 817-824(1986)$

125 Nlenhuls S.J., Vugt J.M.G. van, Hoogland H.,., Rulsisen C.J., Haan J. de Interexaminer variabllity of fetal Doppler velocity waveforms

Gynecol Obstet Invest 25: $152-157$ (1988)

126 Noordam M.J., Whadlimiroff J.W, Lotgering F.K., Struijk P.C., Tonge H.M.

Fetal blood flow velocity waveforms in relation to changing peripheral vascular resistance Early Human Development 15: 119-127 (1987)

127 ott W.J.

Comparison of Dymamic Image and Pulsed Doppler Ultrasonography for the diagnosis of Intrutterime growth retardation

$\mathrm{J}$ Clin Utrasound 18: 3-7 (1990)

128 Pearce J.M. , Campbell S., Cohen-Overbeek T., Hackett G., Hernendez J., Rayston J.P. References ranges and sources of variation for indices of pulsed Doppler flow velocity wavelorms from the uteroplacental and fetal circulation

Br J Obstet Gynaecol 95(3): 248-256 (1988)

129 Peronneau P.A., Bournat J.-P.. Bugnon A., Barbet A., Xhard M.

Theoretical and practical aspects of pullsed Doppler flowmetry: real-time applications to the measure of instantaneous velocity profles

In: Cardllovascular applications of ultrasound: 66-84, Ed: R.S. Reneman, Publ: North Holland Publ. Co., Amsterdam-London 1974

130 Pijpers L., Whadimiroff $J . W_{*,}$ McGhie $J$.

Effect of short-term maternal exercise on maternal and fetal cardiovascular dynamics

Br J Obstet Gynaecol 91: 1081-1086 (1984)

131 Pourcelot $\mathrm{L}$.

L'Examen Doppler des valsseaux peripheriques

AC-D Productions, Paris (1982)

132 Redman C.W.G.

Examination of the placental circulation by Doppler ultrasound

Br Med Journal 298: 621-622 (1989)

133 Reed K.L., Sahn D.J., Marx G.R., Anderson C.F. Shenker L.

Cardlac Doppler flows during fetal arrhythmias: physiologic consequences

Obstet Gynecol 70: 1-6 (1987)

134 Reneman R.S., Clarke H.F., Simmons N, Spencer M.P.

In vivo comparison of electromegnetic and Doppler nowmeters: with special attention to the processing of the analogue Doppler flow signal

Cardiowascular Research 7: 557-566 (1973)

135 Reneman R.S., Merode T. van, Hlck P., Muytjens A.M., Hoeks A.P.G.

Age-related changes in carotid artery wall properties in men

Ultrasound in Med Biol 12: 465-471 (1986)

136 Reuwer P.J.H.M., Sljmons E.A., Rletman G.W., Thel M.W.M. van, Brainse H.w. Intrauterine growth retardation: prediction of perinatal distress by Doppler uitrasound The Lancet: $415-418(1987)$ 
137 Reuwer P.J.H.M., Nuyen W.C., Beljer H.J.M., Heethatar R.M., Haspels A.A., Bruinse H.W.

Feto-placental cinculatory competence

Eur J Obstet Gynecol Reprod Biol 21: $15-26$ (1986)

\section{Reynolds S.R.M.}

Hemodynamic characteristics of the fetal circulation

Am J Obstet Gynecol 68: 69-80 (1954)

\section{Reynolds S.R.M.}

The physical forces of blood now in the umbilical vein

In: Fetal and newborn cardiovascular physioly, Volume 2, Chapter 4. Eds L.D. Longo \& D.D. Reneau Garland STPM Press New York 1978

140 Rightmire D.A. Campbell s.

Fetal and maternal Doppler blood fow parameters in postterm pregnancles

Obstei Gynecol 69(6): 891-894 (1987)

141 Rightmire D.A. Nicolaldes K.H., Rodeck C.H. Campbell S.

Fetal blood velocittes in $\mathrm{Rh}$ isolmmunization: relationshtp to gestational age and to fetal hematocrit

Obstet Gynecol 68: 233-236 (1986)

142 Rochelson B., Schulman H., Farmakides G., Bracero L., Ducey J., Flelbcher A., Penny B,*w Winter $D_{\text {. }}$

The stgnificance of absent end-dlastolic welocity in umbilical artery velocity waveforms Am J Obstet Gynecol 156: 1213-1218 (1987)

143 Rulssen C.J., Vugt J.M.G. van, Hoogland H.J., Hoeks A.P.G., Faan de J. Technical aspects of fetal Doppler measurements

Gynecol Obstet Invest 24: 1-13 (1987)

144 Rulssen C.J., Vugt J.M.G. van, Haan J. de Variability of PI calculations

Eur J Obstet Gynecol Reprod Blol 27: 213-220 (1988)

145 Ruissen C., Haan J. de, Hoogland $H$.

Ultrasonic measurement of fetal circulation

In: Gennser, Marsal, Proc. 10th Conf. Fetal Breathing Movements and other Measurements, p. 75. Malmo (1983)

146 Rulssen C., Jager W., Drongelen M.w., Hoogland H.

The influence of maternal exercise on the pulsatilty index of the umbilical artery blood velocity wavelorm

Eur J Obstet Gynecol Reprod Biol 37; 1-6 (1990)

147 Rulssen C.J., Drongelen v. M.M.H.P., Hoogland H.J., Hoeks A.P.G.

Characteristics of the umbilical artery velocity waveform as function of measurement slte Accepted for publication in Gynecol Obstet Investigation (1990)

148 Saini V.D., Maulik D., Nanda N.C., Rosenzwelg M.S.

Computerized evaluation of blood now measurement indices using Doppler ultrasound Ultrasound Med Blol 9(6): 657-660 (1983)

149 Sainz A., Pinardi G.: Roberts V.C.

Phased-lock loop techniques applied to ultrasonic Doppler signal processing

Ultrasontcs 14: 128-132 (1976)

\section{Satomura S.}

Study of flow pattern in peripheral arteries by ultrasonics

J Acoust Soc Japan 15: 151-159 (1959) 
151 Schoot B.C., Dorr P.I., Stewart P.A., Wladimiroff J.W. De diagnostiek van hariritmestoornissen bil de foetus Ned Tudschr Geneesk 133(21): 1063-1064 (1989)

152 Sindberg-Eriksen $\mathbf{P}$., Marsal $\mathbf{K}$. Circulatory changes in the fetal aorta after maternal smoking Br J Obstet Gynaecoll 94(4): $301-305$ (1987)

153 skidmore R., Woodcock J.P. Physlological interpretation of Doppler shift waveforms Utrasound Med Biol 6: 7-10 (1980)

154 Skidmore R., Follet D.H.

Maximum frequency follower for the processing of ultrasonic Doppler shift signals Ultrasound Med Biol 14: 145-147 (1978)

155 Spencer J.A., Price J.

Intraobserver vartation in Doppler ultrasound Indices of placental perfusion dertved from different numbers of wavefoms

$\checkmark$ Ultrasound Med 8(4): 197 199 (1989)

156 Steegers E.A.P., Buunk G., Binkhorst R.A., Jongsma H.W., Wijn P.F.F., Hein P.R. The influence of matemal exercise on the uteroplacental vascular bed resistance and the fetal heart rate during normal pregnancy

Eur J Obstet Gynecol Reprod Blol 27: 21-26 (1988)

157 Strandiness D.E.

Ultrasound in the study of atherosclerosis

Ultrasound Med Blol 12 (6): 453-464 (1986)

158 Stuart B., Drumm J., Fitzgerald D.E., Duignan N.M.

Fetal blood veloclty waveforms in nomal pregnancy

Br J Obstet Gynaecol 87: 780-785 [1980)]

159 Thompson R.S., Trudinger B.J., Cook C.M.

Doppler ultrasound waveforms in the fetal umbilical artery: Quantitative analysis technique

Ultrasound Med Biol 11[5): 705-718 (1985)

160 Thompson R.S., Trudinger B.J., Cook C.M.

A comparison of Doppler ultrasound waveform indices in the umbilical artery-I Indices derived from the maximum velocity waveform

Ultrasound Med Biol 12(11): 835-844 (1986)

161 Thompson R.S., Trudinger B.J." Cook C.M.

A comparison of Doppler ultrasound wavefonm indices in the umbllical artery-II Indices derlved from the mean velocity and flrst moment waveforms

Ultrasound Med Biol 12(11): 845-854 (1986)

162 Thompson R.S.. Trudinger B.J.* Cook C.M.

Doppler ultrasound waveform indlices: $A / B$ ratlo, pulsatility index and Pourcelot ratio

Br J Obstet Gynaecol 95(6): 581 -588 (1988)

163 Thompson R.S., Stevens R.J.

Mathematical model for interpretation of Doppler velocity waveform indices

Med B Blol Eng \& Comput 27: 269-276 (1989)

164 Truccone N.J., Marlona F.G.

Prenatal diagnosis and outcome of congenital complete heart block: The role of fetal echocardlography

Fetal Therapy $1: 210-216$ (1986] 
165 Trudinger B., Cook C.

Mothers with abnomal Doppler umbilical artery studies are anglotensin sensittive

Abstract SGI 1988, 432

166 Trudinger B.J., Cook C.M., Glles W.B. Connelly A., Thompson R.s.

Umbilical artery llow velocity waveforms in high-risk pregmancy

The Lancet: $188-190$ (1987)

167 Trudinger B.J., Glles W.B., Cook C.M., Bombardler J., Colling L.

Fetal umbillcal artery flow velocity waveforms and placental resistance: clinical sugnincance

Br J Obstet Gynaecol 92: 23-30 [1985]

168 Trudinger B.J., Stewert G.J., Cook C.M., Connelly A., Exner T.

Monitoring lupus anticoagulant-positive pregnancles with umbllcal artery flow velocity wavelorms

Obstet Gynecol 72(2): 215-218 (1988)

169 Trudinger B.J., Cook C.M.

Doppler umbilical and uterne fow waveforms in severe pregnancy lyppertension

Br J Obstet Gynaecol 97: 142-148 (1990)

170 Trudinger B.J.

The umbillcal circulation

Seminars in Perinatology 11: 311-321 (1987)

171 Van Lierde M., Oberwells $\mathbf{D}$., Thomas $\mathrm{K}$.

Ultrasonlc measurement of aortic and umbilical flow th the human fetus

Obstet Gynecol 63: 801-805 (1984)

172 Veth A.F.L., Bemmel J.H. van

The role of the placental vascular bed in the fetal response to cord occluston

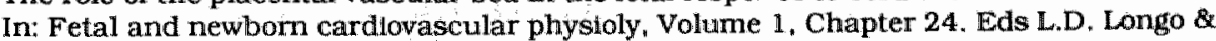
D.D. Reneau Garland STPM Press New York 1978

173 Vugt J.M.G. van, Ruissen C.J., Nienhulls S.J., Hoogland H.J., Haan J. de Comparison of Blood Velocity Waveform Indices recorded by pulsed Doppler and Continuous wave Doppler in the umbilical artery

J Clin Ultrasound 16: $573-576$ (1988)

174 Vugt J.M.G. van, Ruissen C.J., Hoogland H.J., Haan J, de

The blood flow velocity waveform index in the fetal thoracic aorta and its abllity to detect fetal compromise in the small for gestational age fetus

Eur J Obstet Gynecol Reprod Biol 27: 105-114 (1988)

175 Vugt J.M.G. van, Ruissen C.J., Schouten H.J.A., Theunlssen M., Hoogland H.J., Haan J. de

Umbllical artery blood velocimetry: a prospective longitudinal study in search of the intrauterine growth-retarded fetus

Early Human Development 18: 59-71 (1988)

176. Vugt J.M.G. van, Rulssen C.J., Hoogland H.J., Haan J. de

Prospective study of velocity waveforms in the fetal descending thoracic and abdominal aorta in fetuses approplate for gestational age and in growth retarded fetuses

Gymecol Obstet Invest 24: 14-22 (1987)

177 Vugt J.M.G. van, Ruissen C.J, Hoogland H.J., Haan J. de

A prospective study of the umbllical artery waveform in appropriate-for-date and growth retarded fetuses

Gynecol Obstet Invest 23: 217-225 (1987) 
178 Vugt d.M.G. van

Fetal artery Doppler veloelmetry

Thests, University of Limburg, Maastricht, The Netherlands, 1988

179 Wells P.N.T., skidmore R.

Doppler developments in the last quinquennim

Uttrasound Med Btol $11(4): 613-623$ (1985)

180 Wijngaard $\nabla . d . J . A$, Eyck $\nabla . J .$, Wladimiroff J.W.

The relationship between fetal heart rate and Doppler blood flow velocity waveforms

Ultrasound Med Blol 14(7): $593-597$ (1988)

181 wheox G.R., Trudinger B.J., Cook C.M., Wilcox W.R., Connelly A.J.

Reduced fetal platelet counts in pregnancies with abnormal Doppler umbilical flow waveforms

Obstet Gynecol 73(4): 639-643 (1988)

182 whadimiroff J.W., Tonge H.M., Stewart P.A.

Doppler ultrasound assessment of cerebral blood now in the human fetus

Br J Obstet Gynaecol 93: 471-475 (1986)

183 Wladimiroff J. W., Tonge H.M., Stewart P.A. Reuss A.

Severe intrauterine growth retardation; assessment of its origin from fetal arterial fow velocity waveforms

Eur J Obstet Gymecol Reprod Blol 22: 23-28 (1986)

184 woodcock $\boldsymbol{J} . P$.

Ultrasonics

Adam Hilger, Bristol 1979

185 Woodcock J.P.

Uitrasonics in bilology and medicine

Fulpsaynsikl, Polish Scienturic Publishers, Warsaw 1972

186 Yarlagadda $\mathbf{P}$., Wllloughby $L_{\text {., }}$ Maullk $\mathbb{D}_{\text {., }}$

Effect of fetal heart rate on umbilical arterial Doppler indices

$J$ Ultrasound Med 8(4): 215-218 (1988) 
Doppler ultrageluid is een methode waarmee op onbloedige en onschadelike wijze de bloedstroomsnellheid in bloedvaten kan worden gemeten. Deze techniek is daarom bij uitstek geschikt om tijdens de zwangerschap te gebruiken voor de bestudering van de bloedsomloop van het ongeboren kind (foetus). Het foetale hart pompt het bloed pulserend in de grote lichaamsslagader (aorta), waarvan uiteindelijk de twee navelstreng-slagaders aftakken. De navelstreng is een vrij star systeem waarin het bloed nog steeds, zij het minder, pulseert. In de moederkoek (placenta) wordt uiteindelijk het pulserende karakter grotendeels afgevlakt tot een meer continue bloedstroom, waardoor de uitwisselingsprocessen beter verlopen. Van de placenta gaat het bloed via de navelstrengader naar de foetale lever, en vervolgens naar het hart, waar het opnieuw deelneemt aan de bloedsomloop. Met behulp van doppler ultrageluid is het mogelijk om een aantal aspecten van deze circulatie te bestuderen. Het toepassen van deze techniek vereist echter een goede kennis van de natuurkundige processen die de resultaten kunnen beinvloeden. Ook de technische eigenschappen van doppler apparatuur bepalen de uitkomsten van de meting. Met een aantal factoren moet rekening gehouden worden bij het gebruik van de dopplermethode, zoals zendfrequentie, filterinstelling en dergelijke. De afgelopen jaren is het duidelijk geworden dat bepaalde karakteristieken van de bloedstroomsnelheid die in de navelstrengslagader wordt gemeten, verband houden met de conditie van het kind en de werking van de moederkoek. Omdat een aantal factoren, die invloed uitoefenen op het verloop van de snelheid van het bloed in de navelstreng als funktie van de hartslag, nog niet zijn opgehelderd, zijn een aantal studies uitgevoerd, waarvan de resultaten in dit proefschrift zijn beschreven.

Matige inspanning van de moeder, zoals trappen lopen, heeft geen aantoonbare invloed op de bloedsomloop van het kind. Het is daarom niet nodig, om zoals bij een bloeddrukmeting, eerst een periode rustig te liggen, alvorens een dopplermeting te verrichten. Ook de preciese plaats in de navelstreng waar de meting wordt uitgevoerd, is niet van belang. Ook de eenvoudige methode van een meting in een vrij zwevend gedeelte van de navelstreng, levert goed brulkbare resultaten op. Deze bevinding geeft tevens aan dat de navelstreng vooral een transportfunctie heeft.

Met een aantal recent ontwikkelde technieken is ook geconstateerd dat de navelstreng-slagaders maar weinig in diameter veranderen tijdens de hartslag, terwijl de aorta, waarvan ze aftakken, sterk uitzet. Het is nog onduidelyjk waar het omslagpunt van sterke uitzetting, naar geringe uitzetting precies ligt. In de toekomst moet hiernaar verder onderzoek worden verricht. De uitzetting van de aorta als funktie van de hartslag kan onder een aantal aanname's als maat gebruikt worden voor de plaatselijke drukveranderingen. Het blijkt dat er tijdens de hartslag een snelle drukopbouw is, en een langzamere afbouw. Op basis van modelstudies kan hieruit informatie verkregen worden met betrekking tot de weerstandverhouding in het circulatiesys- 
teem. Ook in bijzondere gevallen zoals afwljkingen in een gedeelte van het circulatiesysteem, kan de dopplermethode mogelijk extra informatie verschaffen. In het geval van een blijvend te lage hartslag als gevolg van een blokkade in de elektrische gelelding van het hart, kon de circulatie van het kind, die zich aan deze bijzondere situatie bleek aan te passen, goed worden gevolgd.

Er is ook geprobeerd om onmiddelijk na de bevalling registraties van de bloedstroomsnelheid in de navelstreng te verrichten, voordat de navelstreng werd afgebonden. Het idee was, dat door samentrekking van de baarmoeder de weerstand in de placenta zou toenemen. Deze weerstandsverandering zou dan bestudeerd kunnen worden aan de hand van de uitkomsten van de bloedstroomsnelheid registraties. Er bleek een groot verschil te bestaan tussen de verschillende patiênten. Soms kon nog enkele minuten gemeten worden voordat de navelstreng zich spontaan afsloot, een andere keer kon slechts enkele tientallen seconden worden geregistreerd. Bovendien bleek de navelstreng onder invloed van mechanische prikkeling ook plaatselijk al samen te knijpen, waardoor geen uitspraak gedaan kon worden over de invloed van de afstand tot de placenta.

Een aantal vragen blijven nog onbeantwoord waarnaar in de toekomst verder onderzoek verricht zal moeten worden. Het gebruik van zogenaamde kleuren dopplersystemen, kan daarin een belangrijke rol spelen. Met deze apparatuur kan nauwkeuriger de meetplaats bepaald worden, en kunnen ook kleinere bloedvaten in de placenta zelf bestudeerd worden, die anders niet zichtbaar zouden zijn. Ondanks al deze technische mogelijkheden, dient de patient echter in het middelpunt te blijven staan. 


\section{NAWOORD}

Net zoals in de experimentele geneeskunde modellen worden gehanteerd om de werkelijkheid weer te geven, zo worden ook in vele proefschriften vergelijkingen gebruikt om het ontstaan ervan te beschrijven. Voor het onderhavige proefschrift geldt, dat het er niet een is van het type huis, waarbij de éen het fundament stort, anderen de muren optrekken en de ramen erin maken, en de promovendus uiteindelijk het dak erop zet. Dit proefschrift is meer van het type schilderij. waarbij de schilder uiteindelijk het doek vult. maar natuurlijk niets bereikt zonder de geschikte penselen, de juiste verf in de passende kleuren, en een goed stuk schilderslinnen. Ook een ezel, goed licht en een atelier zijn onontbeerlijk. Ik zal niet in alle gevallen aangeven welke personen geïdentificeerd zouden kunnen worden met welke attributen. Aan een vergelijking met "het licht" zal niemand aanstoot nemen, maar een vergelijking met de ezel of de poetsdoeken, hoe belangrijk ook, wordt wellicht minder gewaardeerd.

Net als in de schilderswereld, leiden de inspanningen slechts zelden tot een "Nachtwacht" of een "Aardappeleters", maar meestal is het resultaat in ieder geval toch wel het aankijken waard. Het is niet te hopen dat het huidige AIO systeem leidt tot werkstukken van het type "Iedereen kan schilderen" van een bekende hobby-artikelen fabrikant. Het inkleuren van voorgedrukte schilderijen mag dan een nuttige oefening zijn, het is fnuikend voor de eigen creativiteit.

Het ultrageluidslaboratorium staat zonder twijfel model voor het atelier; in de bijna vijftien jaar die ik daar heb mogen doorbrengen is "het lab", zowel spiritueel als letterlijk de plaats geweest waar dit boekje tot stand gekomen is. In de beginjaren, toen ik volstrekt nog niet nadacht over zoiets als promoveren, was het lab altijd een prettige werkomgeving, waar ik tegen de achtergrond van de steeds nauwere contacten met de praktische gezondheidszorg. de ruimte had om mijn eigen weg te zoeken en te vinden. In de latere jaren was dile prettige werkomgeving er nog steeds, maar werd het ook de plek waar een gedeelte van de in dit boekje beschreven experimenten zijn uitgevoerd of verwerkt. In de afgelopen jaren is ook de afdeling Gynaecologie en Obstetrie een steeds belangrijker plaats gaan innemen, en vormden de polikliniek en de echokamer de omgeving waar, in analogie met de schilderkunst, de "modellen" vandaan kwamen.

De lange voorgeschiedenis van dit boekje maakt ook. dat er een welhaast eindeloze rij mensen met name te noemen zijn, die op éen of andere wijze kleur aan het schilderij gegeven hebben. Iedereen van harte bedankt. Ik volsta met het noemen van enkele namen: John van Vugt, pionier in het obstetrische doppler gebeuren in Annadal destijds en degene, die mij het "kwastgebruik" heeft geleerd; Arnold Hoeks, copromotor en leverancier van het schilderslinnen, de basis waarop het schilderij kleur kreeg. Henk Hoogland, eveneens copromotor, lichtbron en inspirator. Henk, zonder jouw voortdurende stimulans was dit doek waarschijnlijk leeg gebleven. Verder natuur- 
Ijk de beide promotores Jelte de Haan en Rob Reneman, die op de achtergrond voorwaardenscheppend aanwezig waren. Bedankt ook Frans Smeets en Peter Brands, die enerzijds mede voor de prettige sfeer in het lab hebben gezorgd, en anderzijds met het "vaatwand-systeem" ook in concreto een bijdrage hebben geleverd. Ook mijn collega-schilders, met name Guido Muijsers en Hans van Huisseling, dank voor de collegiale sfeer. Daarnaast dank aan Waltje Jager, Margret van Drongelen, Jacqueline Pieters, Manon Gordijn. Cecile Gorissen, leden van de vakgroep Biofysica en de vakgroep Gynaecologie en Obstetrie, met name Tom Hasaart, leden van de instrumentele dienst op het $\mathrm{BMC}$, die al die jaren voor de onmisbare meetopstellingen, waterbakken en andere hulpstukken hebben gezorgd, het personeel van de polikliniek en van de verloskamers. Natuurlijk dank aan jou, Saskia Nienhuis, die op vele manteren (o.a. de engelse tekst), betrokken bent geweest bij de totstandkoming van dit boekje. Verder vanzelfsprekend dank aan de vele, toendertijd, zwangere vrouwen, die hun medewerking verleenden aan het onderzoek, en de toen nog ongeboren kinderen, die zich van alle kanten lieten bekijken met ultrageluid, zoals een goed schildersmodel betaamt.

Verder de leden van de beoordelingscommissie, en niet in de laatste plaats Rian en Andrea, bedankt dat jullie "thuis" waren. Ik heb ongetwijfeld mensen niet genoemd die wellicht wel genoemd hadden moeten worden, maar net als bij de Nachtwacht is het tableau vivant op een gegeven moment vol. De waardering voor hun bijdrage is er niet minder om. 


\section{CURRICULUM VITAE}

19511 april, geboren te Utrecht

1957-1963 Lagere school in Axel en Geldrop

1970 Einddiploma HBS-B (EPL Eindhoven)

1974 Einddiploma HTS-Elektrotechniek (IHBO Eindhoven)

1974-1976 Projectmedewerker Centraal Technische Dienst. Technische Hogeschool Eindhoven

1976-1990 Aanvankelijk full-time, later parttime onderzoeks-medewerker vakgroep Biofysica, RL te Maastricht.

1982-1988 Studie Geneeskunde. RL te Maastricht

1986 Doctoraal getuigschrift Geneeskunde

1988

Artsexamen

1988-1990 Parttime toegevoegd onderzoeker vakgroep

Gynaecologie-Obstetrie ( $3^{\mathrm{e}}$-geldstroom project)

1990-1992 Assistent Huisarts in opleiding 